\title{
6 Developing National Inclusion Policies
}

A number of countries, such as India, South Africa, Lesotho, Uganda and the UK, and provinces that have responsibility for education policy, such as New Brunswick, Canada and Queensland, Australia, now have well-developed policies on inclusive education. Others, such as Pakistan, are only just developing policies. Sri Lanka and Bangladesh already have policies, but these appear to have little impact on the ground. Quite a few countries have policies that amount to integration, but not inclusion as defined here and in Article 24, for example Malaysia and Singapore.

To implement Article 24 of the UNCRPD, states must develop effective inclusive education in schools, backed by the changes indicated by the UN Special Rapporteur on the Right to Education and UNESCO. The UN Special Rapporteur states clearly that transition from segregated, special education to inclusive education is not a simple matter, and the complex issues it raises must be squarely faced. For example 'integration', often in the guise or in the place of true inclusion in education, has created its own difficulties. Attempts at integration into mainstream schools without accompanying structural changes in organisation, the curriculum, and teaching and learning strategies, have failed to meet the educational rights of disabled persons. Integration may simply lead to exclusion in the mainstream rather than in special schools. Education policy must therefore identify and remedy all structural biases that lead to potential exclusion in the mainstream system. Policies and resources aimed at developing genuinely inclusive practices must take precedence over the old ways.

Following wide consultation and examination of current state practices, the UN Special Rapporteur, in his 2007 Report to the UN Human Rights Council, recommends that states take specific steps towards building an inclusive education system. ${ }^{146}$ These include policy formulation and legislative and financial frameworks. Legislation is not an end in itself and its impact depends on implementation, the sustainability of funding, and monitoring and evaluation. More detailed policy frameworks are also needed that ensure the translation of legal norms into practical programmes. At a minimum, these frameworks should incorporate the suggestions made by the UN Special Rapporteur (Box 6.1).

\section{Box 6.1 UN Special Rapporteur's suggestions on how to develop} inclusive education

(a) Legislation. Eliminate legislative or constitutional barriers to the inclusion of children and adults with disabilities in the regular education system. In this regard States should:

- Ensure a constitutional guarantee of free and compulsory basic education for all children;

- Adopt and entrench legislation aimed at ensuring the rights of persons with disabilities;

- Ensure that legislation prohibiting discrimination in employment is adopted and enforced. This will enable persons with disabilities to become teachers;

- Ratify the Convention on the Rights of Persons with Disabilities.

(b) Ministerial responsibility. Ensure that one ministry is responsible for the education of both children and adults. States may therefore need to: 
- Amend legislation so that the Ministry of Education is responsible for the provision of all education.

(c) Develop a mainstream system for all. Ensure that one school system is responsible for the education of all children in their region. To this end, States may need to:

- Amalgamate budgets and administration of special education and regular education within a geographical area;

- Adopt policy priorities and legislation that promote the inclusion of all students in the mainstream education system.

(d) Transform special schools into resource bases. Transform existing special education resources - special schools or classes - into resources to assist the mainstream system. To do this States may need to:

- Train special educators to serve as additional resources to regular teachers;

- Transfer students from special programmes to regular classes supported by the resource staff;

- Allocate financial resources for the adequate accommodation of all students and for technical assistance to support Ministry of Education officials, at district, school and classroom level;

- Revise testing methods to ensure that accommodation is made for students with disabilities.

(e) Teacher training. Provide pre-service and in-service training to teachers so that they can respond to diversity in the classroom. To this end, States may therefore need to:

- Train teachers in classroom techniques such as differentiated instruction and co-operative learning;

- Encourage persons with disabilities to train as teachers;

- Use pyramid training techniques where teachers, once trained in inclusive education methodologies, teach other teachers and so on.

(f) Train administrators. Provide training for educational administrators and support staff on best practice in response to individual student needs. States may need to: - Provide models of practice that provide support such as 'school-based support teams';

- Provide regular access to new knowledge on school and classroom 'best practices';

- Provide domestic research into best practice as it relates to inclusive education.

(g) Remove constraints on teachers. Ensure that conditions that constrain teachers to teach inclusively are addressed. To do this, States may need to:

- Address class size. Smaller class sizes are generally considered to be most effective;

- Revise and adapt curriculum content in accordance with best practice;

- Ensure that school buildings and materials are accessible to children with disabilities.

(h) Develop inclusive early years. Invest in inclusive early childhood care and education (ECCE) programmes, which can lay the foundation for lifelong inclusion of children with disabilities in both education and society. States may need to:

- Undertake a consultative process, including disabled people's organisations and groups for parents of disabled children, to develop a national ECCE policy; - Include ECCE in key government resource documents such as national budgets, sector plans and poverty reduction strategy papers.

(i) Train and empower parents. Provide training to parents of children with disabilities so that they know about their rights and what to do about it. Here States may need to: 


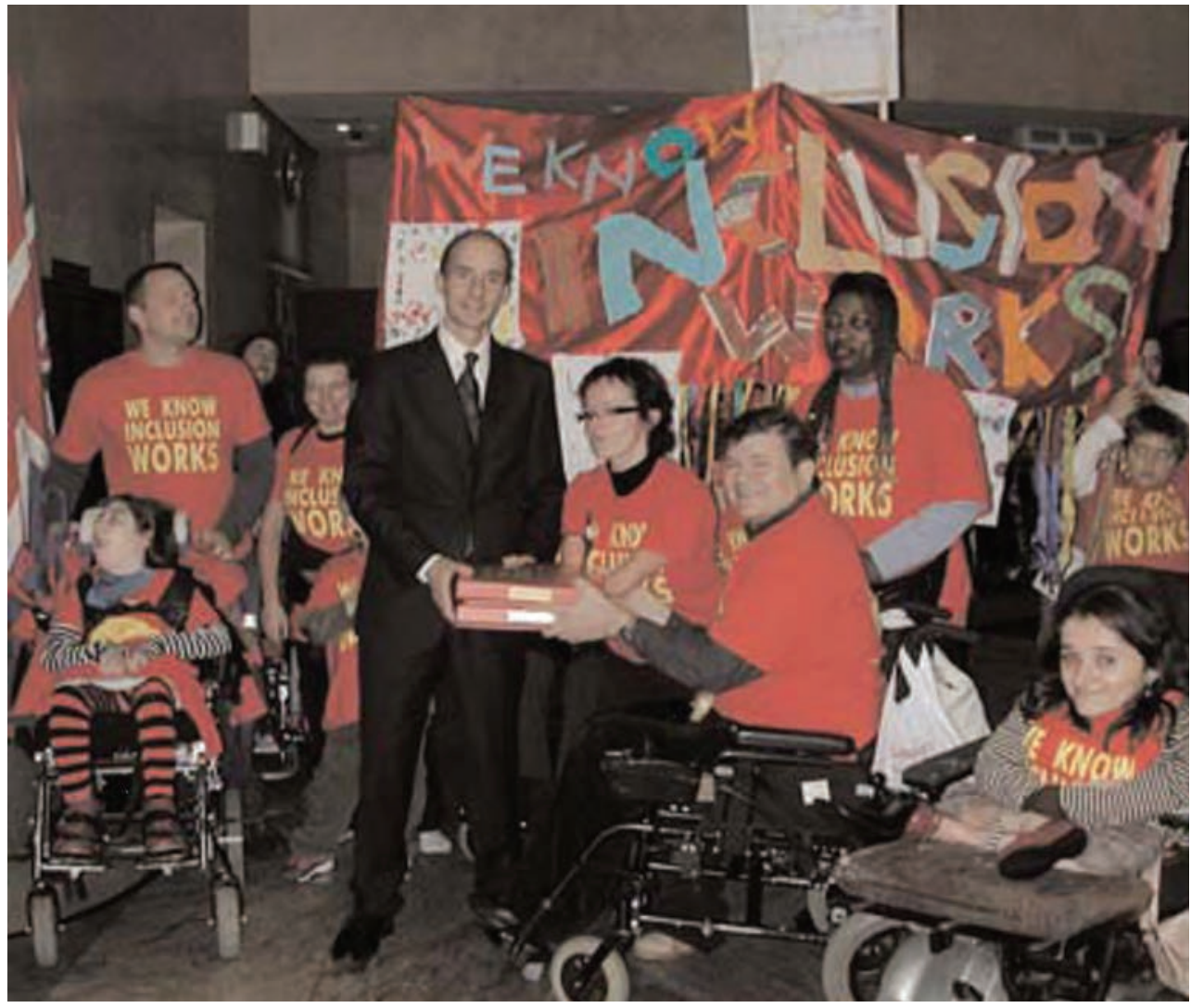

'We know inclusion works' - former UK Education Minister Lord Andrew Adonis with Tara Flood, Richard Rieser and campaigners for inclusive education.

CREDIT: ALLIANCE FOR INCLUSIVE EDUCATION

- Support civil organisations, including those of parents of children with disabilities, to build capacity on the right to education and how to influence effective policy and practice.

(j) Monitor enrolment and participation. Develop accountability mechanisms in order to monitor exclusion, school registration and completion of education by persons with disabilities. States should therefore, as a minimum:

- Adopt and revise reporting mechanisms to disaggregate data on school participation. Such data should specifically include type of disability.

(k) Prioritise international collaboration. Seek, and act upon, assistance as required. To this end, States may need to:

- Seek assistance on best practice from States and international and/or intergovernmental organizations;

- Integrate these best practices into legislative and policy frameworks;

- Where adequate resources are lacking, seek international assistance.

The UN Special Rapporteur also calls on national human rights institutions and civil society to participate actively in the design of inclusive education and to help monitor implementation and raise awareness.

Considerable efforts are being made by the World Bank, UNICEF and international NGOs to develop inclusive education, linked through the UNESCO Flagship on Education for All. These are now operating through regional groupings such as the Asia Pacific Forum. Some of these regional collaborations are far more developed than others. However, states themselves must take the lead in planning, funding and implementing the range of policy changes and initiatives outlined in this chapter. 


\section{Involving disabled people's organisations}

Disabled people and their organisations are key partners in this national process. Those who have experienced isolation and exclusion and attempted to achieve in a system not designed to meet their needs are best placed to ensure that the necessary changes of attitude come about. Without the involvement of disabled people, there is a danger that policy implementers will fail. Disability movements in every country need training to understand these complexities, so that they can become advocates for inclusive education at all levels. A recent training collaboration between the Southern African Federation of the Disabled and Disability Equality in Education showed the powerful effects of such training, with participants from all the eight countries that were involved increasing their understanding and developing strong national action plans (Box 6.3). ${ }^{147}$

\section{Involving the parents of disabled children}

Parents have often been in the vanguard of struggling for inclusion and full human rights for their disabled children. Often it is only parents who see the essential humanity in their children, through their love for them. All too often that relationship is broken by outside interventions. States should work in alliance with these parents and their organisations. However, many parents share the negative attitudes to disabled people current in their culture, as well as experiencing guilt. Parents need training, support and empowerment so that they can become allies of their children in their struggle for human rights. The organisations Parents for Inclusion (Box 6.5), Inclusion International and CAMRODD (Box 6.6) demonstrate how effective such empowered parents can be in advocating the development of inclusive education for disabled children.

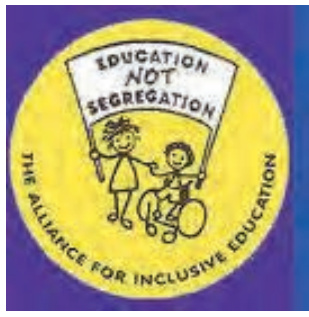

\section{Box 6.2 The Alliance for Inclusive Education}

The UK Alliance for Inclusive Education was founded in 1989 to campaign for integration for disabled children in mainstream schools. It brought together disabled adults and children, the parents of disabled children and professionals such as teachers and psychologists. The majority of its trustees are disabled people. It has run many grassroots campaigns in support of families wanting to get their disabled children into mainstream schools.

In 1994, in collaboration with Save the Children, it organised the Invisible Children Conference, to get the makers of TV programmes and books for children to represent disabled children in non-stereotyped ways. This highly influential conference led to a number of authors including disabled children in stories and illustrations, the founding of the One in Eight Group, that influenced the mainstream media in its portrayal of disabled people, and indirectly to the publication of Disabling Imagery (Rieser, 2004), an online resource and schools pack challenging the portrayal of disabled children in film. ${ }^{148}$

Disabled people's thinking has been the driving force of the Alliance, linked to the energy and will of parents who want an inclusive life for their children. In the 1990s the Alliance co-ordinated a campaign to get rid of compulsory segregation of disabled children in special schools. This culminated in the passing of the UK Special Educational Needs and Disability Act 2001, which gave all parents a real choice of mainstream education. 
In 2006 the Alliance lobbied the Department for Education and Skills. Evidence gathered from schools and families was presented to Education Minister Andrew Adonis. The lobby was held in response to uninformed and negative publicity opposing inclusive education in the UK. In 2010 the Alliance developed a Manifesto for Inclusion, which is currently endorsed by 500 individuals and organisations and forms the basis of the challenge to the current coalition government's policy of removing the so-called 'bias towards inclusion'. The main planks of the Manifesto are:

- All disabled learners have the legal right to attend mainstream courses in mainstream education settings.

- All disabled learners have the legal right to individualised support.

- Education buildings should be made accessible to all disabled learners.

- All mainstream course curricula should be accessible by and inclusive of disabled learners.

- All education assessments and accreditations should be inclusive.

- Compulsory disability equality training for all education professionals and staff. $^{149}$

Alliance for Inclusive Education, info@allfie.org.uk

\section{Box 6.3 Involving disabled people's organisations in Southern Africa}

The Southern African Federation of the Disabled is a regional body that brings together disabled people's organisations in ten countries in Southern Africa. SAFOD has a long history of self-organisation and advocacy for disabled people's rights. Recognising that there was a gap in its advocacy of inclusive education, SAFOD worked with the UK-based organisation Disability Equality in Education to raise funding from DFID for a pilot training week.

The course was designed to give participants an understanding of the rights contained in the UN Convention and how to campaign for them; examine different models of disability and how these can be applied to education; develop an understanding of how inclusive education can work in different contexts around the world; examine the barriers to inclusive education and the actions necessary to bring about inclusion; and design a country-wide action plan. There were participants from eight countries: Botswana, Lesotho, Malawi, Mozambique, Namibia, Swaziland, Zambia and Zimbabwe, comprising 18 disabled activists and leaders, 11 parents and three government representatives.

The workshop was interactive and participative. Surprisingly, much of the thinking developed in the UK was applicable to Southern Africa, when adjusted for poverty and cultural contexts. Many participants changed their thinking over the five-day course, including seven blind and deaf participants who had been educated in special schools. Participants from all the countries represented now want national training and produced national implementation plans to take back to their governments. As Alexander Phiri, then Director General of SAFOD and sadly deceased, said in an appeal for further funding to DFID: 


\section{A SAFOD training session.}

CREDIT: RICHARD RIESER
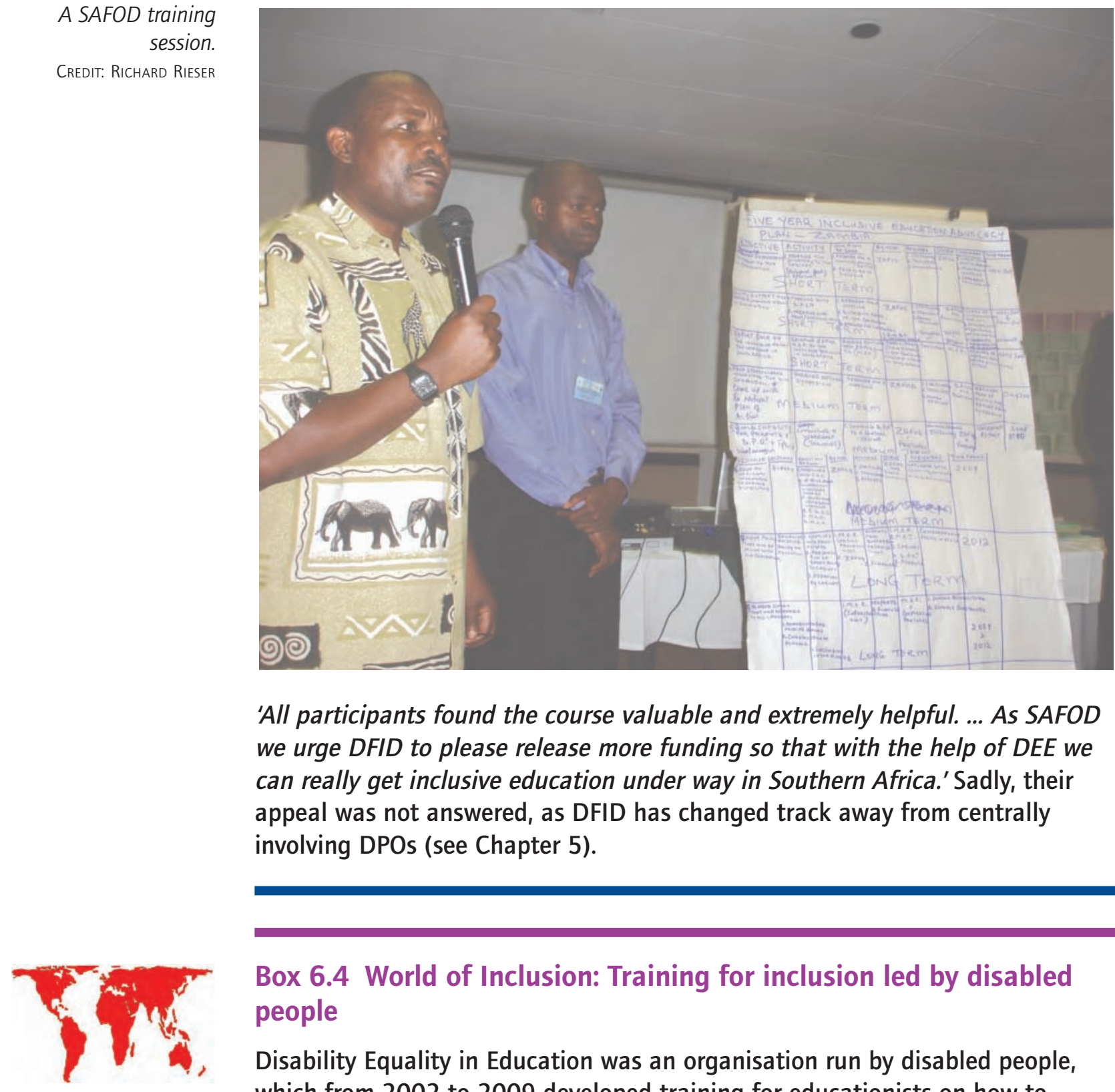

'All participants found the course valuable and extremely helpful. ... As SAFOD we urge DFID to please release more funding so that with the help of DEE we can really get inclusive education under way in Southern Africa.' Sadly, their appeal was not answered, as DFID has changed track away from centrally involving DPOs (see Chapter 5).

Box 6.4 World of Inclusion: Training for inclusion led by disabled people

Disability Equality in Education was an organisation run by disabled people, which from 2002 to 2009 developed training for educationists on how to develop inclusive education from a disability rights perspective. All the training was delivered by a network of disabled equality trainers. The work grew out of a ground-breaking collaboration between a disabled teacher, Richard Rieser, and a disabled parent of a disabled child, Micheline Mason, which produced Disability Equality in the Classroom: A Human Rights Issue (1990). The book was published by the Inner London Education Authority and sent to all local authorities in the UK and to schools in inner London.

The focus was on changing from a deficit special education model to a rightsbased equality model based on the thinking of the disabled people's movement.

Other groundbreaking publications followed: Altogether Better (Mason and Rieser, 1994) with Comic Relief; and All Equal All Different (Rieser, 2003), raising the issue of disability with teachers of 4-7 year olds. This included posters, story books written and illustrated by disabled people and many activities to use in the classroom to raise understanding of disability as social oppression. Disabling Imagery (2004), produced in collaboration with the 
British Film Institute, brought disability and the moving image into the school curriculum (www.bfi.org.uk/disabling imagery). In 2006 a pack was produced for the UK Government that examined best practice in making reasonable adjustments to include disabled children in the mainstream (DCFS, 2006). The 5.5 hours of film clips of 41 schools are still the most comprehensive exemplars of inclusion, working with children with every type and degree of impairment (see DVD 2 and Chapter 9).

Over 600 disabled people from England, Scotland, Wales and Northern Ireland attended 34 courses over 12 years. This led to a change in the thinking of the UK disability movement so that it supported inclusive education and to a network of 150 freelance DEE trainers. More than 120,000 educationists have attended DEE training sessions and this has been shown by independent evaluation to have substantially changed both attitudes and practices. Sadly, in 2009 DEE was wound up due to lack of government and donor support, but the model of training it developed stands as an example to be replicated. ${ }^{150}$ DEE also trained governors, parents, local authorities, educational psychologists and government departments. This type of capacity building needs to occur in every country.

In more recent years, trainers from DEE and its successor from January 2009, World of Inclusion, have delivered training in Mumbai, India, Egypt, Morocco, Argentina, Russia, Southern Africa (with SAFOD), Uganda, Ethiopia, Malaysia, Ukraine, Serbia, Saudi Arabia, Dubai and many European countries. The model developed relates individuals' experiences of education to the historical oppression disabled people have experienced, relating to traditional, medical and social models of disability. This is fused with the person-centred pedagogy developed by the inclusion movement in Canada and the USA. DEE materials are available on World of Inclusion's website, www.worldofinclusion.com

In 2007 DEE produced a film for the South African Government showing ten primary schools with promising inclusive practice in four provinces. This is available and can be viewed online. ${ }^{151}$

In 2008 DEE was commissioned by the UK Department for Children, Schools and Families (DCSF) to assess what impact the new public duty to promote disability equality was having in schools. Working with a youth organisation, Helping Empower Youth Activists (HEYA) and involving 140 disabled young people from over 40 secondary, primary and special schools, DEE ran 11 regional focus groups. The outcomes of this and an analysis of school disability equality schemes - a statutory requirement from 2006 to 2011 in England was given to the Secretary of State. The report demonstrated high levels of bullying and a lack of any consistent approach to disability in the curriculum. ${ }^{152}$

This led to World of Inclusion being commissioned by the Qualifications and Curriculum Authority to carry out action research with 25 schools on ways of bringing the social model approach to disability into the mainstream curriculum. Sadly, the Authority has been closed by the government, but the work the schools did, nine films and over 60 lesson ideas, are all online. ${ }^{153}$ This work led to the founding of UK Disability History Month (UKDHM) which ran for the first time in November/December 2010. UKDHM is not only aimed at schools and colleges but also trade unions, workplaces and the community. 
Training session for young people in the South Pacific. CREDIT: WORLD OF INCLUSION
Its aims are to:

- Help disabled people celebrate their struggles and achievements with their allies, including parents, friends, professionals, colleagues and neighbours;

- Create a greater understanding of the barriers in society that disable people, looking at the history of how such barriers are fuelled by negative attitudes and customs, while recognising this as oppressive disablism;

- Develop and campaign on what needs to be changed for disabled people to achieve full equality in all areas of life;

- Make equality a daily reality: the UK Government has passed the Equalities Act 2010 and ratified the UNCRPD. Much has to happen to make these rights a daily reality for the 12 million disabled children and adults in the UK;

- Recognise the multiple identities of disabled people and cover the full range of impairments, and link with disabled people who are also struggling against sexism, racism, homophobia and other forms of discrimination.

UKDHM is already supported by the main teachers' organisations, the TUC, UKDPC and over 80 UK organisations. ${ }^{154}$

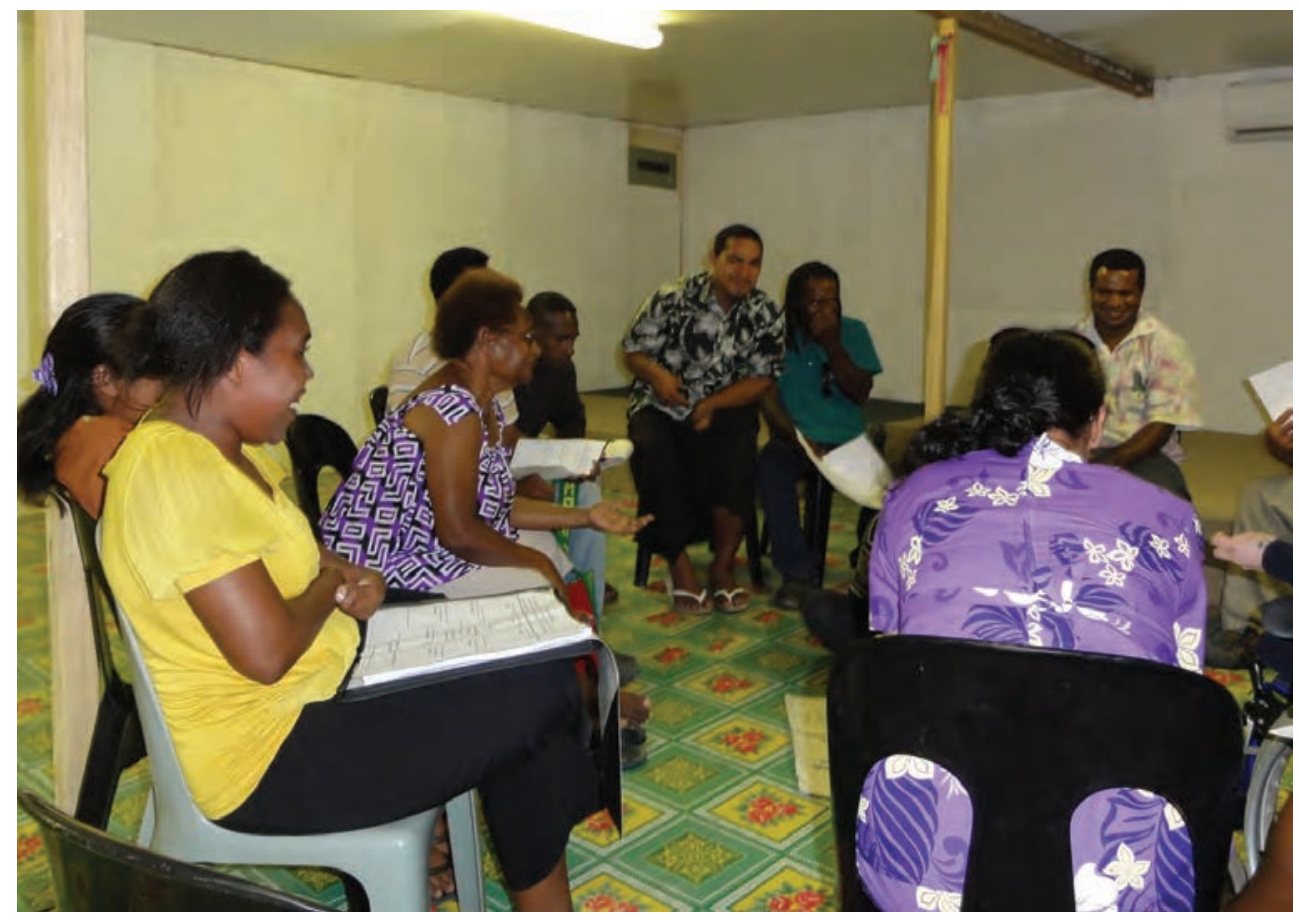

On behalf of the UKDPC, in 2010/2011 World of Inclusion carried out a capacity building project in the South Pacific in collaboration with the Pacific Disability Forum, funded by the Commonwealth Foundation. The training was targeted at two disabled leaders and one disabled youth leader from each of the eight Commonwealth South Pacific island countries. The participating countries were: Kiribati, Nauru, Papua New Guinea, Samoa, Solomon Islands, Tonga, Tuvalu and Vanuatu. The project consisted of a situation analysis, training pack, training materials and final report. Participants particularly liked the fact the training was led by disabled trainers with a focus on gender and youth equality. See www.worldofinclusion.com 


\section{Box 6.5 Parents for Inclusion}

Parents for Inclusion was formed in the 1980 s by parents who wanted inclusion for their disabled children and disabled activists - a fusion which led to an entirely new perspective, so that parents became

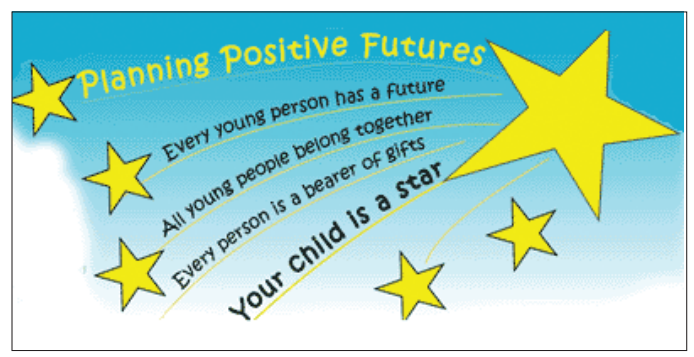
allies in their children's struggle.

Parents for Inclusion's mission statement says: We believe that it is physical and social barriers that stop disabled children from being included, rather than the disabled children themselves. Children often have little power to ask for what they want. They say they want to be able to make friends and be involved in their local community. They want to be able to get out and about, meet new people, enjoy their leisure time and go to their local school.

Parents and professionals have great influence over these children's futures. So we work with them to help them see children as individuals first, with human rights and preferences and a right to an optimistic and self-determined future.

Training: All our training is designed and delivered in partnership with experienced trainers. One trainer is a disabled person and the other is the parent of a disabled child. Listening to disabled people allows parents to see the world from their child's point of view. The disabled trainers use their own life stories to illustrate the training and present a positive role model of how a disabled child can grow up into a successful adult. We help parents to ensure that their child has access to transport, play, mainstream education, leisure and friends. We also introduce parents to disabled people in their own area.

Inclusion groups: Our inclusion group work puts co-operation between schools, parents and young people into practice. We started the first ever inclusion groups in schools in 1989. Meetings are open to anyone who has concerns about their child in school. We work closely with each school and invite all the parents to take part in an inclusion group meeting at the school. On average, eight parents attend each meeting. The facilitators are independent of the local education authority and the school. Only parents attend the first part of the meeting, so it is possible to talk very openly. The school's special educational needs co-ordinator (SENCO) is invited in at the end of the meeting and then everyone tries to come up with solutions. Headteachers are very satisfied with our work. Teachers tell us these groups prevent exclusions, and improve communication between teachers, parents and children. The number of inclusion groups rose rapidly to 180 (1,492 parents) in $2004 .{ }^{155}$

Many of these parents have joined disabled campaigners in the UK to challenge a new threat to inclusion from the UK Government - its determination to remove the 'bias to inclusion'. As many have already said, the bias is all the other way if one wants to choose mainstream education for one's disabled child. A rapidly growing campaign has been launched to counter government thinking - remove the 'bias to segregation'. ${ }^{156}$ The government's stance is ideological and breaks a 30-year political consensus in the UK. 


\section{Box 6.6 Developing a regional organisation in the Caribbean}

The Caribbean Association for Mobilizing Resources and Opportunities for People with Developmental Disabilities (CAMRODD) was launched in Jamaica in 1970 with parent groups from eight Caribbean islands. CAMRODD's members now include Antigua, Aruba, The Bahamas, Barbados, Belize, Bonaire, Cayman Islands, Curaçao, Dominica, Dominican Republic, Grenada, Guyana, Haiti, Jamaica, Montserrat, Puerto Rico, St Kitts and Nevis, St Lucia, St Vincent, Suriname, Trinidad and Tobago, Turks and Caicos Islands and Venezuela.

In its first 20 years, CAMRODD organised conferences every two years and campaigned for services. Themes included early detection and stimulation, vocational training, integrated childcare, special education, counselling programmes, parent-to-parent support and speech therapy. The training included portage, job counselling and placement, organisational development, public and parent awareness, advocacy and parent training.

In the late 1980s, CAMRODD shifted its focus to rights, based on the UN Declaration of Human Rights and the CRC. Slowly, its focus moved from parents working in isolation to collaboration between families, professionals and governments. A leadership training programme, SCOPE, was delivered in a wide range of member countries. The programme was designed for parents, family members, teachers, nurses and other professionals, so that communities could create opportunities for people with disabilities through equality. The training was sponsored by CIDA and the Canadian Association for Community Living, and was conducted by the then Director of the Roeher Institute, Marcia Rioux.

The goals of the programme were to:

- Explore a common vision of human rights based on equality;

- Link this vision to the UN Declaration of Human Rights and countries' obligations as signatories;

- Examine social policy development and its role in social change so that new approaches would be put into practice.

During the SCOPE course, participants design and implement a community development project.

From Enabling Education Network (EENET)

\section{What progress are states making in implementing inclusive} education?

A very mixed picture emerges from an examination of a cross-section of Commonwealth countries. First, no coherent survey exists which compares like with like, so we have drawn on case studies in reports and on the worldwide web. Having a national policy is the key to inclusion. Following the 1994 Salamanca Declaration, a number of countries committed themselves to developing an inclusive education system. They included India (Box 6.14), Lesotho (Box 6.16), Mozambique (Box 6.20), New Zealand (Box 6.21), Papua New Guinea (Box 6.23), South Africa (Box 6.26), Sri Lanka (Box 6.27), Uganda (Box 6.30) and the UK (Box 6.31). Having a plan without allocating 
resources, as in Nigeria or Mozambique, does not help much. Cyprus has a policy that requires every child to be offered a mainstream place and gives strong legal backing to the development of inclusion (Box 6.12). However, having a policy does not mean that it is implemented unless the government takes active steps to do so. Training programmes for teachers have proved a key determinant, as in India, Lesotho, New Zealand, Papua New Guinea, South Africa, Tanzania and Uganda.

Very often NGOs take the lead in initiating conferences and policy development, as the Norwegian agency, International Development Partners (IDP), did in Pakistan (Box 6.22), or in launching projects that include disabled pupils, as in Bangladesh (Boxes 6.8 and 6.9), Jamaica (Box 6.15) and Mongolia (Box 6.19). In Oriang, Kenya (Box 7.10), inclusion started with community-based rehabilitation identifying disabled children not in school and devising a programme in a few schools as a model to be rolled out to 300 schools in Kisumi Province. Crucial to this approach by Leonard Cheshire Disability is making links with a local university to provide longerterm training for teachers in meeting the needs of children with various impairments. LCD has extended this approach to Uganda, India, Sri Lanka and Bangladesh. A similar approach has been initiated by the Norwegian Association for Development Research (NFU) with the Tanzanian and Zanzibar Ministries of Education (Box 6.29), working with local disabled people's organisations.

Disability rights legislation in Queensland, Australia (Box 7.3), New Brunswick, Canada (Box 6.11 and 7.2), New Zealand (Box 6.21), India (Box 6.14), UK (Box 6.31) and South Africa (Box 6.26) has prompted challenges to the existing special educational needs system. School improvement for all lies behind approaches in New Zealand (Box 6.21) and Queensland (Box 7.3). Malaysia (Box 6.18) and Singapore (Box 6.25) are starting from a mixed approach of special and resourced mainstream under the strategy of 'many helping hands'. The central involvement of DPOs has been key in Lesotho (Box 6.16), Malawi (Box 6.17), Rwanda (Box 6.24) and Tanzania (Box 6.29).

There is much room for innovation in developing inclusive education. Schoolbased and district-based support groups in South Africa (Box 6.26) have significantly enhanced to inclusion. Brazil (Box 6.10) is constitutionally committed to challenging inequality and is redistributing funding from richer to poor areas. It is planned that every school should have an inclusion multifunctional resource room. Already 30,000 schools have these with resources for Braille, sign language and Easy Read. In the Amazon basin there are now schools on barges which follow nomadic people. A similar innovation is also taking place in Bangladesh.

International agencies are beginning to have an impact in moving states forward by exchanging good practices and developing conceptual frameworks. UNESCO Bangkok has been particularly proactive. International co-operation is clearly very important in the development of inclusive education (Box 6.32). In looking at how to develop inclusive policies, states should apply Article 32 of the UNCRPD:

States parties recognise the importance of international co-operation and its promotion, in support of national efforts for the realisation of the purpose and objectives of the present Convention, and will undertake appropriate and effective measures in this regard, between and among States and, as appropriate, in partnership with relevant international and regional organisations and civil society, in particular organisations of persons with disabilities.

Such collaborative measures to enhance disability equality include training and capacity building, making the development process accessible and facilitating research and knowledge exchange. 


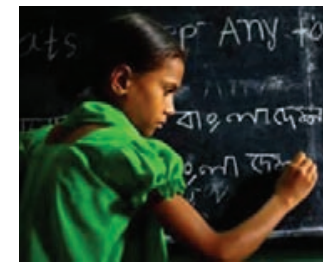

Learning to write in a primary school in Bangladesh. CREDIT: GURU

\section{Box 6.7 Bangladesh: Situational analysis}

The Centre for Services and Information in Bangladesh was commissioned in 2005 as part of a knowledge and research project funded by DFID. Special, integrated and inclusive educational methods are being used to educate disabled children. The Government of Bangladesh has established a special and integrated education service and NGOs are implementing the system. The Department of Social Services (DSS) runs five special schools for blind children, seven for deaf children and one for intellectually disabled children. It also maintains 64 integrated schools for blind children in 64 different districts. NGOs operate many special and inclusive education centres, but no reliable data are available.

There are major shortfalls in the existing educational system for disabled children.

1. In the special education system:

- The number of government special and integrated education institutions operated by the Ministry of Social Welfare is inadequate;

- The non-governmental special education system is very costly;

- Insufficient government resources are allocated;

- Teachers receive low salaries and benefits, causing a lack of interest in teaching children with special needs;

- Early detection and intervention programmes are inadequate: each school has 60-70 places, but there is no system for identifying disabled children or encouraging them to enrol, so many places are not filled;

- Teacher training facilities are inadequate;

- Teachers have an interest in training to enhance capacity and develop skills, but the authorities (government and NGOs) are not interested;

- Most schools are not physically accessible;

- There is no uniform curriculum in the schools run by NGOs to accommodate different types of disabled children;

- Sign language used in special schools for hearing and speech-impaired children is in English, so they cannot communicate with others in their families and communities. Bengali singing has been developed recently, but is not yet widely practised;

- There is a lack of relevant support systems, and of therapeutic and assistive technology;

- The emphasis on vocational training is insufficiently geared to enabling pupils to go on to higher education;

- Children do not have the option of applying for inclusive education.

2. In the integrated education system:

- An integrated education system is only being operated by the government and then only for blind boys;

- The supply of Braille books and equipment is inadequate;

- There are low remuneration and benefits for teachers; 
- Resource teachers have no opportunities to develop further skills;

- Integrated schools receive insufficient resources for the proper support of blind children.

3. In the inclusive education system:

- The inclusive education system has only been introduced very recently and is operated by NGOs in non-formal education settings and primarily in rural areas;

- Most of the schools are pre-primary level;

- Teachers are not adequately qualified and trained;

- Only marginalised children with mild degrees of disability are enrolled in inclusive schools;

- Classrooms and premises are not accessible and seating arrangements are not comfortable for disabled children;

- The classroom environment is not suitable for accommodating different types of disabled children;

- Supply of teaching and learning materials and equipment is inadequate. ${ }^{157}$

A evaluation of inclusive education in Bangladesh (UNICEF, 2003) made the following further points:

- There are many misconceptions concerning disability - even when people with disabilities have the required qualifications, they are discriminated against in the job market.

- Although school enrolment is increasing fast, the enrolment of disabled children is extremely low. Children with disabilities are often marginalised in mainstream schools as a result of negative attitudes. A lack of child-centred approaches in education and the physical inaccessibility of schools are other reasons for low enrolment.

- The curriculum lacks the required flexibility to cater for the needs of children with disabilities.

- There are limited developmentally appropriate teaching and learning materials for children with and without disabilities.

- Special schools lack assistive devices for children with disabilities. The teaching-learning process does not address the individual learning needs of children.

- There is little scope for children's participation in creative activity or critical thinking.

- Bangladesh still practises corporal punishment. The classroom environment is such that students are afraid of teachers, and there is a one-way teachinglearning process in which teachers lecture and children listen.

- However, there is a growing interest among educators and policy-makers in providing education for all children in an inclusive setting.

Many government primary schools are running a 'double shift'; the number of students per class is unacceptably high - often $80-100$. Teachers are poorly 
trained with little supervision or support. The Primary Education Development Plan II (2004-2010) has been designed to tackle many of these problems. However, progress so far has been slow. Even if the plan reaches its targets, it may do little to address the problems of access and large classes.

The success of non-formal programmes in Bangladesh, such as BRAC, needs to be given much greater consideration by government if it is to achieve the Education for All targets.

\subsection{The Bangladesh Rural Advancement Committee Education Programme $e^{158}$}

Primary schools remain the largest component of the BRAC programme. The target groups are the poor, those living in remote areas, girls who have dropped out or never enrolled in school, children from ethnic minority groups and disabled children. To date, 3,115,031 children have graduated from the BRAC primary system and $2,876,472$ have made the transition to the formal system. Each phase has contributed to the overall aim of providing educational opportunities for children who are not served by the mainstream educational system. The programme is NGO based and aims to eventually dovetail with the government primary education system and become a resource provider.

In recent years, the BRAC Education Programme has expanded to include continuing education and life skills training for adolescents. In close co-operation with the Government of Bangladesh it has provided pre-primary education and in-service teacher training for primary and secondary school teachers. In 2006 there were more than 32,000 primary schools serving just under a million children and an additional 20,000 pre-primary schools serving more than half a million children. A total of 25,000 disabled children are catered for in these schools. The expansion to Grades 4 and 5 in 1999 posed challenges, especially in maintaining the child-friendly environment and stopping a drift to traditional teaching methods. However, unlike in government primary schools, the full cycle is covered in four years and the same teacher remains with the class for all subjects through the full cycle.

According to the baseline survey conducted for the Primary Education Development Plan II, the net enrolment rate in the primary education system for the baseline year 2005 was 87 per cent (gross enrolment of 95\%), with a survival rate to Grade 5 of about 54 per cent. When compared to government primary schools, there is a very low drop-out rate in BRAC schools. In 2005, for example, the survival rate to Grade 5 in BRAC primary schools was 94 per cent. In 2006, 98.6 per cent of BRAC primary school Grade 5 leavers went on to secondary school, compared to less than half from government schools.

When setting up a new primary school, BRAC ensures there are sufficient poor children (30-33\%) in the area; that 65 per cent are girls; that pupils with special educational needs are not in school in the area; that there is no other school within $1.1 \mathrm{~km}$; that there is a suitable person to become the teacher - a female aged 20-35 years with SSC (Grade 10), preferably married; that a certificate of non-enrolment is signed by the local government primary school; and that there is a suitable building or land on which to build a school. 


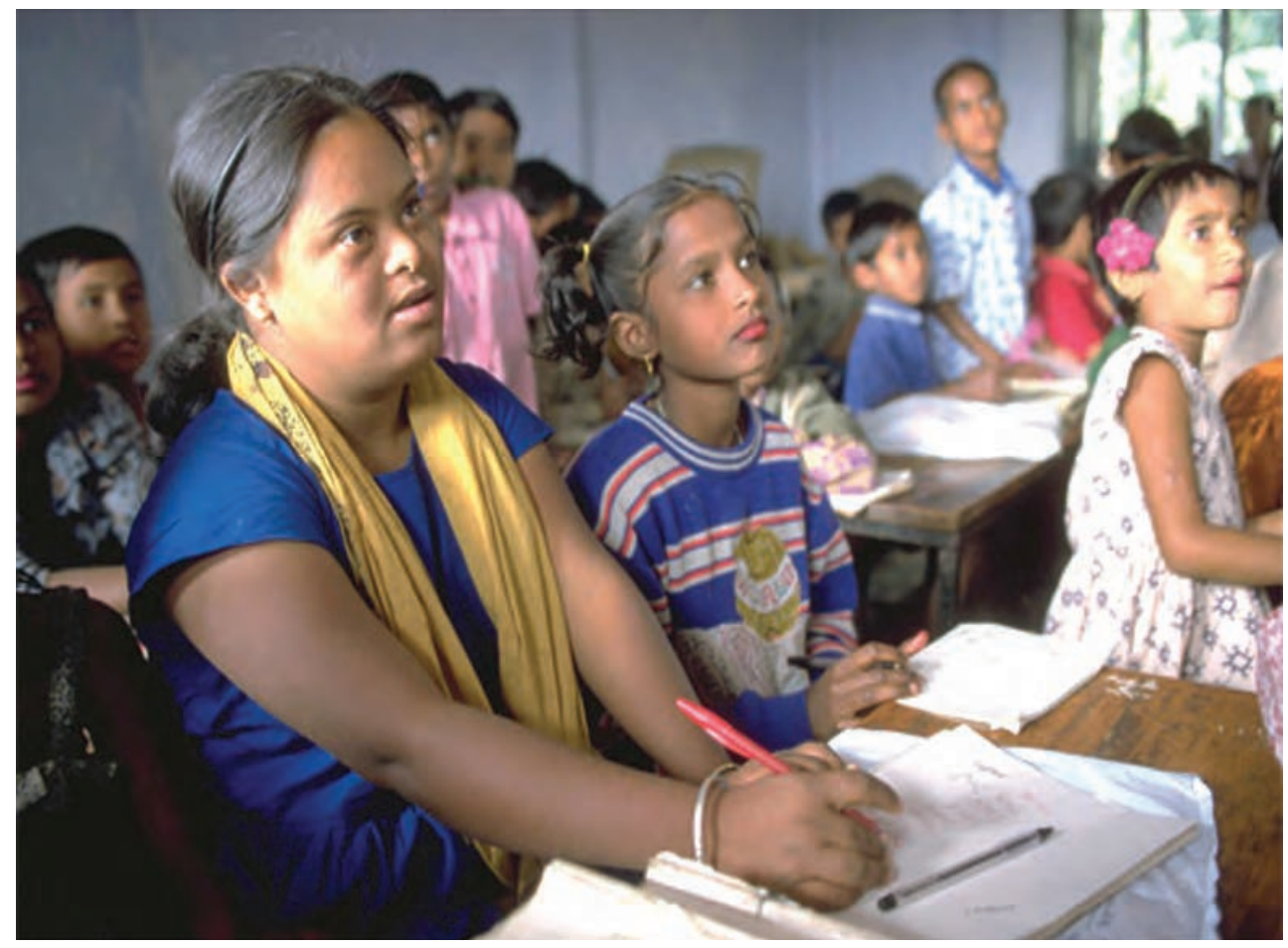

Over the years, all the numerous reports on the BRAC Education Programme praise its capacity to maintain high standards; to offer in-service training; to deliver supplies on time to even the most remote schools; to recruit, train and retain women teachers; and to achieve relatively high levels of literacy and numeracy among the students. These accomplishments are all the more amazing considering that the students in BEP's schools come mainly from families with little experience of education. The 2007 review notes that these characteristics remain key features of the programme.

At the end of 2006, the education support programme (ESP) was supporting 624 NGOs in providing education from Grades 1 to 3 for 164,838 children in 5500 non-formal primary education (NFPE) schools. The coverage extends to 63 of the 64 districts in Bangladesh. The materials and methods used in the ESP schools are the same as those used in BRAC Education Programme schools with a few modifications, and a number of studies have confirmed that children achieve similar levels in the two programmes at the end of Grade 3. This also empowers local disabled people's organisations and NGOs. Including schools that are to be opened with new funds approved by the European Commission, the ESP expects to have 7,000 schools in 2007 with over 200,000 pupils.

In 2003, BRAC set out to include disabled children in its schools. With four central staff and 14 regional trainers, staff were trained, assistive devices supplied and materials produced to develop positive attitudes. By 2006, 24,565 children with some form of special need had been enrolled in BRAC primary schools and pre-schools. In the Bangladesh context the mere enrolment of such a large number of children with special needs and their integration are major achievements, particularly considering that a few years ago there were no disabled children in BRAC schools and that even today there are very few in mainstream government schools. Training has been provided for 1,861 teachers and staff, medical support (surgery and/or treatment) for 2,324 children and 


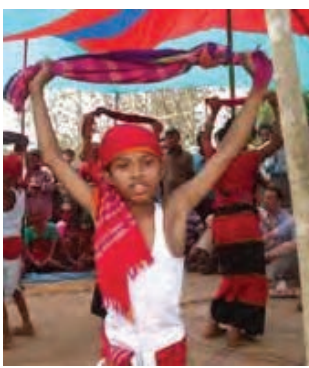

Celebrating inclusive primary education.

CREDIt: EENET assistive devices for 2,300 disabled children. Where needed, entry to centres has been adjusted to allow for wheelchair access. The unit has produced a number of materials, including a guide on disability issues for BEP staff, an awareness poster, a video on children with special needs and story books.

One of the most notable recent initiatives undertaken by ESP is a joint programme with Sightsavers International (SSI) to integrate sight-impaired children into ESP schools. SSI has provided training for staff of BRAC and partner NGOs as well as for teachers, including in the use of Braille. A number of sight-impaired children are now enrolled in ESP schools. Discussions are underway with SSI on setting up a Braille production centre. The additional costs are not high, and the initiative represents a major step forward. The initiative is at a pilot stage and issues such as the additional resources required will be considered before scaling up the programme.

\subsection{Bangladesh: Sightsavers Programme}

In Bangladesh, disabled children are among the most marginalised groups in the mainstream education system, especially children with visual impairment. The education of people with disabilities is still administered by the Department of Social Services under the Ministry of Social Welfare (MoSW).

Since late 2004, Sightsavers Bangladesh Country Office, with its NGO partners Centre for Disability in Development (CDD), Action for Blind Children (ABC) and Gram Bikash Sangstha (GBS), has put in place an inclusive education programme for disabled children (especially blind and low vision children) with permission from the Ministry of Primary and Mass Education in Narsingdi and Bogra districts. The programme includes capacity-building initiatives, provision for supply of educational materials, and school adaptation and awarenessraising. At the same time, advocacy initiatives at local and national levels have continued, creating significant changes for disabled children in selected mainstream schools.

The ultimate aim of Sightsavers' 'education change theme' under the Sightsavers strategic framework 2009-2013 is that governments will ensure that all disabled children can receive a quality education within the wider education system. The short- to medium-term aim is that: 'Sightsavers will demonstrate approaches to delivering high quality education for visually impaired children in their local context which are scalable, adaptable and costeffective'. Sightsavers' programme has meant that:

- 517 visually impaired children are studying in 105 mainstream primary schools ( 214 children) and 36 GIEP schools (303 children);

- 182 government primary school teachers received training in inclusive education and Braille;

- 38 mainstream schools were adapted for visually impaired learners;

- 23 instructors at Cox's Bazar Primary Teachers Training Institute have been trained in inclusive education;

- 48 self-help group members have been provided with training in Braille; 
- 18,896 students were tested, diagnosed, received treatment or were referred to eye care services for refraction. 698 students were prescribed spectacles through a schools sight testing programme;

- Nine resource centres were established at Narsingdi, Gaibandha, Chuadanga, Moulvibazar, Dhaka, Khagrachari, Barisal, Lalmonirhat and Laxmipur schools under the Government Integrated Education Programme (GIEP);

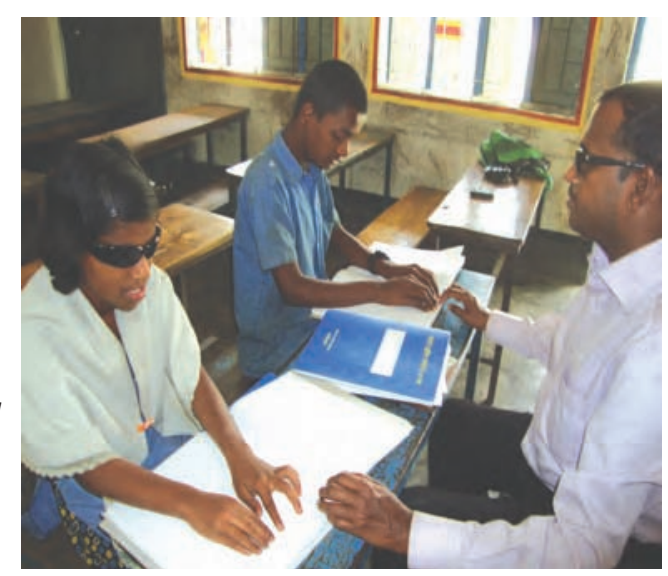

An itinerant teacher of blind students.

CREDIT: Sichtsavers

- 441 Braille books and 275 Braille equipment were supplied to GIEPs; ${ }^{159}$

- 58 resource teachers and house parents/GIEP teachers received training on inclusive education and mathematics for visually impaired children;

- 48 general GIEP teachers attended a one-day orientation course on inclusive education;

- 14 DSS instructors and trainers received orientation on inclusive education, 30 November-2 December 2010.

Despite many NGO initiatives showing how disabled pupils can be successfully included, the Government of Bangladesh has not yet developed a comprehensive plan to scale up inclusive education. This needs sufficient political will and funding to make it a reality, as required under the progressive realisation provisions of Article 24 of the UNCRPD. There are many DPOs in Bangladesh and they need to be systematically trained and involved at all levels.

\section{Box 6.10 Brazil: Whole country change}

Inequalities in access to education and educational performance are very evident among Brazilian children, young people and adults. This particularly affects some ethnic groups, poor people, rural populations, disabled students, and youth and adults who have not concluded compulsory education at the conventional age. However, a firm commitment from President Lula and his successor, Dilma Rousseff, to social equality, a steady economic growth of 10 per cent and support from donors is leading to the development of real social change and inclusive education in Brazil.

The 1988 Federal Constitution defined education as a social right for all Brazilian citizens and an obligation on the state and family. The responsibility for enforcing this right falls on the federal government and the states. The federal districts and the cities divide this responsibility between them. The federal government organises the system, finances public education institutions and exercises a redistributive function to guarantee equalisation of educational opportunities and a minimum quality standard. The cities have the main responsibility for early years and primary education. Since 2008 , this covers all 


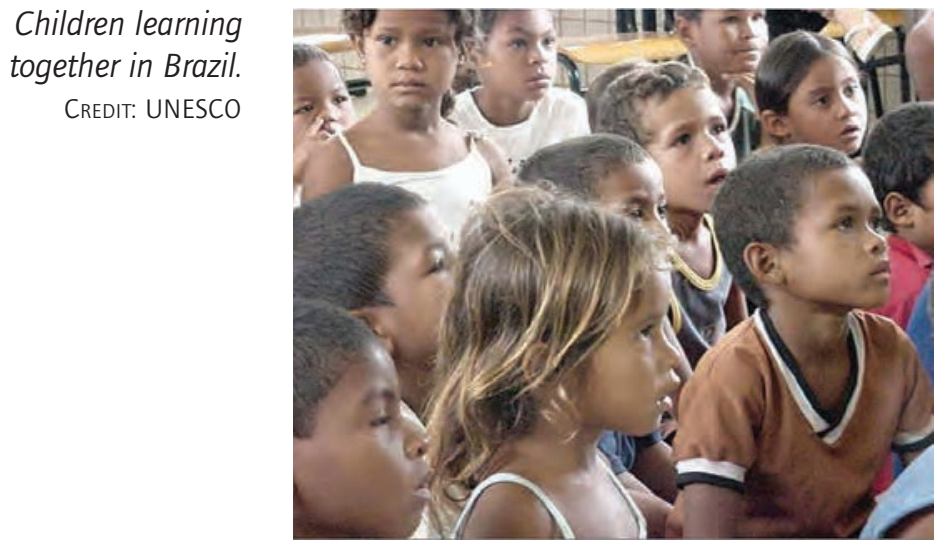

6-14 year olds, together with preschool children from birth to 5 years old. From 2001 the National Education Plan's objectives have included special education partnerships, health and social care providers in all cities; adequate educational interaction in early childhood; transport, spoken textbooks, large print, Braille and Brazilian sign language, and access to buildings. In the same year, national guidelines on special education provided for the enrolment of all students in basic education and made schools responsible for providing quality education.

Article 7 required the care of all students with SEN to be realised in regular classes, ${ }^{160}$ drawing on Law 10.098 of 2000 and 10.171 of 2001. This provides that education systems must 'ensure access for students who show special educational needs, through the elimination of urban architectural barriers, in buildings - including the facilities, equipment and furniture - and in school transport, as well as the barriers in communication, providing the schools with necessary human resources and materials'.

In 2006, 56 million children out of a population of 170 million were enrolled in early years and school education. Primary net enrolment was 96 per cent, compared with 90 per cent in 2000 . However, the census identified 28 million disabled people, so there is still a long way to go to get all into basic education. Traditionally, special education was organised as a parallel system with strong presence private sector involvement. The proportion of pupils with special needs who attend ordinary schools rose from 21 per cent in 2000 to 47 per cent in 2006.

'A cornerstone in Brazil's economic and social development has to embrace all Brazilians, especially disabled children who can escape lives of poverty and blunted opportunity by getting the education that others in the community take for granted', says Vinod Thomas, World Bank Country Director for Brazil. ${ }^{161}$

In 2007, the Ministry of Education launched the Educational Development Plan (PDE). This includes 40 programmes or actions to reduce social exclusion and cultural marginalisation. A big focus is on improving literacy and preventing drop-out by guaranteed minimum wages and hours for teachers, guaranteed one-third non-contact time, libraries and books. Most crucially for disabled students, the PDE provides for the installation of multifunctional resource rooms, equipped with television, computers, DVD and software for accessibility, furniture and educational material specific to Braille, sign language LIBRAS, and augmentative and alternative communication. ${ }^{162}$ At the Conference of States Parties on the UNCRPD held in September 2010, it was reported that 22,000 such rooms had been installed and Brazil would meet its target of 30,000 by 2011 . At the same meeting it was reported that the Brazilian Government was also supporting mobile classrooms on barges in the Amazon basin to reach out-of-school indigenous children. ${ }^{163}$ 
Infrastructure is only part of the picture and since 2001 there has been a major programme of training administrators and teachers in the methods of inclusive education on a trickle-down, diffusion model, from federal government to the cities. The themes developed include the fundamentals of inclusive education; specialised education services for mentally handicapped people; assistive technologies in the educational process; the inclusion of deaf and hearingimpaired students and blind and visually-impaired students; and the inclusion of autistic students. ${ }^{164}$

Independent assessments of the development of inclusive education identify teacher training and training for administrators as the two largest barriers. ${ }^{165}$ Improvements in the training and quality of the teaching are key and since December 2009 a national minimum salary came into force and representative committees of different stakeholders oversee teacher training.

There is still much unevenness in the development of the education system in Brazil, but the clear resolve of the government is leading to innovative practice in various municipalities.

Brazil's FUNDEF programme devotes 60 per cent of its resources to recruiting and training more teachers in poorer states. Qualified teachers help students to avoid grade repetition and drop-out. ${ }^{166}$

Changes are still being made, but there have been major advances with new values and beliefs being internalised after questioning of the milestones and objectives imposed by the political commitment to overcome exclusive practices.

\section{Box 6.11 Canada: Profile of inclusive education}

In far too many Canadian schools, pupils who fall outside the norm are sent away to segregated special education services. Over 40 per cent of children with intellectual disabilities in Canada aged 5-14 are in special classes or segregated schools. Gordon Porter, Director of Inclusive Education at the Canadian Association for Community Living (CACL), argues that it is time to end this archaic practice. Canadian children should be educated in heterogeneous classrooms where the diversity of students is welcomed, celebrated and nurtured, and Canada's schools must become inclusive and reflective of the values of the society they serve (Porter, 2004).

CACL is a national association with over 40,000 members, 400 local, family-led groups and 13 provincial and territorial associations. It campaigns for people with intellectual impairments to:

- Have the same access to choice, supports and services as other people;

- Have the same opportunities as others to live in freedom and dignity, and receive the support they need to do so.

One of CACL's key demands is for full inclusive education for all disabled young people, but particularly those with intellectual impairments.

In 2009 CACL provided a useful overview of the state of inclusive education in Canada. ${ }^{167}$ Due to Canada's federated structure, the provision of education rests almost exclusively in the jurisdiction of provincial and territorial 


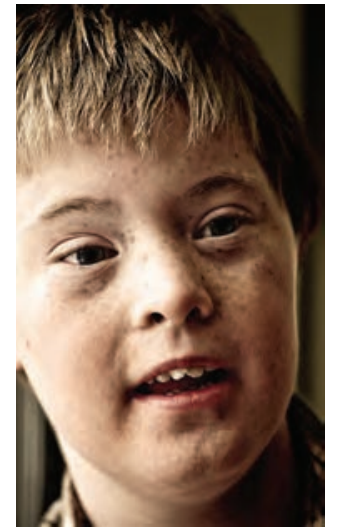

Eager to learn inclusive education in Canada. CREDIT: CACL governments. There is no federal education department and no national education system. The federal government does, however, provide financial support through transfer payments for post-secondary education.

Each of Canada's ten provinces and three territories have departments or ministries of education; in some cases there are two ministries - one for elementary and secondary education and one for post-secondary. While there is some consistency between provincial and territorial education systems throughout the country, each jurisdiction has a separate legislative and policy framework and practices guiding the delivery of education.

Generally, all jurisdictions have legislation protecting the right to a free public education for all between the ages of 5 and 18. There is, however, no consistent legislative provision regarding the education of disabled children. The Yukon, Nunavut and Northwest Territories, as well as the province of New Brunswick, have strong policies on inclusive education. The policies of most other provinces, while allowing and even encouraging inclusion, are based on the special education model. From a legislative perspective, the province of New Brunswick remains the sole jurisdiction that explicitly mandates inclusion.

Canada's broader legal framework, at both the provincial/territorial and federal level, offers protections for disabled students. The Canadian Charter of Rights and Freedoms and the Canadian Human Rights Act secure equal rights for disabled people. Similarly, equality rights protections are entrenched in provincial and territorial human rights acts. Provincial and territorial courts and human rights tribunals, as well as the federal courts, provide parents and students with mechanisms to mount legal challenges to discrimination in education on the basis of disability.

Education in Canada is provided in public, private and separate schools. Separate schools are predominantly based on religion. According to the Council of Ministers of Education, public and separate school systems that are publicly funded serve about 93 per cent of all students. Historically, disabled students did not receive equal benefit from public education: exclusion from any form of public education was the norm.

Early efforts relating to the education of disabled students were largely confined to a special education/segregated model. In the late 1950s and throughout the 1960s and 1970s, a growing community living movement, led by families, pushed for change and called for the provision of special education. By the 1970s, separate special education classes located in regular schools were increasingly the norm (Hutchinson, 2007).

The history of inclusive education in Canada can be traced back to Hamilton, Ontario, when in 1969 the Hamilton-Wentworth Separate School Board changed from a special education model to an inclusive model (Box 7.4). It was not until the 1980s that the demand for including disabled children in regular schools and classrooms took off. This call for reform was supported by the equality provisions of the Canadian Charter of Rights and Freedoms in 1985.

Currently, educational settings for disabled students typically include: full-time education in the regular classroom and part-time or full-time special education. While segregated schools are relatively uncommon in Canada, they do still exist in most jurisdictions. 


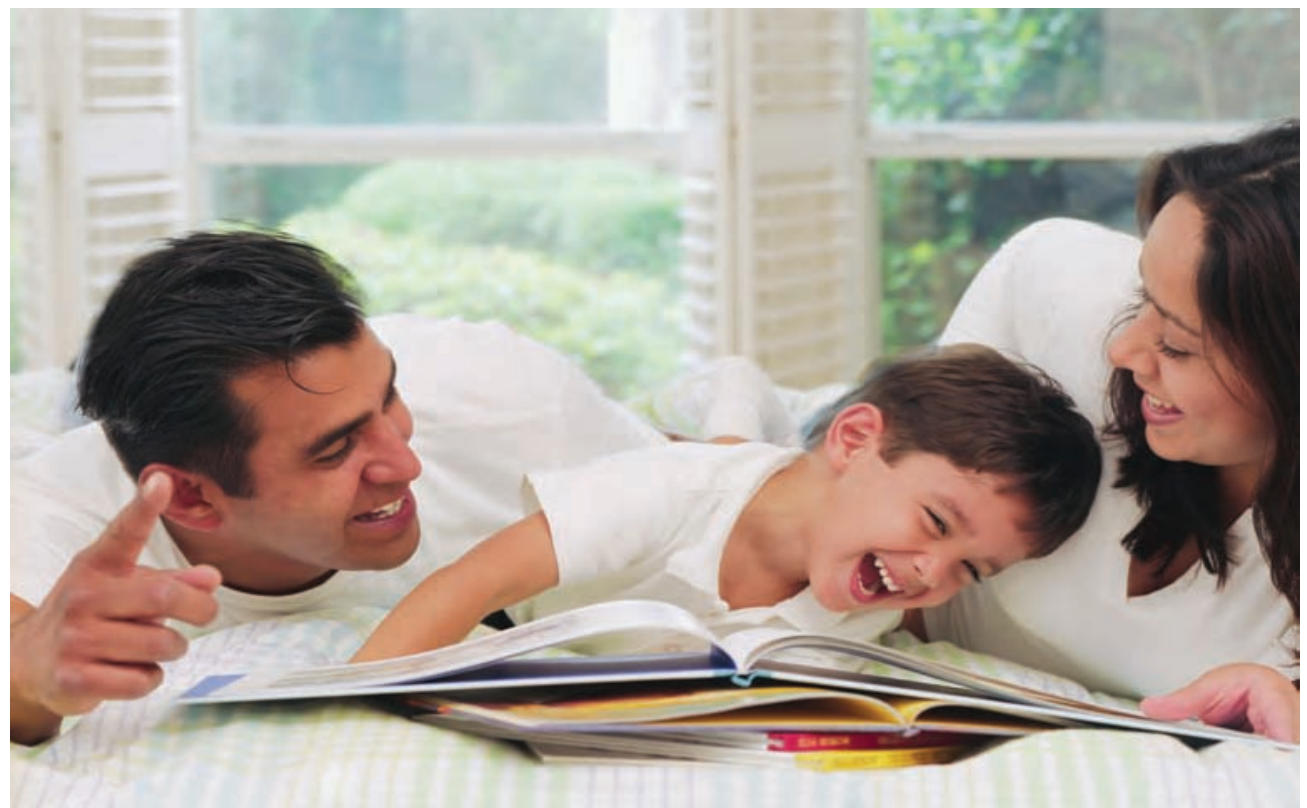

A report published by the Roeher Institute (2005) explains:

The special education model has grown from roots in the medical/psychological approach to disability. It is based on the belief that academic and social differences between students with and without disabilities are of such significance that separate educational provisions are required for many individuals. Students are clustered according to type and degree of disability (e.g. developmental delay, learning disabilities, giftedness, etc.) and are often set apart from other students through special settings, special teachers, special pedagogical approaches and formal identification and categorisation (i.e. 'labelling').

In a special education framework, disabled students may sometimes be integrated in regular classrooms on a full- or part-time basis. However, there is always the chance that the inability of a disabled student to keep up with the other students will lead to an alternative placement because this inability is typically framed as the failure of the student, rather than the shortcomings of the teaching methods or resources. Once designated as a learner with 'special needs' and assigned to special education, it can be difficult for the student to overcome this status.

The inclusive education model challenges the cornerstone of the special education model, notably the belief that differences in academic or social achievement between students with and without disabilities cannot be accommodated in a regular educational setting and that special settings are more effective than regular classroom environments for disabled students.

The most recent data relating to the education of disabled children in Canada can be found in the 2006 Participation and Activity Limitation Survey (PALS) (Statistics Canada, 2008). According to PALS, 56.7 per cent of disabled students aged 5-14 are in regular education; 26.9 per cent are in part-time special education; and 16.2 per cent are in full-time special education.

A closer look reveals that inclusion in regular education is more common for younger students. 63.6 per cent of students aged 5-9 are included in regular education; this falls to 51.7 per cent for students aged 10-14. 
In its 2008 National Report Card on the Status of Canadians with Intellectual Disabilities, CACL reveals that:

- In most schools there is a separate budget for the education of disabled students;

- Nearly 70 per cent of adults with intellectual disabilities have less than high school graduation;

- Only 15.5 per cent of adults with intellectual disabilities have participated in any form of post-secondary education;

- 22.5 per cent of children with intellectual disabilities have had to leave their community to attend school;

- Two-thirds of school-age children with intellectual disabilities are segregated in special classes or schools some or all the time, or do not attend at all;

- Students with intellectual disabilities are half as likely as students with other disabilities to be only in regular classes and four times more likely to be only in special education;

- Parents report that regardless of placement, the overall level of interaction with other children is less than satisfactory;

- Only 33 per cent of the Canadian public is fully supportive of inclusive education of children with intellectual disabilities;

- While more and more teachers value inclusive education, they report that in-class supports, preparation time and teacher training are lacking.

Despite a clear shift towards inclusive education over the past 50 years and compelling evidence for the effectiveness of inclusive education, there are still disabled students, in particular with intellectual disabilities, who do not have access to quality inclusive education.

Porter (2008a) asserts: 'creating inclusive schools is not a one-time job. Successful inclusion requires persistence and innovation to sustain the effort and to develop approaches to meet the new challenges that emerge over time'.

Gordon Porter was a school leader in New Brunswick, who pioneered the development of an inclusive school from 1982 to 1985 and is currently Chair of the New Brunswick Human Rights Commission. Looking back over the last 20 years, from a position where 99 per cent of disabled children in New Brunswick now attend their local school, Porter suggests the following steps:

1. Drawing up a plan for transition and change - and accepting that it will take at least 3-5 years to do this properly;

2. School staff must know how to make their schools and classrooms effective for diverse student populations - so there is a need for investment in training for existing teachers and school leaders, as well as for new teachers;

3. Understanding that teachers need support to meet this challenge, we need to work with them and their associations to develop supports they need;

4. The creation of positive models of success - classrooms, schools and communities that do a good job and can share their strategies with neighbours; 
5. Identifying a cadre of leaders and innovators at all levels and helping them build networks where they can share knowledge unique to their communities;

6. Sharing best practices from research and knowledge that is already available and that can be enriched and enhanced by local experience;

7. Understanding that innovations and changes that will make a difference will require resources - this means money and people (Porter, 2008a).

\section{Outcomes}

Lifelong patterns of inclusion are established in early childhood education, pre-schools, in the classroom and on the playgrounds of neighbourhood schools. Research reveals that children who are included in their early years have better outcomes for inclusion as adults. When disabled children and young people grow and learn alongside their peers, they are more likely to continue in education, get a job, and be included and valued in their communities. Research has shown that inclusive education is better for all children. Children learn from their experience: inclusive education enables non-disabled children to learn about diversity, and to respect and value everyone.

Wagner and Timmons (2008) find 'a clear association between inclusive practices and positive health, social and academic outcomes'. Crawford (2008b) concurs and states that the research has found 'a fairly consistent, positive relationship between the inclusiveness of educational arrangements and a range of social and economic states that are generally considered desirable and to be preferred'.

Regardless of the type or severity of impairment, people in a high inclusion group are more likely to be employed and have a history of paid work; to have incomes above the 'poverty line'; and to have graduated from high school. Those most likely to have incomes below Statistics Canada's 'low income cut-off' (the unofficial 'poverty line') are in the low inclusion group.

Outcomes also include increased social capital. Disabled students who attend regular classes are more likely than their counterparts in other educational arrangements to:

- Socialise with other children at school during recess or lunch hours;

- Interact with schoolfriends at home and elsewhere after school;

- Take part in extra-curricular activities.

Lastly, inclusive education is found to be a positive benefit for all students, and not just for disabled students. Willms $(2000 ; 2006)$ found that academic and social achievement is higher in regular education with groupings of students with mixed ability and from diverse backgrounds. Similar findings have been documented by the Roeher Institute (2005).

In 2008 a forum on 'Defining a Rights Based Framework: Advancing Inclusion of Students with Disabilities' brought together over 200 people knowledgeable about human rights, disability, education and, in particular, inclusive education. ${ }^{168}$ Participants provided their views of the current state of inclusive practice in Canada. They found that while there are pockets of excellent practice, overall the situation is very uneven. Progress towards more inclusive educational practice is hampered by unsupportive perceptions of disability, 
conflicting demands and a lack of consistent demand for inclusion, inconsistent definitions of inclusive education and a lack of clarity about whether there is in fact a clear right to inclusive education. Decentralised governance of education in Canada means that inclusive education is a low priority in some areas of the country and that in some areas there is even movement away from inclusion. Parents who wish to use the human rights and judicial system to challenge the exclusion of their children from regular classrooms face a range of difficulties. Funding in education that is nominally allocated to support inclusive practice can be diverted to cover other priorities. Educators typically lack knowledge of the principles behind effective inclusive practice. The result is that many families feel beleaguered, unsupported and exhausted.

\section{Box 6.12 Cyprus: An effective legal framework for inclusion ${ }^{169}$}

There has been some progress on integrating disabled children into a common learning environment in Cyprus. The 1999 Act of Parliament on the Education and Training of Children with Special Needs $113(1)^{170}$ established a legislative framework that regulates the identification of, and support for, children with educational needs. The state is responsible for safeguarding the right of disabled children to an inclusive education at all levels of the education system. The legislation foresees the early identification of children with special educational needs, stating that it is the duty of the parent, the director or any other member of the education staff at a school (nursery, elementary, secondary or higher) to notify the district committee for special education and training that a child may have special educational needs. The committee then has responsibility for conducting a full multidisciplinary team assessment and must provide all necessary measures in terms of curriculum adaptation, technical and staffing support for the effective education of the child in an ordinary school. ${ }^{171}$ The law provides that all children with special educational needs must be accepted in the regular school system and if necessary receive extra after-school education from specially trained teachers assigned to the school. ${ }^{172}$ Specifically, Section 4 (1) states that the attendance of a child with special educational needs at a special unit of an ordinary school, or a school for special education and training, or anywhere else, shall be prohibited 'except to the extent and for the period the training in such places is determined under the law'. ${ }^{173}$ Finally, the law requires evaluation of the child's progress at least once a year.

The Cypriot experience demonstrates positive ways of implementing Article 24 of the UNCRPD and should be considered as good practice.

\section{Box 6.13 Ghana: Evaluating provision for children with autism and intellectual impairment ${ }^{174}$}

No provision for disabled children existed in Ghana before 1936, when missionaries set up an institution. Due to parental advocacy this became the first special school in 1970. Anthony (2009) identified 12 state special schools for those with mental impairments, and 23 units and 129 inclusive schools that 
enrolled children with less severe mental impairments. However, there was also evidence that around 1 million children with minor impairments were enrolled in basic education primary schools. There was also private provision for 80 children at the Autism Care and Training Centre, 20 at Horizon Special School and 80 at Operation Hand in Hand. Government statistics on prevalence rates are unreliable, but a recent survey of carers of 2-9 year olds suggests that around 4 per cent may have learning difficulties, including autism.

In a young population of 23 million the numbers must be significantly greater than the 101 children who the Ministry of Education has screened as autistic. Estimates of the prevalence of autism vary greatly, but a conservative figure from the USA is 1 in 150, which would give an estimated 150,000 people with autism in Ghana.

The Ghanaian Government has a policy of inclusive education in line with Education for All, but in recent years the proportion of the education budget spent on special needs has fallen as efforts to reach the EFA goals have intensified. There are only four regional assessment centres for disabled children and these focus mainly on hearing impairment. An analysis of policy statements suggests that units in mainstream schools are considered to meet the criteria for inclusion of children with autism and other mental impairments. Ghana adopted the UNCRPD in 2007, but has not yet ratified it. There is comprehensive national legislation, but it is often not applied.

1. The 1992 Constitution provides for the protection of persons with disabilities from discrimination and abusive treatment (Article 29); mandates the legislature to enact appropriate laws (Article 37); and requires access to free compulsory universal basic education (Article 38).

2. The Government of Ghana's Education Strategic Plan (ESP) 2003-2015 embodies its commitment to Education for All and provides that all schools must become inclusive environments for children with 'non-severe' disabilities by 2015.

3. Ghana's national disability policy, adopted in June 2000, secures specific rights for people with disabilities. The policy was largely a response to the 1993 UN Standard Rules on the Equalization of Opportunities for Persons with Disabilities. It legislates for rights for people with disabilities in regard to education, transport, community acceptance, housing and employment.

4. The 2006 Persons with Disability Act fulfils Ghanaian constitutional requirements and incorporates suggestions from ratified human rights conferences.

5. The Special Educational Needs Policy Framework (2005) is based on key policy objectives indicated in the ESP. The framework addresses the challenges of marginalisation, segregation and inequality that have previously constituted barriers to the education of disabled students.

Autism is a pervasive intellectual impairment characterised by difficulties in social and communicative interactions, together with a restricted repertoire of interests and activities - known as the 'triad of impairments' from a medical model point of view. From a social model point of view, with difficulties in dealing with social situations, emotions and communications, many individuals 


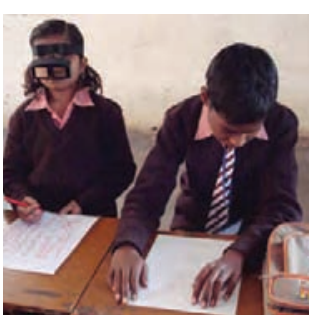

Visually-impaired students learning together. CREDIT: CMS with autism rely on routine, particularly individual support and repetition, but there is much evidence that people with autism can develop and achieve educationally. They need teachers, peers and school communities that understand their needs and who do not create barriers. Given this, educational progress in mainstream classes is feasible (Biklen, 2005).

There is evidence from interviews with teachers, government officials and families of negative attitudes and traditional views towards people with autism (Anthony, 2009). In Ghana, religious and spiritual beliefs have a big influence on conceptualisations of disability and these views are widespread. The following are typical comments:

'... if they are deaf or blind ... they look normal. People would not know and they have come to be perceived as people who can and should work in society. But with the mentally retarded, especially the severe, they are seen as the ones not to waste the resources on ... CP, autism, MR, they are taken as the most severe, and the most associated with curses and other spiritual causes' -Teacher

'It was the behaviour that I found very abnormal. They are always jumping and spinning and can't stay in one place' - Teacher

'If there is anything abnormal in our society, we attribute it to witchcraft' - Parent

'They are thought to be not whole, not normal, sick. They are thought to be cursed by the gods, bewitched if you will. Also it is thought that they [families] are being punished. ... There are a lot of misconceptions. It is felt by many that they are not needed. [But] the old ways are dying out. They are no longer as shy to come out. People no longer always believe they are cursed. They are beginning to learn it is the result of a medical condition' - Senior professional

'We have a saying in Ashanti - literally it means "I have cared for you for all your teeth to grow so now you care for me for all my teeth to drop out". So if you have a child who is not going to be successful or they are not going to be able to do that then that is a massive loss' - Professional

'... [people believe] you must have done something in your past, or the family did something' - Mother

All these cultural attitudes create a massive barrier that must be seriously addressed if the rights of people with autism and intellectual impairments are to be respected. This will require a training and in-service programme for teachers, run together with disabled people's organisations, and a significant increase in resources. Only in this way will Ghana be able to implement Article 24 of the UNCRPD and implement existing constitutional rights to education.

\section{Box 6.14 India: National planning and training for inclusive education}

There are up to 50 million disabled children in India and fewer than 10 per cent attend elementary school (Peters, 2003). In 1998, India's National Council of Educational Research and Training reported that 20 million children require special needs education, but as the enrolment of disabled children is 5 per 
cent, compared to 90 per cent for non-disabled children, this is a big underestimate. Tembon and Fort (2007) show that the gender difference in school attendance rates is lower for disabled children, reflecting low attendance levels. Illiteracy is 52 per cent for disabled people, compared to 35 per cent in the general population, and in India as a whole the proportion of disabled children who do not attend school is 5.5 times that for the general population. Even in the best-performing states, a significant proportion of out-of-school children are disabled ( $27 \%$ in Kerala and over $33 \%$ in Tamil Nadu). Disabled children rarely progress beyond primary education. (See Box 2.1 for barriers to inclusion in India.)

Unprecedented economic growth and a strong desire for equality and the development of inclusive education have characterised the Government of India's approach to education. Singal (2008) points out that there are huge variations in the statistics on the prevalence of disability. In terms of the percentage enrolment in primary education, these vary from less than 1 to 67 per cent. The variations are caused by differences in the definition of disability; stigma and shame among responding families; variation in the training and skills of enumerators; and political sensitivities now that inclusive education has become a major policy objective. Nevertheless, despite statistical problems, in recent years there has been a big push to establish inclusive education in India.

Singal $(2006 a, b)$ suggests there is growing evidence that the focus in the field continues to be on identifying and assessing disabled children, and responding to their needs through the provision of assistive appliances. This focus on changing structural issues, rather than reviewing the teaching and learning processes in the classroom, is limiting. The perception of disability as a problem located in the child which must be corrected still dominates, and little attention is paid to examining the environmental factors that might impact on the child's ability to participate. Overall, the emphasis is on giving access to children with disabilities, with little regard to their participation in the classroom, its culture or the curriculum.

Indian society, although inclusive in accepting and valuing diversity in many ways, has a social construct of disability which is negative, discriminatory and exclusionary. Until recently the Indian government has tried to develop services through voluntary agencies. The 2010 Right to Education Act took a step in the right direction by including disabled children in its remit. Mainstream schools are now mandated to include 'disadvantaged children', among whom disabled children are included. ${ }^{175}$

Historically, NGOs established special schools on the European model. There are now 3,000 special schools - nearly all in urban areas - but such schools can only cater for a small minority of disabled children. An integration programme has gradually developed, but without any training or support in the mainstream. The government is committed to universal elementary education and this was given new impetus by the 86th amendment: 'The State shall provide free and compulsory education to all children aged six to fourteen years in such a manner as the State may, by law, determine'.

In 1994, the government launched its district primary education programme (DPEP). Starting in one or two blocks in each state, with one or two clusters of 


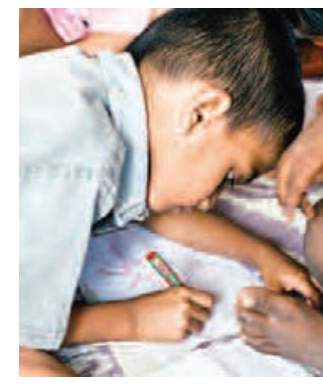

Learning to write in a school in Mumbai.

CREDIT: INCLUSION INTERNATIONAL districts, the DPEP has now reached the majority of districts, especially in the most backward areas.

In 1997, disabled children were explicitly included in the DPEP. Initially, the focus was on children with mild or moderate learning difficulties. Recently this was extended to the full range and severity of impairments. In the first six years, 877,000 disabled children were identified across India and 621,760 were enrolled. Through a combination of state, regional and district resource centres and widespread in-service teacher training, practice has begun to change significantly. By 2003 over one million teachers had received a day's training, 171,000 had attended three- to five-day orientation courses and over 4,000 had attended a 45-day orientation course to become master trainers. Different states have adopted different training models, some relying on NGOs, some on consultants and others on full-time district officers. The project has identified the following key aspects of training for inclusive education:

- Awareness generation

- Community mobilisation - especially of parents

- Early detection of impairment

- In-service teacher training

- Resource support

- Curriculum adaptation

- Multi-sectoral convergence

- Provision of essential assistive services, aids and appliances

- Removal of barriers to access

Because many children do not attend school, the DPEP has set up an alternative schools programme. This provides schools for children aged 6-14 years old, organised flexibly to meet local conditions, which open for four hours a day in single or double shifts. Each school has two teachers, one of whom must be female so that girls are encouraged to attend and their particular needs are met. 200,000 such schools have been built (UNESCO, 2001a: 78).

In 2005, India's then Minister of Human Resource Development, Shri Arjun Singh, ${ }^{176}$ made this important statement to Parliament:

My Ministry has formulated a comprehensive action plan for inclusive education of children and youth with disabilities. The need for inclusive education arises precisely because it is now well understood that most children with disabilities can, with motivation and effort on the part of the teaching institutions, become an integral part of those institutions. The government is committed to providing education through mainstream schools for children with disabilities, in accordance with the provisions of the Persons with Disabilities Act, 1995. Non-specialist schools, whether at elementary or secondary or higher levels can, with appropriate support within the education community adapt themselves to work with children with disabilities. Worldwide there is a conscious shift away from special schooling to mainstream schooling of education for children with disabilities. It should, and will be, our objective to make mainstream education not just available, but accessible, affordable and appropriate for students with disabilities. I also believe that if we make our schools 
Table 6.1. Progress on inclusive education in India under Sarva Shiksha Abhiyan, January $2010^{177}$

\begin{tabular}{|c|c|c|c|c|c|c|c|c|}
\hline State & $\begin{array}{l}\text { Total no. of } \\
\text { children } \\
\text { with special } \\
\text { needs } \\
\text { identified }\end{array}$ & $\begin{array}{c}\text { No. } \\
\text { enrolled }\end{array}$ & $\begin{array}{l}\text { No. of } \\
\text { children } \\
\text { with special } \\
\text { needs given } \\
\text { appliances }\end{array}$ & $\begin{array}{l}\text { Teachers } \\
\text { trained } \\
\text { (intensive } \\
\text { short } \\
\text { course) }\end{array}$ & $\begin{array}{l}\text { Teachers } \\
\text { trained } \\
\text { (20-day } \\
\text { course) }\end{array}$ & $\begin{array}{l}\text { Teachers } \\
\text { completed } \\
(90 / 45- \\
\text { day } \mathrm{RCl} \\
\text { course) }\end{array}$ & $\begin{array}{l}\text { Resource } \\
\text { teachers } \\
\text { appointed }\end{array}$ & $\begin{array}{c}\text { Schools } \\
\text { provided } \\
\text { with ramps, } \\
\text { handrails, } \\
\text { etc. }\end{array}$ \\
\hline $\begin{array}{l}\text { Andaman and } \\
\text { Nicobar Islands }\end{array}$ & 815 & 815 & $100 \%$ & $\begin{array}{c}40 \\
\text { (1 day) }\end{array}$ & $\begin{array}{c}150 \\
\text { (3-6 day) }\end{array}$ & & & $\begin{array}{c}24 \\
(5.6 \%)\end{array}$ \\
\hline Andhra Pradesh & 181,999 & $\begin{array}{r}159,266 \\
2500 \mathrm{~S}\end{array}$ & 197,282 & & $\begin{array}{l}22,0871 \\
(3-6 \text { day })\end{array}$ & 633 & 856 & $\begin{array}{c}31,559 \\
(39.4 \%)\end{array}$ \\
\hline Assam & $\begin{array}{r}7 \\
5 \\
19\end{array}$ & $\begin{array}{l}72,084 \\
5,405 \mathrm{~S} \\
9,197 \mathrm{ht}\end{array}$ & 28,023 & 167,267 & $\begin{array}{c}91,624 \\
\text { (3-6 day) }\end{array}$ & 4,135 & & $\begin{array}{c}37,659 \\
(86.8 \%)\end{array}$ \\
\hline Bihar & 31,3500 & 241,995 & 94,296 & $\begin{array}{l}179,499 \\
\text { (1 day) }\end{array}$ & $\begin{array}{l}139,557 \\
\text { (3 day) }\end{array}$ & 6,449 & & $\begin{array}{c}33,246 \\
(34.6 \%) \\
\end{array}$ \\
\hline Chattisgarh & 46,153 & $\begin{array}{r}45,196 \\
517 \text { ESG } \\
187 \mathrm{ht}\end{array}$ & 33,788 & $\begin{array}{l}71,168 \\
\text { (1 day) }\end{array}$ & $\begin{array}{l}38,867 \\
\text { (3 day) }\end{array}$ & 612 & 30 & $\begin{array}{c}15,617 \\
(33.9 \%)\end{array}$ \\
\hline Chandigarh & 3,704 & 3,532 & & $\begin{array}{c}896 \\
\text { (3 day) }\end{array}$ & & 289 & 15 & $\begin{array}{c}37 \\
(18.1 \%)\end{array}$ \\
\hline Daman and Diu & 141 & $\begin{array}{r}70 \\
33 \mathrm{ht}\end{array}$ & & 11 & & & & $\begin{array}{c}50 \\
(59.52 \%) \\
\end{array}$ \\
\hline Delhi & 8,015 & 6,504 & 6,371 & 47,792 & & & 50 & $\begin{array}{c}3,475 \\
(100 \%)\end{array}$ \\
\hline Goa & 2,140 & $\begin{array}{r}1,393 \\
4 \mathrm{ht}\end{array}$ & & & & 95 & & $\begin{array}{c}653 \\
(42.6 \%) \\
\end{array}$ \\
\hline Gujarat & 78,900 & $\begin{array}{l}64,944 \\
1,250 \mathrm{~S}\end{array}$ & 158,179 & 191,044 & & 9,823 & 1,193 & $\begin{array}{c}32,123 \\
(52.27 \%) \\
\end{array}$ \\
\hline Haryana & 25,075 & 20,431 & 39,625 & $\begin{array}{c}660,000 \\
\text { (1 day) }\end{array}$ & $\begin{array}{c}42,850 \\
\text { (3-6 day) }\end{array}$ & & 70 & $\begin{array}{c}9,391 \\
(64.27 \%) \\
\end{array}$ \\
\hline Himachal Pradesh & 22,040 & $\begin{array}{r}19,643 \\
10 \mathrm{~s} \\
2,387 \mathrm{ht}\end{array}$ & $62.98 \%$ & $\begin{array}{l}45,319 \\
1 \text { day }\end{array}$ & $\begin{array}{l}32,716 \\
\text { (5 day) }\end{array}$ & 1,172 & 120 & $43.64 \%$ \\
\hline Jammu and Kashmir & 25,906 & 20,117 & $52.43 \%$ & $\begin{array}{l}41,797 \\
\text { (1 day) }\end{array}$ & $\begin{array}{c}1,067 \\
\text { (3-6 day) }\end{array}$ & 415 & & $\begin{array}{c}3,160 \\
(10.9 \%) \\
\end{array}$ \\
\hline Jharkhand & 47,312 & $\begin{array}{r}35,695 \\
213 \mathrm{ht} \\
105 \mathrm{~S}\end{array}$ & 30,855 & $\begin{array}{l}42,260 \\
\text { (1 day) }\end{array}$ & $\begin{array}{c}11,838 \\
\text { (3-6 day) }\end{array}$ & 348 & 25 & $\begin{array}{l}20,001 \\
(37.1 \%)\end{array}$ \\
\hline Karnataka & 135,301 & $\begin{array}{r}121,153 \\
4,148 \mathrm{ht}\end{array}$ & 59,593 & 69,846 & 185,894 & 29,352 & 606 & $\begin{array}{c}38,021 \\
(52.7 \%) \\
\end{array}$ \\
\hline Kerala & 157,147 & $\begin{array}{r}145,476 \\
2,544 \mathrm{~S} \\
809 \mathrm{ht}\end{array}$ & 13,793 & 100,545 & 132,000 & & 730 & $\begin{array}{l}14,157 \\
(100 \%)\end{array}$ \\
\hline Madhya Pradesh & 111,492 & $\begin{array}{l}102,567 \\
2,126 \mathrm{ht}\end{array}$ & 90,450 & 18,264 & 75,204 & 13,533 & 162 & $\begin{array}{l}59,943 \\
(52.9 \%) \\
\end{array}$ \\
\hline Maharashtra & 414,277 & $\begin{array}{l}380,723 \\
11,412 \mathrm{ht}\end{array}$ & 191,553 & 380,000 & & 19,446 & 1,417 & $\begin{array}{l}85,211 \\
(80 \%)\end{array}$ \\
\hline Orissa & 124,741 & 115,344 & 131,033 & 164,004 & & 5,293 & 253 & $\begin{array}{c}43,393 \\
(63 \%)\end{array}$ \\
\hline Punjab & 114,473 & $\begin{array}{r}86,696 \\
4,174 \text { ht }\end{array}$ & 84749 & 108 & & $\begin{array}{r}970 \\
(59 \%)\end{array}$ & 220 & 11,513 \\
\hline
\end{tabular}




\begin{tabular}{|c|c|c|c|c|c|c|c|c|}
\hline State & $\begin{array}{l}\text { Total no. of } \\
\text { children } \\
\text { with special } \\
\text { needs } \\
\text { identified }\end{array}$ & $\begin{array}{c}\text { No. } \\
\text { enrolled }\end{array}$ & $\begin{array}{c}\text { No. of } \\
\text { children } \\
\text { with special } \\
\text { needs given } \\
\text { appliances }\end{array}$ & $\begin{array}{l}\text { Teachers } \\
\text { trained } \\
\text { (intensive } \\
\text { short } \\
\text { course) }\end{array}$ & $\begin{array}{l}\text { Teachers } \\
\text { trained } \\
\text { (20-day } \\
\text { course) }\end{array}$ & $\begin{array}{l}\text { Teachers } \\
\text { completed } \\
(90 / 45- \\
\text { day } \mathrm{RCl} \\
\text { course) }\end{array}$ & $\begin{array}{l}\text { Resource } \\
\text { teachers } \\
\text { appointed }\end{array}$ & $\begin{array}{c}\text { Schools } \\
\text { provided } \\
\text { with ramps, } \\
\text { handrails, } \\
\text { etc. }\end{array}$ \\
\hline Puducherry & 2,926 & $\begin{array}{l}2,816 \\
110 \mathrm{ht}\end{array}$ & 1,602 & 130 & & & 3 & $\begin{array}{c}343 \\
(58 \%)\end{array}$ \\
\hline Tamil Nadu & 118,151 & $\begin{array}{l}90,976 \\
459 \mathrm{~S} \\
26,716 \mathrm{ht}\end{array}$ & 96,677 & 201,604 & & & 826 & $\begin{array}{c}35,408 \\
(67 \%)\end{array}$ \\
\hline Uttarakhand & 21,577 & $\begin{array}{l}18,483 \\
59 \mathrm{~S} \\
1,248 \mathrm{ht}\end{array}$ & 9,441 & & 43,629 & 13,622 & 8 & $\begin{array}{c}9,494 \\
(52.8 \%)\end{array}$ \\
\hline West Bengal & 219,075 & $\begin{array}{l}133,662 \\
7,613 \mathrm{~S} \\
21,733 \mathrm{ht}\end{array}$ & 46,377 & 149,116 & 258,533 & 1,013 & 1,023 & $\begin{array}{l}49,589 \\
(83.4 \%)\end{array}$ \\
\hline Total & $2,264,682$ & & & & & & 7,607 & \\
\hline \multicolumn{9}{|c|}{$\begin{array}{l}\text { ht = home tutored; } \mathrm{S}=\text { special school. } \\
\text { Note: The table omits ten territories, tribal areas or states. } \\
\text { Not all disabled children of school age have been identified. }\end{array}$} \\
\hline
\end{tabular}

accessible to children with disabilities, we will be improving the quality of education for all our children, a key objective of Sarva Shiksha Abhiyan.

The main objectives of the plan will be

(i) To ensure that no child is denied admission in mainstream education;

(ii) To ensure every child would have the right to access anganwadi and school and not be turned back on ground of disability;

(iii) To ensure that mainstream and specialist training institutions serving persons with disabilities in the government and non-government sector facilitate the growth of a cadre of teachers trained to work within the principles of inclusion;

Outdoor school in Orissa, India. CREDIT: NRCIE, MUMBA

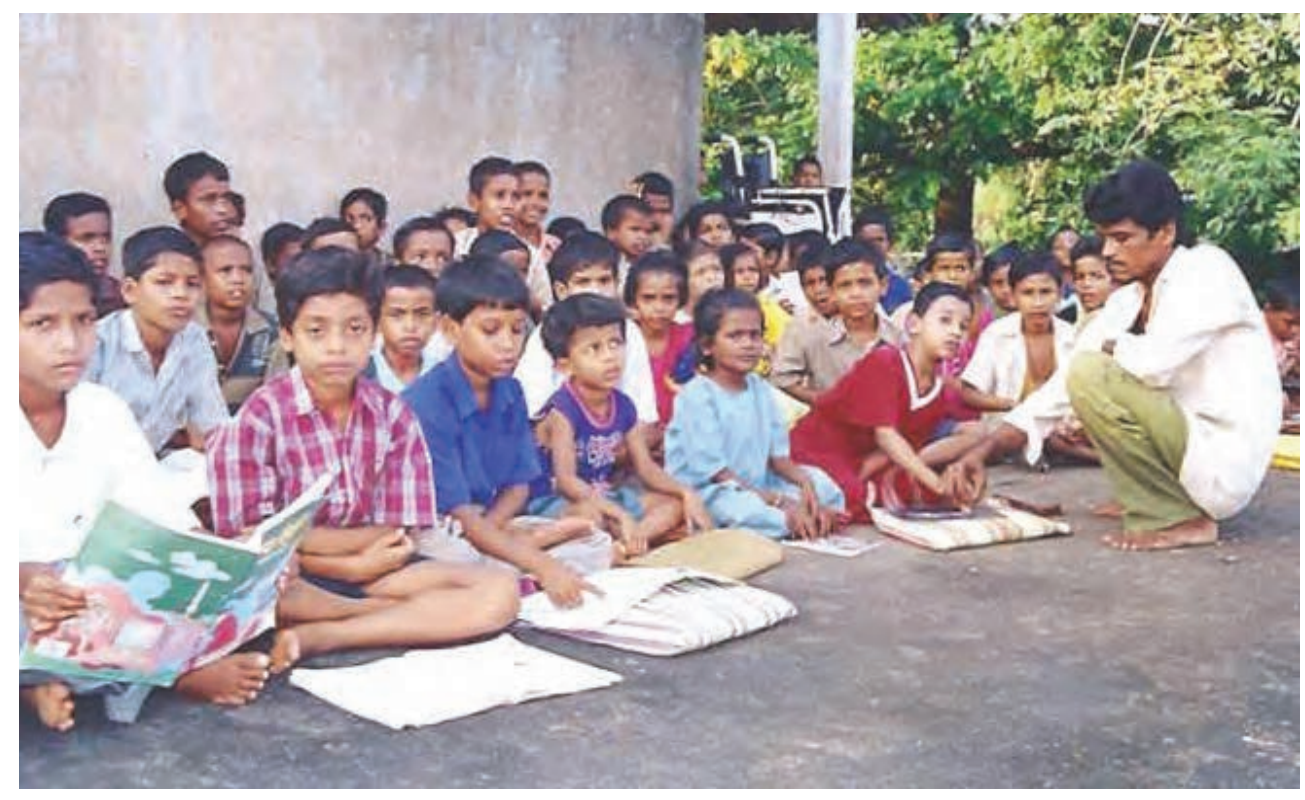




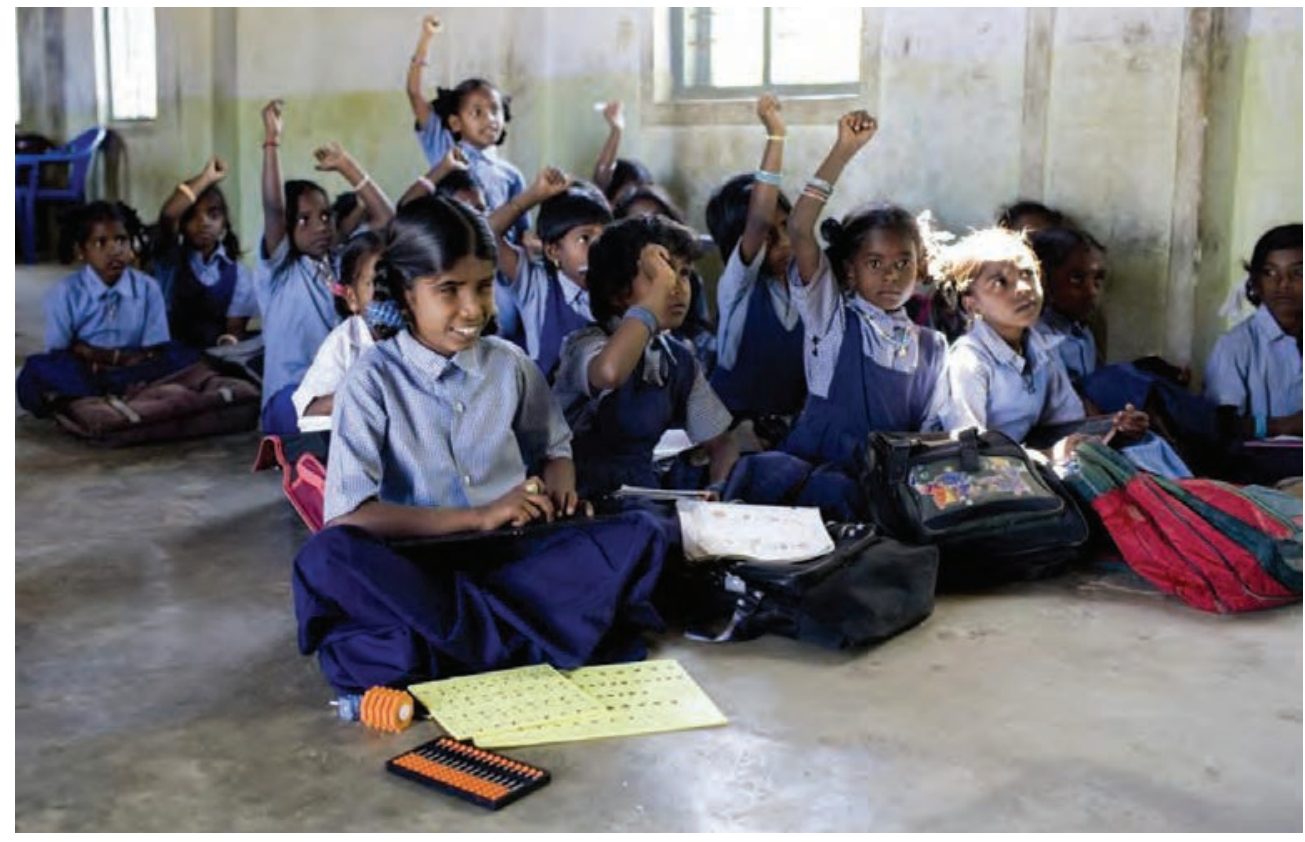

A blind girl joins $a$ mainstream class.

CREDIT: CLAUDIA JANE, SIGHTSAVERS

(iv) To facilitate access of girls with disabilities and disabled students from rural and remote areas to government hostels;

(v) To provide home-based learning to persons with severe, multiple and intellectual disability;

(vi) To promote distance education for those who require an individualised pace of learning;

(vii) To emphasise job training and job oriented vocational training;

(viii) To promote an understanding of the shift from charity to development through a massive awareness, motivation and sensitisation campaign.

The promised action plan has been developed and is now part of the Eleventh National Plan for India 2007-2012. The main implementation mechanism is Sarva Shiksha Abhiyan (Education for All), which was started in 2001 to bring about universal elementary education by 2010. Extended as a vehicle for introducing and spreading the inclusive education of disabled children, SSA is a decentralised planning process with an emphasis on participatory planning approaches to ensure full participation. ${ }^{178}$ How well is it doing?

SSA was launched by the government with the aim of providing eight years of elementary schooling for all children in the 6-14 age group, including disabled children, by 2010. The programme provides an additional Rs 1,200 per 'challenged' child to meet additional needs. Disabled students in the 15-18 age group are given free education under the Integrated Education for Disabled Children (IEDC) scheme. Under SSA, a continuum of educational options, learning aids and tools, mobility assistance and support services are made available to disabled students. They include education through an open learning system and open schools, alternative schooling, distance learning, special schools, home-based education, itinerant teachers, remedial teaching, part-time classes, CBR and vocational education. ${ }^{179}$

However, overall, the spending share on inclusive education in SSA is low - only 1 per cent. There is a wide variation in inclusive education spending between states, ranging from 5 per cent of total spending on education in Kerala to 
Learning to lip read. CREDIT: Mimi MolLica/ LeONARD ChEShIRE DISABILITY

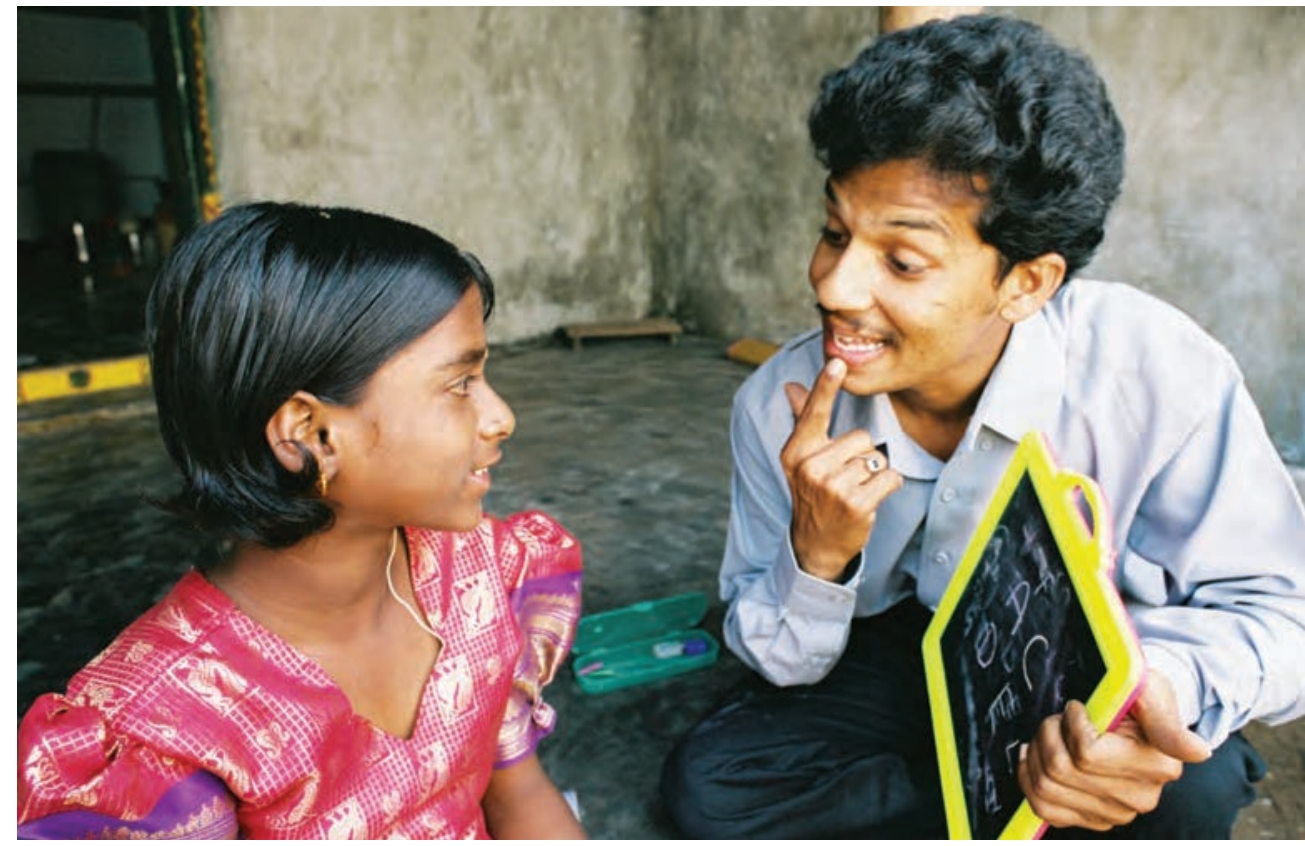

under 0.5 per cent in Madhya Pradesh, Jharkhand, West Bengal and Rajasthan. Overall funding is too low, based upon inaccurate census data. This will improve with different questions and better trained enumerators and more reliance on door to door visits.

The Ministry of Human Resource Development is currently in the process of developing a comprehensive action plan on the inclusion in education of disabled children and young people by consulting with experts, NGOs, disability rights groups, parents' groups and government bodies.

In June 2008, as part of its inclusive education programme, the government increased resources to help a range of disabled pupils complete four years of secondary education. They include students with learning difficulties, mental illness, autism, cerebral palsy, blindness, low vision, leprosy, hearing impairment and loco-motor impairments. The programme includes a child-specific support allowance for teachers in specialised teaching styles and identification. ${ }^{180}$ Despite the variety of methods employed, for example home tuition, distance learning, and special classes and special schools for disabled learners, which would not fit within a definition of inclusive education, there is no doubt that progress towards inclusive education is well underway across the huge demographic, linguistic and cultural diversity that is India. This can be seen in Table 6.1 above, drawn from a presentation by Dr Anupriya Chadha, Chief Consultant on SSA at a National Workshop in November 2009. ${ }^{181}$

A considerable number of resource teachers have been trained and appointed, but there is a tendency for class teachers to defer to the resource teacher on teaching disabled children. The issue is to get all teachers to feel confident about teaching the disabled children in their class. A considerable amount of building adjustment has occurred, with several states now having 100 per cent adapted buildings. From 2001 to 2006 the number of elementary schools grew by 22,000 ; these are all built to accessibility standards and enrolment went up by 28 million in Classes 1-8. The pupil-teacher ratio remained at 1:41 despite an increase of 630,000 elementary teachers. Drop-out rates have fallen by 10 per cent. Identification of disabled children has been carried out by door to 
door visits; this leads to placement in school to varying degrees, based on the capacity of local schools and teachers. Too many children appear to receive education at home because of lack of readiness of their local school to include them. More teacher training is required. The curriculum has moved towards a more child-friendly model, though it is still dominated by assessment and needs further reform to support a more flexible approach conducive to full inclusion. Aids and appliances have been issued, but these are often delayed and do not work as well as they should. Many more disabled children are now progressing from elementary school to lower secondary, as eight years of education is now compulsory, but more work is needed to prevent drop-out on transition. Considerable progress has been made, but much more remains to be done.

\subsection{Jamaica: Working in partnership}

The Jamaican Ministry of Education and the Jamaica Association for Persons with Mental Retardation (JAPMR) are co-operating to address the educational needs of a group of children who have not been achieving success in school. Children with 'moderate to profound levels of learning difficulty' are sent to schools operated by JAPMR with government funding. Children with 'mild learning difficulty' are catered for in the regular public school system. Founded in 1956, the private and segregated School of Hope (SOH) programme has 29 units all over the country. They serve a total of 1,250 students. JAPMR estimates that between 3,000 and 4,000 children qualify for their programmes (Duncan, 2001). So for every child who receives a place, two or three others who are eligible do not.

Since 1996, the Primary Intervention Program (PIP) has been assisting schools and teachers to educate children designated as slow learners or children with 'mild mental handicaps'. They are not eligible for $\mathrm{SOH}$ special education programmes, and they are not doing well in the regular classrooms in which they have been placed. Traditionally they have been enrolled in school, but as their learning problems have developed, many of these children have dropped out - in many instances to the relief of their teacher. The PIP was set up as a consequence of JAPMR staff being inundated by requests from principals of regular schools for assistance in dealing with children who were not coping.

The PIP started with staff from the educational programmes operated by JAPMR providing direct assistance to Grade 1 students in two regular schools. In the first year, they assessed the learning needs of 144 students in Grade 1. They found that 50 of them met the readiness criteria jointly established by the Ministry and the Association. The other 94 children were deemed to be at some risk. The process led the teachers to be much more aware of the diverse learning needs of students entering Grade 1.

The agency staff noted that classroom teachers wanted these children removed from the classroom because they felt they were unable to teach them. Over time, the programme led to agency staff providing training for the teachers and supplying materials, as well as sharing strategies for meeting students' needs.

The programme was built on the underlying principle that all children can learn and that teaching styles must be matched with learning styles. The programme's

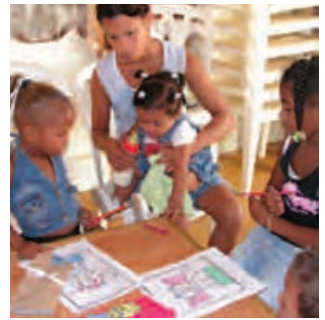

Nursery class in Jamaica.

CREDIT: InCLUSION INTERNATIONAL 


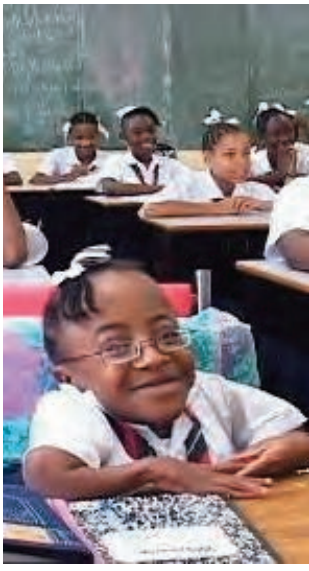

Alia Clement has passed the Common

Entrance exam

CREDIT: THE SUNSHINE FOUNDATION, GRENADA

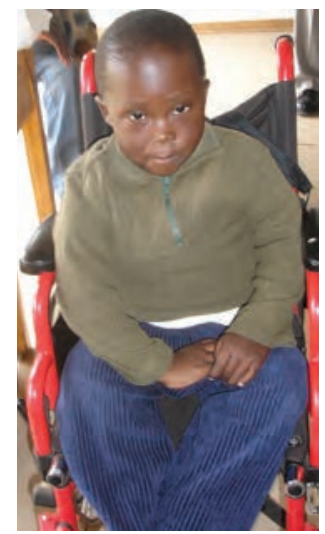

Pupil at Leseli School, Lesotho.

CREDIT: Richard RIESER key objective is to allow students to stay in their community schools and yet achieve their fullest potential. Workshops were held to educate teachers about how to identify a child's special needs and how to work with the student even when resources are limited.

During the pilot, many of the children missed many days of school. Nonetheless, post-testing showed that all the students made gains, and 52 of the 94 attained a reasonable level. The exam results at the end of the year were even better. At the end of the pilot project, the classroom teachers '... realised that these children could be taught'.

The PIP pilot experience indicated there was a need to:

- Revisit the primary school curriculum and ensure that the first term is dedicated to exploring student differences and providing experience in school readiness skills;

- Acknowledge that children with mild impairments can achieve in the regular school system.

JAPMR continues to practise principles of inclusion. It has recently started to refer children in the 12- to 15-year age group from the School of Hope to regular community schools. It reports that '... the demand is overwhelming, and the greater part of our involvement is a result of requests from regular schools that continue to struggle with these children for whom very limited provisions are being made'. The pilot project was considered successful and the number of schools in the programme was increased from two to four. Many more would welcome a place in the project, but resources are limited.

Disabled children are at even greater risk, as limited national resources reflect the government's inability to address the needs of this group even in the regular schools. The provision of education for children with special needs, including disabled children, continues to receive national attention. JAPMR will continue to support the government programme to provide inclusive education for children who are at risk. ${ }^{182}$ Jamaica, having been first country to ratify the UNCRPD, needs to give serious attention to how to bring this and similar projects to scale across all schools.

\section{Box 6.16 Lesotho: Situation analysis and national training}

Lesotho is a mountainous country surrounded by South Africa, with a population of 1.8 million people. A study in 1987 showed that very few disabled children were receiving education. Prompted by the 1990 Jomtien Declaration, the Ministry of Education has stated that it will promote the integration of children with special educational needs at all levels of the regular school system.

To implement this policy, the Unit of Special Education has developed the following strategies:

1. Provide special education for all children who need it;

2. Create awareness in the whole society about children with special needs and the services available; 


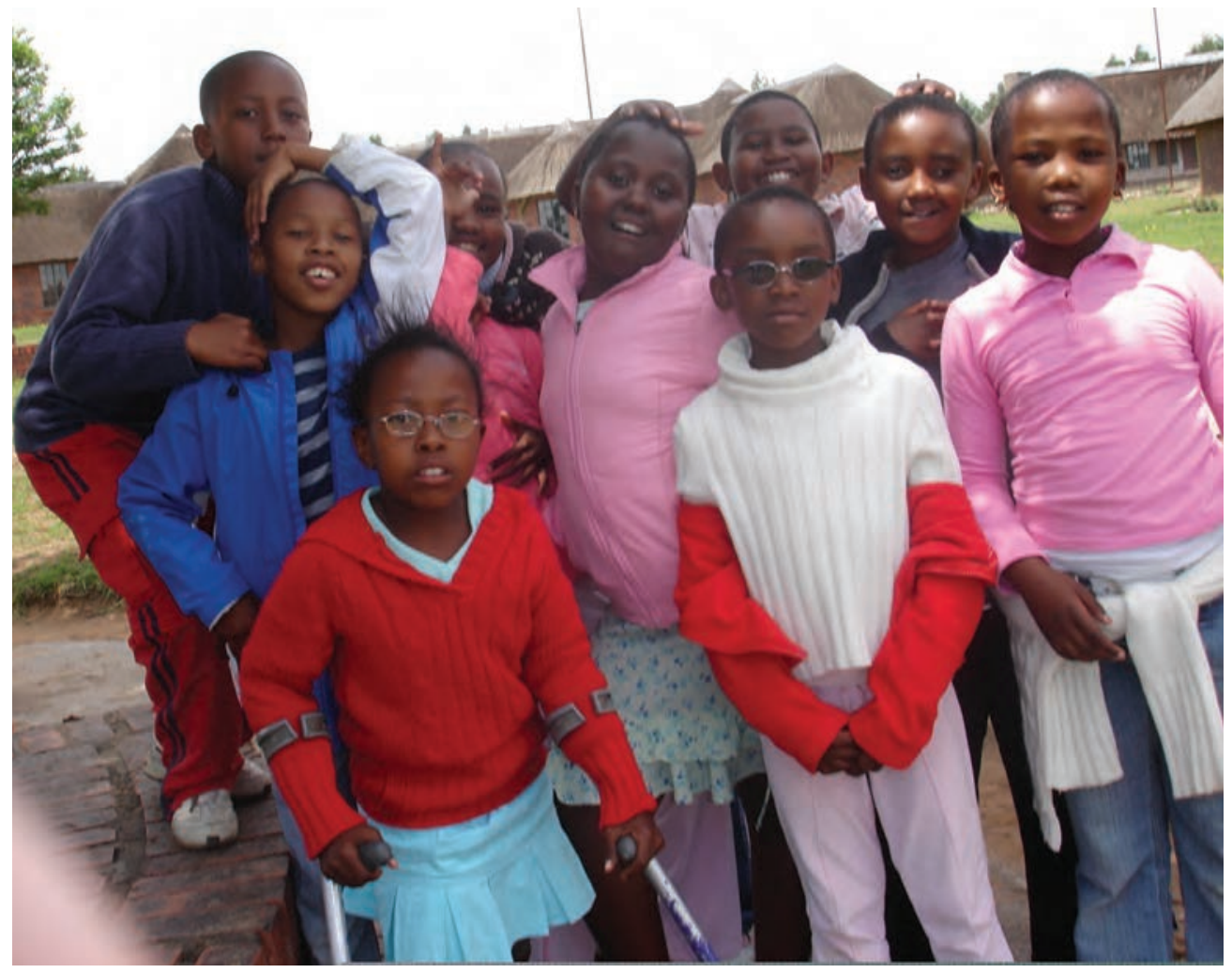

3. Conduct a study to determine the feasibility of integration and identify children with special educational needs in regular primary schools;

4. Develop in-service teacher training materials;

5. Conduct in-service teacher training;

6. Develop and conduct parent training programmes.

From 1990 to 1992 the Unit of Special Education carried out an investigation with the following objectives (Mariga and Phachaka, 1993):

- To create awareness among primary school teachers of the integration policy;

- To determine the number of children with special needs in regular primary schools;

- To investigate the attitude of teachers, pupils and parents towards integrating children with special needs into their schools;

- To identify schools in which integration could be introduced on a pilot basis.

In 1992 about 371,950 pupils were enrolled in 1,201 primary schools with a pupil teacher ratio of 1:54. Visits were made to 26 per cent of schools and all teachers were interviewed; classes were observed and pupils informed. A sample of Year 5, 6 and 7 pupils and three parents per school were interviewed. This showed that 17.4 per cent of pupils had some form of impairment. The lack of appropriate teaching was thought to account for a high drop-out rate and a high incidence of repeated years.

A multi-sector committee was established prior to the development of a national inclusive education programme. The committee was made up of representatives from the Ministries of Education and Health and Social Welfare, the National Disabled People's Association, parents of non-disabled children, 


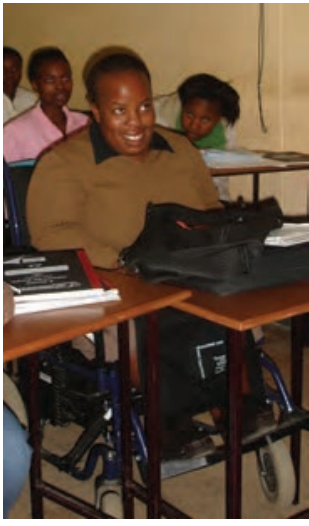

College students studying accountancy in Lesotho.

CREDIT: RICHARD RIESER and later the National Organisation of Parents of Disabled Children. It discussed the implementation of the new programme and the development of a new inservice teacher training curriculum. This ensured that there was full co-operation from all professionals and stakeholders. Fifteen years later this programme is still supporting inclusive education at national level.

Short in-service training courses in schools gave teachers the confidence to respond to the individual needs of disabled children, even though they were sometimes teaching large classes of over 100 pupils. Teachers from schools for the deaf and the blind were involved in training teachers in Braille and sign language. The involvement of the specialist teachers helped to reassure them about the valuable role they could play in implementing inclusion. Previously they had been resistant to inclusive education as they feared losing their jobs.

The teachers were trained to do simple assessments of children with learning difficulties and in how to meet their needs. They began to see the children as individuals, rather than as a class, and they felt they had become better teachers as a result. The Ministry of Education produced a training package and video material which was piloted in ten schools and then rolled out across the country. ${ }^{183}$ Despite promising practice in the 1990s, Lesotho has not made the expected gains in inclusive education. Greater leadership, better funding, teacher training, and involvement of the community and DPOs are necessary.

\section{Box 6.17 Malawi: Support from DPOs and NGOs}

The umbrella organisation Federation of Disability Organisations in Malawi (FEDOMA) has a strategy to enable local communities to identify and address the needs of disabled community members. Since 2004, the Norwegian Association for the Disabled, in collaboration with Malawi's Ministry of Social Development and People with Disabilities (MSDPWD) and the Malawi Council for the Handicapped (MACOHA), has operated in three pilot districts working across sectors to promote inclusion. FEDOMA collaborates with international agencies, including UNICEF, European voluntary organisations, NAD, NORAD, Firelight Foundation, CIDA, ILO, DFID, USAID, AusAID and Development Co-operation Ireland (DCI). Effective partnership resulted in the launch of a community-based rehabilitation programme in the late 1980s by the government, through MACOHA, with financial and technical support from the United Nations Development Programme (UNDP) and the ILO.

From the 1970s to the mid-1980s the disability sector in Malawi was based on charity. Activities and care-givers for disabled persons came mostly from churches and missions. Disability issues were the responsibility of the Ministry of Health, Ministry of Community Services and other social ministries. In December 1998, the Ministry Responsible for People with Disability was formed. Today it is called Ministry of Social Development and Persons with Disabilities. In November 2005, a national policy paper on the equalisation of opportunities for persons with disabilities was adopted. Its aim is 'to integrate fully persons with disabilities in all aspects of life', and 'to promote equal access and inclusion of persons with disabilities in education and training programmes'. ${ }^{184}$ The barriers to the implementation of this policy are similar to those in Lesotho. 


\section{Box 6.18 Malaysia: Developing integrated education}

Malaysia is a signatory of the Salamanca Statement and for the last 16 years has been implementing it following UNESCO initiatives. In 2003 free compulsory primary education was introduced and in 2008 all school fees were abolished. Also in 2008 a free text book loan scheme was extended to all five million school students.

There is a standard curriculum and also a special curriculum for those with special educational needs. Learning modules for indigenous people such as the Orang Asli were piloted in 2007 and have now been disseminated. However, those in the interior are still viewed as 'unreachable children'. Malaysia has 32 special schools and 1,282 integration units which have separate classes for visually and hearing impaired students and students with learning difficulties. Most of these offer boarding facilities and 29,169 pupils attended them in autumn 2008. Physically disabled pupils are integrated into mainstream education if they can manage the system as it is: otherwise they stay at home.

Hearing impaired pupils in vocational secondary schools are integrated for 90 per cent of the time; in academic secondary schools they have separate lessons. There are no special schools for pupils with learning difficulties, so students from units are integrated in the mainstream if they can manage without help and their behaviour is not a problem. ${ }^{185}$ An academic study in 2006 examined teachers' attitudes to disabled pupils and their perceived knowledge of inclusive education. The respondents were the mainstream and special education teachers in the public primary and secondary schools. Data from a questionnaire were analysed using descriptive statistics such as frequency and percentages. The main finding was that in general teachers have positive attitudes towards inclusive education. They agreed that inclusive education enhances social interaction and inclusion among the students and thus minimises negative stereotypes about special needs students. The findings also show that collaboration between the mainstream and the special education teachers is important and that there should be clear guidelines on the implementation of inclusive education. ${ }^{186}$

The Malaysian Government appears to view placement as inclusion and the general practice is not to adjust current practice to accommodate disabled pupils. Teachers will need considerable in-service training and new teachers should have a compulsory module on inclusion. The government will need to back this up with the necessary resources and make it a political priority if Malaysia is to implement Article 24 of the UNCRPD.

Box 6.19 Mongolia: Changing attitudes towards teaching disabled children ${ }^{187}$

During the crisis in Mongolia sparked by transition to a free market economy, early primary school attendance collapsed from over 90 per cent in the mid1980 s to 7 per cent in 1992. Efforts were made to revive the sector, but even where more schools were becoming available, it was clear that disabled children were still excluded. Some disabled children had previously been in 


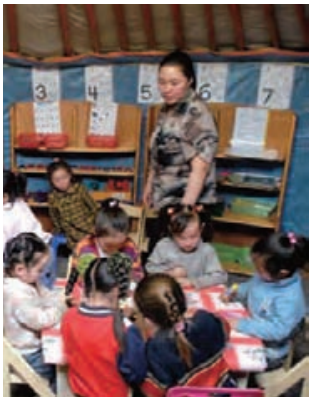

Tent school in Mongolia.

Credit: Save the Children

special schools, but as funding was reduced, very few special schools remained. Many families were ashamed of their disabled children and kept them at home. The few disabled children who made it to school were likely to be turned away by the teachers. Teacher training colleges did not develop trainees' confidence in working with disabled children. Many teachers assumed that disabled children were ineducable in mainstream schools and therefore refused to teach them. Where disabled children did attend school, many teachers were unaware of their circumstances and needs, and provided no support for them. The limited reach of the health system meant that basic rehabilitation interventions, which can help disabled children participate more actively in life and learning, were not available to most families.

Save the Children ran in-service inclusive training sessions for teachers and parents of young children in Dornod, Khovd, Bayan Ulgii and Bayanhongor aimags (provinces), as well as in Ulaanbaatar. The sessions focused on methodologies for teaching disabled children in mainstream classes. Several workshops have been run for teachers at different levels within the pilot aimags, including for pre-school and lower primary school teachers.

The design and content of the training drew on the expertise of special educators who had been trained under the previous segregated education system. Their knowledge of ways to support learning and active living for disabled children was important. Involving special educators meant they did not feel shut out of inclusive education efforts, making it less likely they would resist change towards inclusive education in mainstream schools.

- Those who received the training were encouraged and expected to then train and support colleagues in their own school or kindergarten. In Bayanhongor aimag, for example, one teacher from each of the 28 schools involved in the pilot received training. Teachers were selected for the training on the basis of demonstrated levels of commitment. Between 1998 and 2005, 1,600 teachers were trained in inclusive education approaches.

- Follow-up support to teachers was provided in almost every school in the pilot aimags.

- Regular sharing of learning between schools was promoted.

A 2005 review indicated that teachers who were trained were convinced of the difference they can make for disabled children. They were more keen to work with parents, partly to show them the results of their children's progress and achievements, and partly to persuade other parents to bring their disabled children to school. There was an increase in the number of disabled children enrolling in pre-school and primary school - from 22 to 44 per cent in aimags where the approach was used.

Four teaching resource centres were established by 2005 at aimag level. These were based on an inclusive education resource centre established by Save the Children at the Institute of Education, the main pre-service teacher training institution. This resource centre is now supported by the Institute. The resource centres provide materials and advice on inclusive education practice for mainstream teachers.

Disabled children have expressed their confidence in coming to school because 
they are treated well by teachers. Parents and classmates of deaf children have attended sign language classes as part of a programme to improve community support for disabled children. Classmates have enjoyed learning to sign and are happy to be able to communicate with and support their friends. Such processes contribute to further attitude change. Previously,

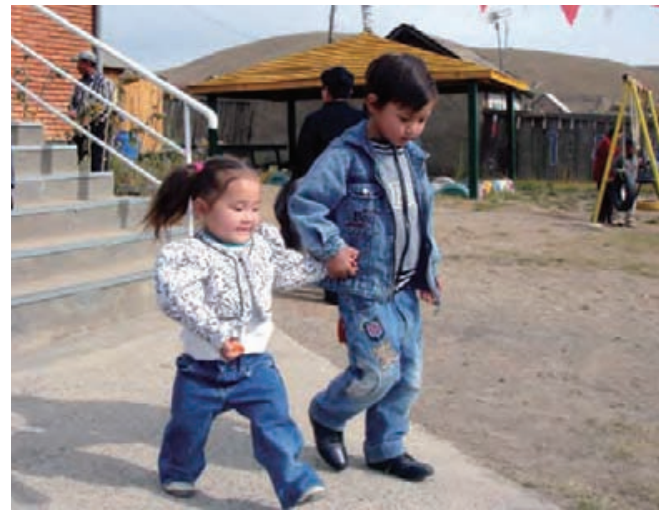
deaf children were isolated within their families - now they are part of the community. The kindergartens and schools involved in the pilot are promoting themselves as the best facilities in their community for disabled children and are encouraging parents to enrol their children. Even if they move to a different school, teachers who have done the training tend to be more motivated to stay in the aimag and continue to work in education. This has had the effect of further cascading the training, as they share their knowledge with new colleagues.

Teachers now plan their work with disabled children, instead of simply planning one approach for the whole class and leaving it to chance whether disabled pupils will benefit. Systems for monitoring the progress of disabled children are in place in schools where teachers were trained. There are individual plans for each child and greater emphasis on showing their achievements. The children's individual work plans are incorporated into the annual kindergarten and primary development plan. Recently, with funding from the FTI, over 100 mobile schools in tents have been established.

\subsection{Mozambique: Has success in Education for All impacted on disabled children?}

Mozambique has been a success story for the EFA Fast Track Initiative, with a high proportion of GNP (20-22\%) spent on education in the last five years. ${ }^{188}$ This has provided 20,000 new teachers. Sixty-two per cent of new recruits to primary education are girls and from 2004-2009 girls' completion rates doubled. Overall, the number of children in primary education has doubled in the last ten years - an increase of 3.4 million. There has been a massive school building programme. During the last ten years the pupil-teacher ratio has increased from 61 pupils per teacher in 1998 to 73 pupils per teacher in 2008. ${ }^{189}$ However, it must be remembered that Mozambique is a very poor country with a long history of social dislocation caused by colonialism and civil war.

What is the position of disabled children? ${ }^{190}$ Every child has a right to free education. Mozambique's National Education Plan foresees meeting the needs of pupils with special educational needs through integration into special classes and into regular schools. This envisages all children with different impairments being integrated in regular schools. The policy requires differentiation and work against the stigmatisation of disabled children. In policy terms this sounds promising.
Learning to walk in Mongolia.

CRedit: SAVE the ChiLdRen 


\section{What has been achieved?}

- Rehabilitation of 46 classes for hearing impaired students in regular schools in Maputo;

- Launch of the inclusive schools programme;

- Integration of special educational needs and psycho-pedology into basic teacher training;

- A training programme for teachers in sign language and Braille, set up with NGO support

- Reform of the basic curriculum, leading to a more outcomes-based approach;

- Twenty-three disabled teachers have been trained, offering role models to pupils;

- Inclusion of 62,357 disabled children out of a total population of $4,844,077$ in mainstream schools.

Constraints and barriers still exist and may mean that targets for inclusion are not met. The Commonwealth Education Fund (CEF) was set up in 2002 to co-ordinate international NGO funding for education in 16 Commonwealth countries. A partnership with the Association of the Blind and Partially Sighted in Mozambique (ACAMO) has initiated innovative work on advocacy for the education of blind and visually impaired children.

According to ACAMO, for a population of around 720,000 visually impaired people there exists one special school for the education of visually impaired children; less than 200 children and young people are studying in this school, other mainstream schools or in further and higher education institutions. It is estimated that only 300 people have knowledge of Braille. The only place that offers formal rehabilitation for newly blind people has a maximum capacity of six people each year. Fewer than 60 blind people are in paid employment, and most of these work in government institutions as teachers or telephonists. ${ }^{191}$

In Beira province, ACAMO has trained teachers to work with disabled children and promote inclusive teaching. Meanwhile, with support from the Commonwealth Education Fund, ACAMO aimed at developing a curriculum for children with special needs and bringing it to the attention of the Ministry of Education. CEF supported ACAMO in sharing this work with a neighbouring country, Malawi. Unfortunately, the work on a new curriculum was not completed due to CEF's lack of funding. ACAMO received only half of the approved budget. At policy level, ACAMO participated in the preparation of Mozambique's annual plan for special needs education.

A study commissioned by the Secretariat of the African Decade of Persons with Disabilities (SADPD) has explored effective strategies for the incorporation of disabled children into future education plans in Cameroon, Rwanda and Mozambique. ${ }^{192}$ Although based on focus groups and visits to five schools, it is rights based and carried out by disabled people. There are only five special schools in the country and this should be used as an opportunity to develop inclusive education, not build more, as in donor aid programmes. Pilots on inclusive education are running in mainstream schools in eight provinces. 
Charawa (2010) found many barriers to inclusion:

- 80 per cent of disabled children are still not in school;

- Negative attitudes and stigma are widespread;

- Special education methodologies dominate, rather than rights-based principles;

- The laws and policies on inclusive education are not generally implemented;

- Not enough teachers have been trained and those who have been move on;

- In Zambezia, only five teachers were trained in 2000 and only one was still in post in 2007;

- Class sizes are increasing and teachers do not know how to meet the needs of disabled pupils so in the main they are ignored;

- Transport and buildings, including toilets, are inaccessible for disabled pupils;

- Curriculum and syllabuses ignore inclusion and disability rights.

\section{Recommendations}

- Allocate money to relevant ministries specifically for inclusion initiatives;

- Incorporate inclusion issues into all Ministry policies;

- Consult DPOs, disabled children and their parents, using a rights-based approach;

- Prioritise measures to eradicate poverty and ensure there is a focus on disabled children, e.g. in feeding programmes and transport to school;

- Carry out a survey to ascertain the number of disabled children and their impairments;

- Analyse the conditions required to implement inclusive education;

- International NGOs and other donors should fund projects that incorporate disability issues into the mainstream;

- DPOs should have a programme to raise disability equality in the community.

Mozambique has shown its willingness to engage actively with Education for All. Now it and other governments in similar positions need to shift gear to implement inclusive education by building the capacity of the school system and engaging with DPOs along the lines of the disability rights education model (Chapter 4 ) in order to firmly establish inclusive education.

The Forum for Mozambique Associations of Disabled People (FAMOD) is an umbrella organisation of disabled people's organisations. It has found it very useful to work with other DPOs in the region to develop its capacity. It also says there is a great difference in working with disabled people's organisations in the North compared to NGOs, with the latter being too rigid, wanting to set the agenda and bring in non-disabled experts. DPOs are more flexible and usually offer long-term support. This is much more useful in overcoming the barriers against working in rural areas and developing a leadership that goes further than rehabilitation issues. ${ }^{193}$ 


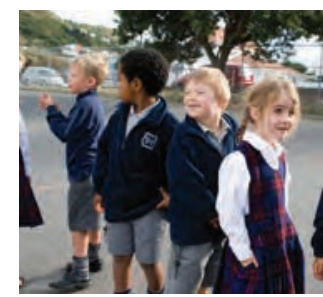

Pupils at St Francis School, New Zealand. Credit: IHC New Zealand

\section{Box 6.21 New Zealand: The challenge of equality}

New Zealand has a range of policy and legislative initiatives that aim to increase the participation and achievement of disabled students in an inclusive education system. People who have special educational needs (whether because of disability or otherwise) have the same rights to enrol and receive education in state schools as people who do not (1989 Education Act). All children have the right to 'quality education that meets their specific needs as learners' and schools have a legal and ethical obligation to cater for all students, irrespective of age, gender, ethnicity and ability. ${ }^{194}$ As stated in New Zealand's Special Education Policy Guidelines, ${ }^{195}$ young children and students with special education needs have the same rights to a high quality education as people of the same age who do not have special education needs.

The New Zealand Disability Strategy (2001) outlines 15 objectives that would help New Zealand progress towards becoming a non-disabling society (New Zealand Office for Disability Issues, 2001). While they are all indirectly related to the inclusion of disabled students in mainstream schools, the third objective - 'to provide the best education for disabled people' - is especially relevant.

The New Zealand Children's Commissioner ${ }^{196}$ has examined how well the current system of inclusive education is meeting the needs of disabled children and has found many causes for complaint. These are mainly about attitudes and the way resources are allocated. To support the country's Education Review Office in implementing a schools disability strategy, eight to ten young people, aged between 12 and 17 years, are selected to be members of their Young People's Reference Group (YPRG). They come from diverse backgrounds and represent rural and urban communities. Their role is to provide advice about issues concerning young people; assist in the strategic direction of the office; facilitate consultation with children and young people; and inform the Children's Commissioner of regional issues. Making inclusion happen is a key concern of the YPRG.

Neilson (2005) considers the New Zealand Disability Strategy to be 'an illustration of the rights discourse in action'. Eight actions are associated with the education objective:

1. Ensure no child is denied access to their local school because of their impairment;

2. Support the development of effective communication by providing access to education in New Zealand sign language, communication technologies and human aids;

3. Ensure that teachers and educators understand the learning needs of disabled people;

4. Ensure that disabled students, families, teachers and other educators have equitable access to the resources available to meet their needs;

5. Facilitate opportunities for disabled students to make contact with their disabled peers in other schools;

6. Improve schools' responsiveness to and accountability for the needs of disabled students; 
7. Promote appropriate and effective inclusive educational settings that will meet individual needs; and

8. Improve post-compulsory education options for disabled people, including promoting best practice, providing career guidance, increasing lifelong learning opportunities and better aligning financial support with educational opportunities.

According to the New Zealand Office for Disability Issues, the UNCRPD will provide greater impetus for New Zealand's disability strategy because it makes explicit that states must ensure the full realisation of all human rights and fundamental freedoms for all disabled people, without discrimination of any kind on the basis of disability. Courts can choose to use the Convention as an international legal framework for their decision-making.

Yet despite the policies and legislation already in place, the nature and extent of complaints to the Office of the Children's Commissioner suggest that some students with diverse needs continue to be denied access to an inclusive education. The following examples of exclusion have been regularly reported:

- Students with disabilities are being sent home whenever they 'misbehave';

- Students with behavioural difficulties are not allowed to go on school camp;

- Parents are asked to keep 'difficult' children home during Education Review Office visits;

- Students with diverse educational needs have faced Board of Trustees disciplinary hearings and are regularly suspended or excluded for behaviour that is a recognised symptom of a medical condition or disability;

- Students with high physical and intellectual needs are not taken on school outings because they require too many resources;

- Children with diverse needs are often the targets of bullying by their peers.

These complaints mirror a study by Kearney (2009) that investigated the nature of school exclusion in relation to disabled students. Kearney categorised a wide range of exclusionary practices. The complaints and a consultation led to a four-year strategy to improve the quality of inclusive education. ${ }^{197}$

'Success for All - Every School, Every Child' (2009-2014) is the government's four-year plan of action to achieve a fully inclusive education system. The plan builds on the views of more than 2,000 people from across the country who made submissions to the government's review of special education. 'Success for All' is a plan for everyone - the Ministry of Education, school boards, principals, classroom teachers, specialists, children and their families. Its aim is to make New Zealand's world class education system even better by building on what is working well and improving what is not. It aims to create a fully inclusive system of 'confident schools, confident children and confident parents'.

To achieve this objectives the government is increasing resources for in-service teacher training. It will increase flexibility and support for deaf and blind children, and those with significant learning difficulties through the mechanism of the ongoing and reviewable resourcing scheme (ORRS), greater collaboration between agencies and more support for struggling families and children with

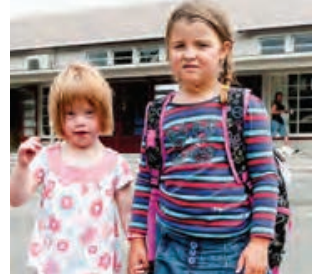

Does all mean all? Including children with intellectual impairments.

Credit: IHC New Zealand 
behavioural difficulties. It will improve accountability for tracking and monitoring the progress of all children's learning and improve the transition to tertiary education.

The government aims to turn 80 per cent of mainstream schools into effective inclusive schools by 2014 and get the other 20 per cent well on their way. In 2010 the Education Review Office carried audited inclusion in New Zealand mainstream schools and found that 50 per cent operated an effective inclusion policy, 30 per cent did so in some areas and 20 per cent did nothing at all. ${ }^{198}$

In effective schools, the Education Review Office found that staff demonstrated good practice in teaching students with high needs and in ensuring that they took a full part in the social, cultural and sporting life of the school.

Positive points were:

- Commitment in the face of challenges, e.g. a 'can do' attitude that ensured that the school made adaptations to cater for students with high needs and for their families;

- A caring culture - creating a welcoming and supportive environment;

- An experienced leadership and staff, who drew on a wide range of strategies and networks to support students with high needs and their families;

- The ability to manage the available funding and use it to enhance inclusion, even in challenging circumstances;

- Teamwork, systems and relationships - constructive relations with family and outside agencies taking a problem-solving approach;

- Working with families and whānau, e.g. focusing on issues the family and student identify as important;

- Use of information, e.g. good SEN register data and evaluation of all initiatives or systematic review of lesson observations;

- Managing school transitions, e.g. several staff, working together with a student and their family, so that the specific needs of a student were taken into account in making a transition as effective as possible;

- Innovative and flexible - an inclusive pedagogy involves understanding what a student can achieve and designing a programme that engages that student, e.g. using learning styles, differentiation and parallel activities;

- Using strengths and interests to develop a curriculum for students, for example selecting what works best from different curriculum documents;

- Developing networks of students around students with high needs to promote their social inclusion in the school, e.g. buddy systems and circles of friends;

- Specific adjustments for particular pupils, e.g. visual signs for autistic student or yellow lining playground for visual impaired student.

\section{Areas for improvement at inclusive schools}

Despite good practice in inclusive schools, there were still ways in which many of them could further include students with high needs. ERO's concerns included: 
- Teachers at a secondary school having insufficient knowledge of formative assessment and/or differentiated teaching to specifically meet the needs of students;

- Teachers having insufficient time to plan for students with high needs;

- Little Māori or Pacific presence in the school although several of the students with high needs were Māori or Pacific;

- Some individualised education programme goals lacking in detail, making it difficult to identify progress;

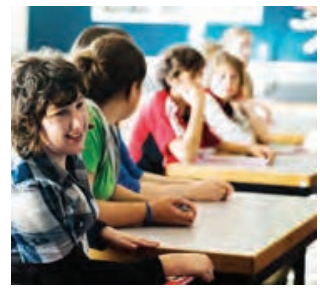

Onslow Secondary School, New Zealand. CRedit: IHC New ZeALAND

- Teacher aides doing too much of the programme planning with too little input from the teacher;

- Weaknesses in writing ORRS applications, which meant that some students with high needs might not have received funding to which they might have been entitled;

- The principal of the school also operating as the SENCO;

- Physical access difficulties (including a split site and some two-storey buildings);

- Evidence of teasing/taunting by other students in some contexts;

- A shortage of teacher aide cover;

- Too heavy a workload for the SENCO.

There are still special schools and many separate classes in New Zealand for blind and deaf children and for those with learning difficulties. The plan is to integrate these into the system with more children on outreach, but there is no end date for transfer to a mainstream inclusive system. Local DPOs, particularly those for people with learning difficulties, are critical of these plans.

Criticising both New Zealand's draft report to the CRPD committee and 'Success for All', an advocacy organisation for people with intellectual impairments says: ${ }^{199}$

- It is not acceptable to have 20 per cent of schools not operating any inclusive practice.

- When will the government bring forward a plan to close the remaining special schools as this counters Article 24's requirement for an inclusive system at all levels?

- There should be comparable outcome data for disabled children in mainstream and special education.

- There needs to be more effort and resources to make mainstream schools inclusive.

- Special school teachers should not provide the main support and training for inclusive education; this should be provided by those with expertise in inclusion.

- All teaching students should do mandatory modules on SEN inclusion.

While parents and DPOs are entitled to, and do, criticise the inadequacies of New Zealand's inclusive provision, there have been great changes in pedagogy 
in the last 20 years, which have undoubtedly supported the development of inclusive education in those 50 per cent of schools with promising practices.

MacArthur (2009), in concluding an excellent booklet on developing inclusive education in New Zealand schools, ${ }^{200}$ argues:

Change has been a long time coming. Many of the issues about segregation and 'special' education described in this book have been raised in the research literature of the past three decades. There is now an overwhelming body of research that supports an end to segregation and 'special' education thinking.

While the field of 'special education' has provided much debate, it has led to little action toward social change for disabled people (Connor and Ferri, 2007).

In contrast, inclusive education has been scrutinised, conceptualised, described and explored in the research literature to a point where there has been a remarkable maturing of ideas. In particular, the research that explores inclusion through the day-to-day practices of teachers and other school staff, and research that gives priority to the views and experiences of disabled students, provides a rich foundation from which to move forward.

There are some sticking points (Slee, 2005: 159), with the research recognising that regular schools still have some way to go before all children are welcome and included as fully participating members. Some of the remaining barriers come from policies that do not yet commit to inclusion and hamper the progress

of teachers and schools working on an inclusion agenda. Other barriers come from values, school structures and practices that still associate diversity with negative interpretations of deviance and difference. Yet others come from a failure to listen to disabled students as they negotiate their school lives.

However, as Slee (2005: 157) points out:

Many of our neighbourhood schools are not good places even for those children whose right to a desk therein is never questioned. Clearly, the solution to the sticking points is not to return to the flawed system of special education, or to keep channelling more and more children who are considered as 'not fitting' regular schools into segregated places. Sticking points are an impetus to do better for all children and young people in our regular neighbourhood schools.

\section{Box 6.22 Pakistan: Education for All in an inclusive setting}

'Persons with disabilities are mostly unseen, unheard and uncounted persons in Pakistan. They are the most marginalised group.' So wrote the Japanese International Cooperation Agency in 2002. ${ }^{201}$ Have things changed?

Interpreting a wider set of data for the Disability Education and Poverty Project (DEPP), Singal and Bhatti (2009) set out to examine the connection between poverty, disability and education in two areas of Pakistan, focusing on 15-30 year olds, an often overlooked group. In a stratified random sample of households in nine districts in Punjab and North-West Frontier with around 9,000 respondents, questions were based on functional limitation, following the WHO and UN Statistical Division interactional approach, rather than 
previous medical approaches. The survey found an overall impairment rate of 20 per cent, far higher than the 2.5 per cent found in the 1998 census, and 9 per cent of the target group, young people. Despite a constitutional right to education, over one-third of children had not attended primary school and only 25 per cent had attended secondary school. The UN Economic and Social Commission for Asia and the Pacific (UNESCAP) estimated that only 4 per cent of disabled children are enrolled in school (UNESCAP, 2006).

At federal level, the Directorate General of Special Education within the Ministry of Social Welfare and Special Education runs 51 institutions for children with various impairments as single disability schools. Provincial governments run over 200 institutions. There are about 230 private special schools with a total enrolment of about 13,122 disabled children. ${ }^{202}$ More than 30,000 children with disabilities are already in ordinary schools. This amounts to less than 4 per cent of the total number of school-age disabled children being in school. ${ }^{203}$

The researchers found that young disabled women are less likely to enrol in school than young disabled men, and that even if they do acquire some primary education they are much less likely to complete secondary school than their male peers. The disabled boys are less likely than their non-disabled peers to attend school. If the impairment involves learning or requires personal care they are much less likely to attend school. 35 per cent of girls have no schooling compared to 44 per cent of girls with moderate or severe impairments. For boys, the comparable figures were 12 and 29 per cent. The data suggest casual integration, with 97 per cent of those who went to school attending mainstream classes. A higher proportion of the disabled young people had been privately educated, 19 per cent compared to 11 per cent of non-disabled. There are many low fee private schools in the villages and the proportion went up for secondary school students, perhaps due to distance to state secondary schools from the villages. Parents, contrary to stereotypes, seemed prepared to spend money on their disabled children's education. Koranic education is chosen more often for disabled boys than for non-disabled boys.

There are some examples of change. In the Punjab, the provincial government has established an independent department for special education and there has been a substantial increase in financial allocations. Ninety new special education centres have been established at tehsil level and special education teachers receive double pay. There are also incentives for disabled students.

In 2005, the Secretary of Education and the Secretary of Social Welfare signed the Islamabad Declaration on Inclusive Education on behalf of their respective ministries. The Declaration was drafted during a comprehensive national consultation process, involving federal ministries, provincial departments, universities, DPOs, UN agencies and international organisations. This was followed up by a national conference in February 2007, where a pilot scheme was launched.

In the run-up to the 2007 conference, ten schools in Islamabad were selected by the Federal Directorate of Education as pilot schools for inclusive education. This initiative was supported by IDP Norway and Sightsavers International. There are now 16 pilot schools, in both rural and urban areas. In July and August 2007, teachers from the pilot schools went out into their communities 


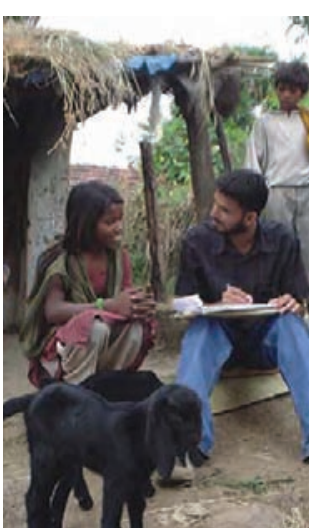

Pakistan: communitybased rehabilitation. to find children who were out of school. Hundreds of children were identified. The majority had never been enrolled in school or had dropped out. Many parents were sceptical about sending their disabled children to school - some were worried that their children would be bullied, some were embarrassed and others needed their children to beg on the streets. Most of these children are now enrolled in school.

Waleed, aged six, had enrolled in a kindergarten when he was five years old, but was asked to leave because he had a physical and developmental impairment. He could not speak and showed no interest in interacting with other children. However, the teachers in the nearby pilot school persuaded his parents to send him to their school. After four months he can speak, knows his name, enjoys playing with his classmates, and his mobility has improved. He is just one success story among many.

However, the rigidity of the curriculum, the lack of resource teachers in schools, poor quality paediatric health services and lack of specialists to help assess the special needs of children are some of the main barriers to inclusion in Pakistan.

The American Institutes for Research's (AIR) report on the USAID-funded programme in the Bagh district of Azad Jammu and Kashmir is known as ENGAGE (Caecers et al., 2010). ENGAGE selected an existing teacher programme, 'Revitalising, Innovating and Strengthening Education' (RISE), to show the benefits of integrating inclusive education curriculum and materials. 7,000 teachers were trained with these materials. It was introduced to selected areas after the 2005 earthquake. Teachers undergo a 12-day training course, which is focused on student-centred learning methods. After completion, RISE brings together teachers to support each other in monthly cluster meetings. A further three-day follow up workshop is provided at the end of the two-year cycle.

After the first cohort of teachers had completed the two-year cycle in Bagh district, ENGAGE initiated a pilot inclusive education project providing extra training so that 25 teachers would be able to educate disabled children in their classes. Bagh consists of 230 villages in the Himalayan foothills. There are 123 primary schools, Grades 1-5. Teachers were selected by RISE and the District Education Office, taking into account gender balance, location and whether they already taught disabled pupils. Most disabled children in the district were not enrolled. The teachers enrolled 48 disabled children. Nineteen schools were involved, mostly with multigrade classes. Four local teachers who had completed a Master's course in inclusion were taken on as mentors. The mentors, professors and trainees had regular meetings and training sessions throughout. Teachers' attitudes, knowledge and skills were recorded as becoming more pro-inclusion with increased confidence. The trainee teachers changed their classroom environment and made it much more conducive to inclusion and more interactive, project work and peer tutoring was witnessed. As a result, some of the disabled children showed improvement in school assessment, parental involvement increased dramatically and more resources were provided, such as audiology and hearing aids. The positive change demonstrates that inclusive methods can succeed in rural Pakistan. Such projects need to have a longer timescale and to be built into the administrative structure of the whole country.

To develop a pilot on inclusive education the Federal Directorate of Education 
(FDE) and IDP Norway have:

- Published a compendium on conventions, agreements and laws guaranteeing all children equal rights to quality education in an inclusive setting;

- Received guarantees from the Ministry of Women's Development, Social Welfare and Special Education that it will make a special educator available to each of the 16 pilot schools;

- Held extensive training for headteachers and class teachers in managing inclusive and child-friendly classrooms. This programme ran from February 2007 to the end of 2009; 200 teachers were trained;

- Collaborated with the Pakistan Disabled Foundation to provide a team of disabled young people who will tutor children and assist their class teachers with the orientation and mobility activities needed for daily living and Braille literacy;

- Trained school counsellors, because many children (with and without impairments) experience social and emotional difficulties;

- Worked with activists within the deaf community to assess different sign languages used in schools and communities throughout Pakistan, to ensure that the use of indigenous sign languages is promoted in the inclusive schools (complementing the use of the standard Urdu sign language);

- Developed a glossary of terminologies (in English and Urdu) related to disabilities, inclusion, barriers to learning, development and participation to reduce the 'disabling' labelling of children.

These initiatives, combined with the strong motivation of teachers in the pilot schools, will ensure that the implementation of inclusive education is successful and replicated in schools throughout the country. Pilot implementation of inclusive education started in four schools in Quetta, Balochistan in April 2008. By 2010, 843 children with moderate impairments had been successfully included in the 16 schools in the Capital District. This initiative was financed by the Norwegian Government (Rs30m) and implemented in collaboration with the Provincial Education Department in Balochistan, IDP Norway, the FDE and the Pakistan Disabled Foundation.

Following the success of these 16 pilot schools, President Zadarie introduced an education policy, approved by the Federal Cabinet in September 2009, to achieve Education for All. This focused on the building of two inclusive schools in every district and the adoption of a child-friendly inclusive school framework. ${ }^{204}$ In November 2010, the Federal Government, in conjunction with UNESCO, UNICEF, Sightsavers and the Federal Education College, ensured that the Secretary of Education from each provincial ministry of education signed the Islamabad Commitment to Child Friendly Inclusive Education. ${ }^{205}$

This focused on four key dimensions for such schools, stressing they must be:

- Inclusive of all learners who had been systematically excluded from schooling and learning;

- Academically effective, including the social, emotional, spiritual and physical aspects of child development; 
- Healthy, hygienic and safe, and protective of teachers and students;

- Participatory, encouraging the active and democratic involvement of students, families and communities.

Pakistan has failed to introduce compulsory primary education over a number of years, with a stubbornly large proportion of children not in school, especially girls. The development of a full programme of inclusive education for all holds out the hope of resolving this.

Tahir (2009) sets out the challenges to a full-fledged programme for large-scale implementation of inclusive education in mainstream schooling:

1. Attitudinal change on the part of parents, teachers, headteachers, professionals, politicians, service providers and community members towards children who are vulnerable to exclusion from and within education (including disabled children);

2. Parental awareness about disabilities and children's potential;

3. Accessibility of school buildings, classrooms, toilets, playgrounds and transport;

4. The curriculum and the assessment and examination system;

5. Limited financial resources;

6. Inadequate support system, including insufficient trained and qualified professionals, medical and paramedical staff;

7. The need for continuous follow-up and monitoring of activities.

All stakeholders must join hands, share experiences and provide support for the implementation of the inclusive education project in letter and in spirit. ${ }^{206}$

\section{Box 6.23 Papua New Guinea: Education for disabled children}

Papua New Guinea is a South Pacific island nation with approximately 5.2 million people. It is heavily forested, with many mountains and swamp areas, making travel within and between the 20 provinces very difficult. This regional isolation has ensured the retention of the culture, language and customs of over 700 distinct indigenous tribes and clans, scattered over an area which is still mainly rural with very poor infrastructure. More than 75 per cent of the population live in the rural areas. Rural communities in particular have a deep sense of taking care of one another within their own community.

The government is committed to inclusive education. It is embodied in its 1994 Special Education Ministerial Policy Statement and in the Department of Education's National Special Education Plan, 2004-08. It is also committed to UNESCO's target of Education for All by 2015, but this will not be reached. Inclusive education priorities include capacity building through pre-service and post-service special education teacher training.

The 1990 national census identified approximately 12,000 disabled people over the age of ten years. The number of disabled children enrolled in schools 


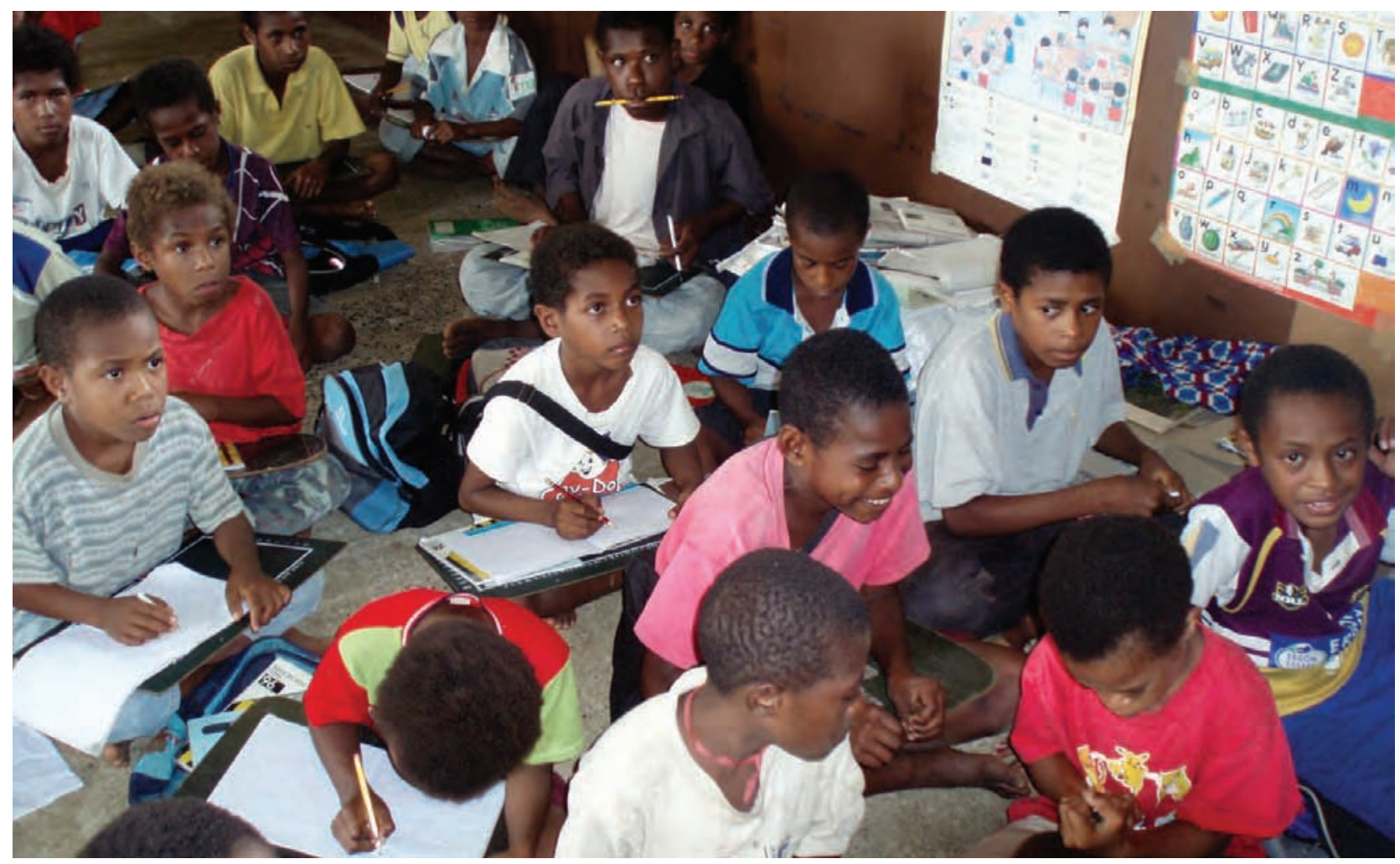

has not yet been documented, due mainly to the absence of a national data collection mechanism. Special education service provision is managed through the government's national special education committee and national special education unit. Special education services are delivered through 14 special education resource centres, based in major towns and cities. The resource centres are operated by NGOs, including the Christian Brothers, Callan Services Network, the Red Cross and the St John's Association for the Blind. They support families and disabled children, educators and school administrators, and provide community-based rehabilitation services for disabled children who do not attend school.

A university course trains specialist teachers in the methods of inclusive education at Port Moresby. ${ }^{207}$ In order to achieve inclusive education the government decided to introduce changes at teacher training level to ensure that new graduates take the principles of inclusion into schools. The country has ten teacher training colleges, all within reach of a Special Education Resource Centre (SERC). A post was created at each of the teacher training institutions for a lecturer to develop and oversee the special education training component. These post-holders liaised with the staff at the resource centres to provide practical and experiential input to college courses. SERC staff provide the essential hands-on, community-based experience essential to student teachers to enable them to put theory into practice.

Deaf pupils have been successfully included in rural areas; in urban areas they are taught in specialist classes attached to mainstream schools. In the 1990s, regular screening indicated that some children with severe to profound hearing loss attended regular schools, often without any specialist support and without the class teacher knowing about their hearing difficulty. This approach requires specialist teachers of the deaf to be responsible for the delivery of such a facility. Their role is to deliver a special curriculum for children within the special class
An inclusive class in Mandang District, Papua New Guinea. Credit: Charlye Ramsey 
which leads to inclusion, while at the same time supporting mainstream teachers in providing an inclusive curriculum. ${ }^{208}$

In order for an inclusive approach to be successful for deaf pupils, the following measures are required:

- Full audiometric assessment and the provision of medical audiological and rehabilitation support services;

- An understanding of the different communication approaches required to meet each child's individual communication needs;

- The provision of an early medical and educational intervention programme that includes, among other services, early identification, medical intervention (when required), audiological services, auditory training, language development and communication approaches for the child with hearing impairment and also for parents, siblings and community members;

- Teachers and classroom assistants who can identify children with hearing difficulties and are fluent in oral, total and bilingual communication;

- The provision of a pre-school which caters for the communication needs of both deaf and hearing children;

- Additional staff to provide individual support, including additional speech and language programmes;

- In-service training for classroom teachers and assistants;

- In-service training for community school teacher in preparation for integration and inclusion;

- Provision for deaf adults to become involved in the provision of services.

Following the success of including deaf pupils in rural areas, the government has supported moves to establish specialist classes in urban schools. As of 2011 Papua New Guinea resource centres have been set up in 17 districts, staffed by two or three specialist trained teachers. These provide training and support for mainstream schools and teachers. A Department of Special Education Unit co-ordinates training and the resource centres. Some of this is supported by NGO workers. The country's 2004-2008 National Education Plan encouraged inclusion and has now been extended to 2013. The problem with implementation is lack of funding and expertise. There is still no mandatory right to basic education and the number of disabled children is not accurately known. Moves to adopting and ratifying the UNCRPD backed by AusAID will give progress to inclusion a sharper focus in years to come. ${ }^{209}$ The plan 'Achieving Universal Education for a Better Future'210 aims to remedy the current shortcomings by incorporating the Callan Institute as a provider of inservice training and disability studies. There are two other higher education providers and distance learning courses.

\section{Box 6.24 Developing inclusive education in Rwanda211}

Figures for the numbers of children in Rwanda who are educationally disadvantaged are not currently available, but it is planned to collect this data 
in the near future. The 2002 census identified 4.7 per cent of the population as disabled. Despite the increase in impairment caused by the recent genocide, this seems to have been balanced out by non-reporting caused by stigma and social pressures. This would give an estimate of 217,861 disabled people aged under 19 years and 105,104 5-14 year olds.

The Education Sector Strategic Plan (ESSP) for 2006-2010 states that 10 per cent of all students have some form of impairment. Rwanda's Special Needs Education (SNE) policy reiterates this 10 per cent figure and suggests that around 175,205 learners could 'have some degree of disability'. A small number of disabled children are catered for in segregated education. In 2006 it was estimated that only 800 disabled children were being educated in the country's special schools and centres. Recent increases in the number of special schools and centres (to around 34) may have raised this enrolment figure, but precise data are not available.

Of an estimated 10,000 deaf children, just 3 per cent are in school. No reliable figures for children with special educational needs in mainstream education are available, but Handicap International has identified 468. UNICEF has identified 7,500 disabled children.

The Ministry of Education estimates that state schools only have the capacity to educate 0.5 per cent of disabled children, but this does not include casual integration.

Post-genocide efforts in Rwanda to remove the use of negative ethnic labels have not been extended to the use of negative words associated with disability (for example words for disabled people still have prefixes that denote objects, not people). One ethnographic study reports wealthier, urban households in the study sample were more likely to hide or mistreat their disabled children than poorer households. In the former, disabled children did not seem to have a place in the family, whereas in poorer households they were more active and visible family members (Karangwa, 2006).

Disabled learners who are enrolled in a mainstream school may still be marginalised and not participate or achieve. There are various reasons for this, including lack of sign language skills among teachers; resource and infrastructure constraints; inflexibility - schools not adjusting to meet learners' needs; teachers' lack of information and training on how to adapt teaching methods for a more diverse range of learners. Teacher education institutions have few staff with suitable experience, and training materials are out-dated or not relevant to the country context. There is a lack of early identification of learning needs and limited or inappropriate assessment processes. Limited attempts by special schools to move some children into mainstream schools have involved little preparation of mainstream teachers and inadequate follow-up.

Rwanda's special needs education policy (2007) reveals that the national curriculum, the National Examination Council and the General Inspectorate do not yet have provision for the education of disabled children.

Rwanda's EFA Plan of Action aims for 'no disparity in education, by sex, region or other group'. Disability is not specifically listed. The strategy that accompanies this aim is also vague, when compared to the details provided in the genderfocused strategies. Rwanda's special needs education policy does at least 


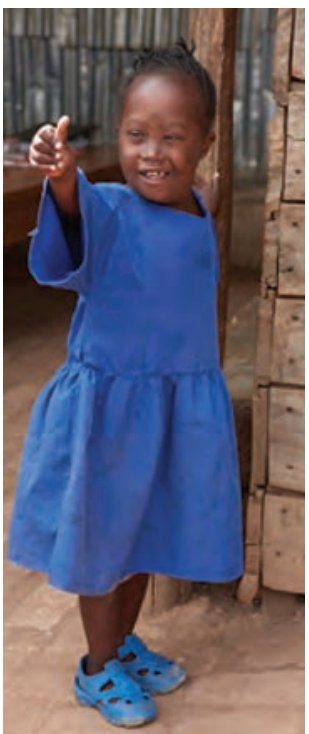

Happy at school. Credit: J Clarke, Handicap INTERNATIONAL outline the steps it expects implementers to take on special educational needs. Some of these focus specifically on disability issues and include:

- District annual strategic plans, and periodic mapping for learners with special educational needs;

- National and district co-ordination of responses regarding mainstreaming vulnerable groups;

- Itinerant teachers supporting clusters of schools;

- District level special health and social workers;

- Undertaking assessment and placement work, and introducing a scheme for providing material support to help children with special educational needs;

- Orientation towards learners' special educational needs for all educators and inspectors.

Handicap International's work in Rwanda focuses on developing sustainable links between special centres for disabled children and local mainstream schools, in order to increase the inclusion of disabled learners in their communities and mainstream schools.

The work recognises the resources and expertise within special schools and uses this to offer quality education for disabled learners through a wider range of options than just special schools. Handicap International has been raising the capacity of centres for children with profound and multiple learning disabilities to become resource centres for local schools trying to develop inclusive education approaches. Centre staff have received management training and staff at local mainstream schools have received disability awareness and teacher training. UNICEF has been supporting over 50 schools in Rwanda to become more child friendly in terms of teaching and learning methods, extra-curricular activities and the school environment. The government has embraced the concept as a key way of supporting learners with special educational needs, aims to expand this approach to 400 schools nationwide by 2012 and has made child-friendly principles the standard for all its over 2,000 primary schools.

\section{Box 6.25 Singapore: Integration rather than inclusion}

Singapore is a highly developed and urbanised country with a population of approximately 4.5 million and an estimated 131,000 disabled people (UNESCAP, 2008). This is a significant underestimate. The country's 2007-2011 Enabling Master Plan recommended that a prevalence study should be carried out, but the results are unavailable. ${ }^{212}$ In his inaugural address in 2004, Prime Minister Lee said he wanted a 'more inclusive Singapore which left no one behind'. However, the Compulsory Primary Education Act of 2003 excluded children with special educational needs.

The education of disabled children is the responsibility of the Ministry of Community, Youth and Sports and not of the Ministry of Education, but there is some liaison between the two ministries. There are 21 special schools funded 
by government but run by voluntary organisations. In 2006, around 4,000 disabled children were in mainstream schools. There has been a programme to provide special needs officers to support dyslexic and autistic pupils in mainstream education. Some schools have been resourced to accommodate various groups of impaired pupils, including two for children with hearing impairments; four for visually impaired pupils; 59 primary and secondary places for students with some form of physical impairment; all schools for dyslexic pupils; 20 primary and 12 secondary schools for pupils with autism spectrum disorders. Ten per cent of teachers received 108 hours training by the National Education Institute and a further 10 per cent will have received this by 2012 .

A Committee of Enquiry recommended more purposive integration:

Not every child with a special need needs to be in a special class. A case in mind is the student with a physical disability who essentially needs a barrier free physical environment and an inclusive whole-school culture. Each child's individual education plan (IEP) should seek to determine the settings that are most appropriate for the education of that child. For those who need special support, research has shown best education results in integrated models where these students reap the best of both mainstream and specialised settings.

Although change is occurring, it is still very slow and the dual ministry responsibility makes it more difficult. Singapore still has an integration rather than an inclusion model. A public awareness campaign and a plan to make all buses accessible by 2023 show wider societal change.

An evolving vision of inclusive society, change in attitudes, and improvements in practices and employment are all hallmarks of Singapore's approach to participation of disabled people in the economic and social sectors. The 'Many Helping Hands' approach sometimes lacks sufficient co-ordination, but nevertheless great progress has been made, while much remains to be done. ${ }^{213}$

\section{Box 6.26 South Africa: Situational analysis and policy developments}

The South African Schools Act (1996) requires educational institutions to be receptive to learners with special needs and to provide the legal basis for an inclusive education system. Public schools are required by law to admit all learners and to meet the necessary educational requirements without discrimination. However, in White Paper No. 6 the government acknowledged that there were massive problems (South African Department of Education, 2001). The White Paper set out the need to convince the parents of around 280,000 disabled children - who are younger than 18 years and not in school that these children should be included. To redress the great inequalities inherited from the apartheid years, the government made clear that special schools would be strengthened rather than abolished. It argued that the considerable expertise and resources invested in special schools should be made available to neighbourhood schools, especially full-service schools and colleges.

The Department of Education stated that it appreciated that a broad range of learning needs existed among the learner population at any point in time, and that where these were not met, learners might fail to learn effectively or be 


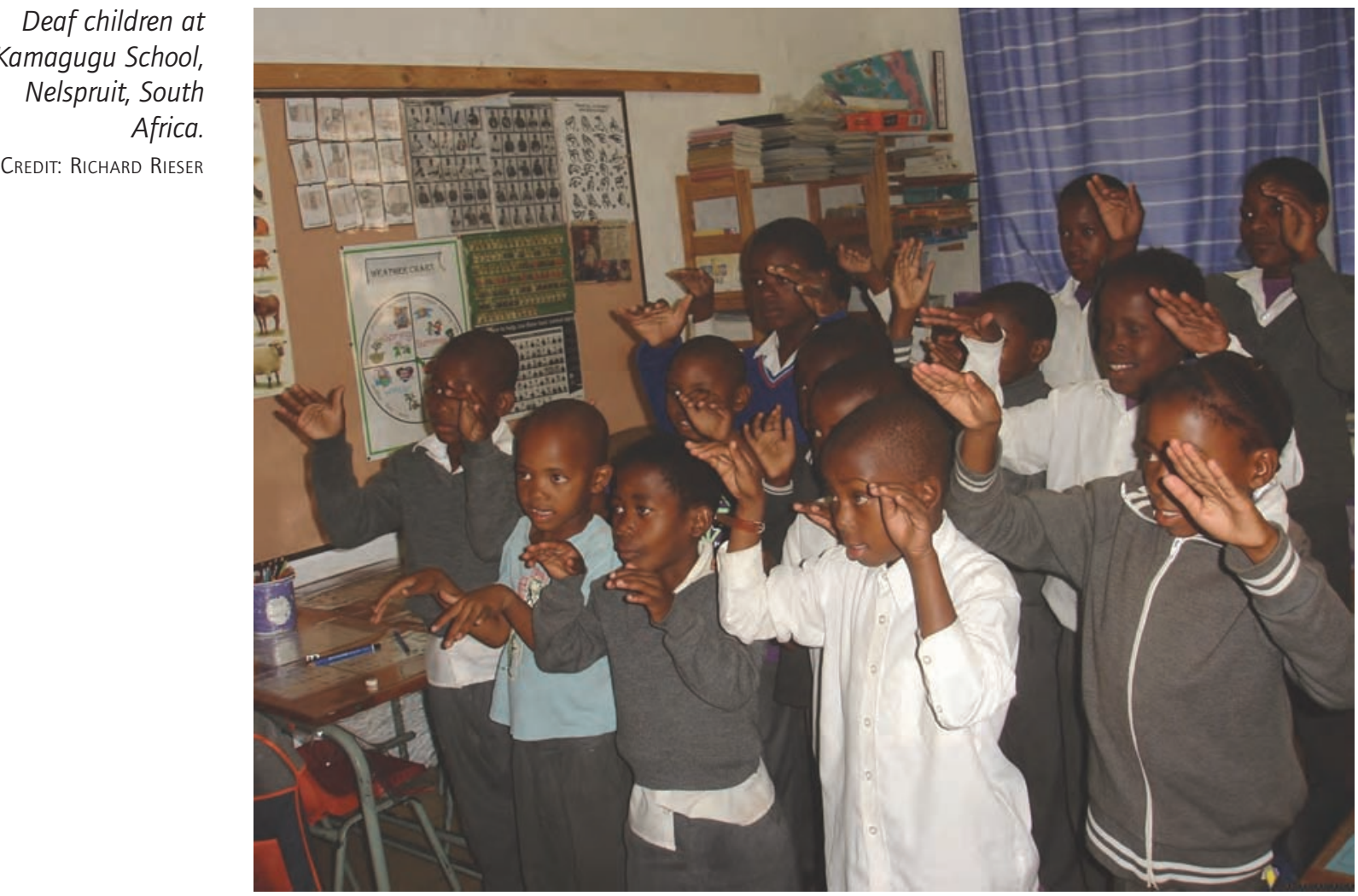

excluded from the learning system. It recognised that different learning needs arise from a range of factors, including physical, mental, sensory, neurological and developmental impairments, psycho-social disturbances, and differences in intellectual ability, particular life experiences or socio-economic deprivation.

Different learning needs might also arise because of negative attitudes, an inflexible curriculum, an inappropriate language of learning, inaccessible and unsafe built environments, inadequate support services, inadequate policies and legislation, failure to involve parents and inadequately and inappropriately trained education managers and educators.

In accepting an inclusive approach, the Education Department acknowledged that the learners who were most vulnerable to barriers to learning and exclusion were those who were historically termed 'learners with special education needs', i.e. learners with disabilities and impairments. It said that their increased vulnerability had arisen largely because of the historical nature and extent of the educational support provided.

Accordingly, the White Paper outlined the following key strategies and levers to establish an inclusive education and training system:

- The qualitative improvement of special schools for learners with severe difficulties (Level 5) and their phased conversion to resource centres that provided professional support to neighbourhood schools and were integrated into district-based support teams;

- The overhauling of the process of identifying, assessing and enrolling learners in special schools, so that it acknowledged the central role played by educators, lecturers and parents; 
- The mobilisation of out-of-school disabled children and youth of school age;

- Within mainstream schooling, the designation and phased conversion of approximately 500 out of 20,000 primary schools to full-service schools,

beginning with the 30 school districts that were part of the national district development programme to accommodate moderate impairments (Level 4);

- The general orientation of management, governing bodies and professional staff to the inclusion model, and early identification of diverse learning needs and intervention in the foundation phase (accommodating children with mild impairments, Levels 1-3);

- The establishment of district-based support teams to provide a co-ordinated professional support service that draws on expertise in further and higher education and local communities, targeting special schools and specialised settings, designated full-service and other primary schools and educational institutions, beginning with the 30 districts out of 85 that are part of the national district development programme. In the full-service schools, schoolbased support teams were to be developed;

- The development of the inclusion model, focusing on the roles, responsibilities and rights of all learning institutions, parents and local communities, and reporting on their progress.

The biggest problem with the change required to transform the South African education system is that it left the 'medical model' deeply entrenched and the categorising system of professionals trained under apartheid largely intact. For example, psychologists recommended moving a larger number of disabled children into special schools from the mainstream. The number of children redirected by mainstream schools to special schools rose from 77, 752 in 2004 to 93,000 in 2007, suggesting that children with special learning needs may face barriers to progress within the education system, even after they are admitted. ${ }^{214}$

Sigamoney Naicker (2006), Chief Director Education Planning in the Western Cape, argues that while there was reason to be highly optimistic about the future of inclusive education in South Africa, the complexities of developing a single education system for all learners should not be underestimated. Naicker suggests that because of concern for the conservatism of many academics, the training needed to implement White Paper No. 6 was left largely to government bureaucrats, who did not connect with wider pedagogical and philosophical change and did not allocate sufficient time for training. Second, 'teaching practices do not emerge from just anywhere. They are informed and shaped by theories of learning'.

Naicker explained

The problem was that education departments and teacher training institutions in South Africa adopted or developed theories of learning that supported this idea that teachers should be controllers in the classroom. The following example illustrates this point: Psychopedagogy was a 'sub-discipline' within the broad tradition of fundamental pedagogy, which is widely acknowledged to be the educational theory of apartheid. Psychopedagogicians, when speaking about learning, placed a lot of emphasis on innate ideas (in the most extreme versions, blacks had less
The new South

Africa we are

building should be

accessible and

open to everyone.

We must see to it

that we remove

the obstacles ...

whether they stem

from poor access

to facilities; poor

education; lack

of transport; lack

of funding or

unavailability of

equipment such

as children's

wheelchairs. Only

then will the

rights of disabled

people to equal

opportunities

become a reality.

Nelson Mandela, at

the opening of the

First South African

Junior Wheelchair

Sports Camp, 1995 


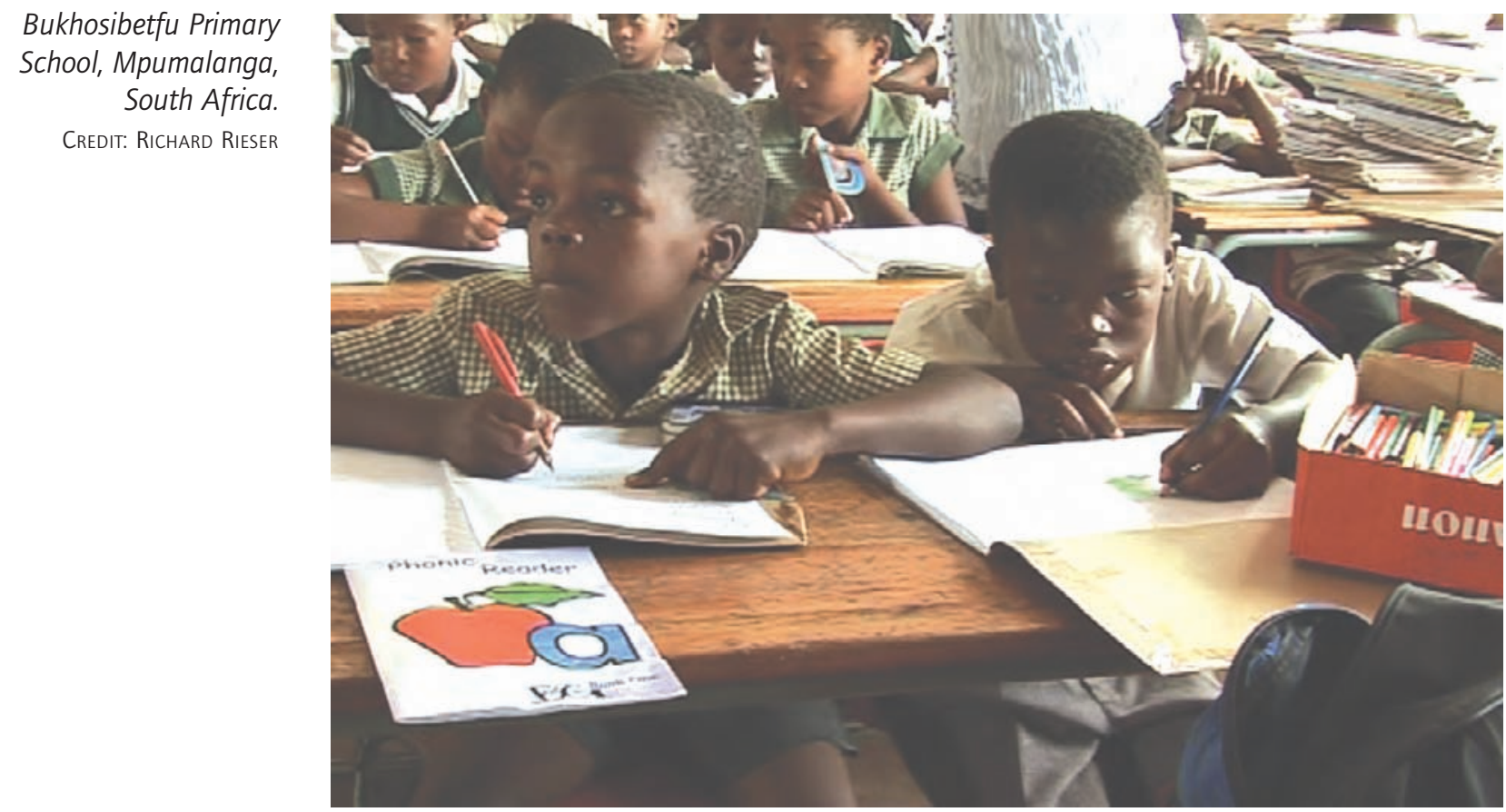

innate ideas than whites!). Teaching was thus seen as providing, in the classroom, the well-established facts, exercises and mental drills which would get these ideas going. Knowledge came to be seen as fixed, innately known, and learning involved its repetition in order to get it out and get it going.

According to Fulcher (1989: 28):

... the medical discourse suggests, through its correspondence theory of meaning, that disability is an observable or intrinsic, objective attribute or characteristic of a person, rather than a social construct. Through the notion that impairment means loss, and the assumption that impairment or loss underlies disability, medical discourse on disability has deficit individualistic connotations. Further, through its presumed scientific status and neutrality, it depoliticises disability; disability is seen as a technical issue [and] thus beyond the exercise of power. Medical discourse individualises disability, in the sense that it suggests individuals have diseases or problems or incapacities as attributes.

Thus disability was seen negatively as a deficit. This could have been challenged more quickly if the disabled people's movement had been more directly involved in training. In 2008, the author carried out a series of workshops in five provinces for educational professionals which were well received and demonstrated the need for the social model approach to form a firm basis for implementing inclusive education.

Curriculum 2005 was introduced in 1996 as a counter-hegemonic strategy to the apartheid curriculum. However, teachers were not given disability equality training to bring about a mindset that would enable them to introduce the curriculum inclusively.

Widespread criticism saw the revision of the curriculum in 2002. The Revised National Curriculum Statement (RNCS) was introduced, highlighting principles of inclusion, human rights, a healthy environment and social justice. However, 
teacher training did not inject any difference in terms of theories of knowledge. One of the central thrusts of the RNCS related to inclusion and access for all, but 'training' and orientation did not adequately contrast the radical departure of the RNCS at a theoretical level from the traditional curriculum (Naicker, 2006).

For such a radical change to be taken on by teachers they need to have ownership of the process as a whole. Rapid dissemination of the new curriculum, combined with mistrust and insecurity, may have left many without any 'buy-in'. Until recently, South Africa had a rigid curriculum dominated by traditional forms of assessment and a grade system. It has now adopted outcomes-based education (OBE), where the specification of (often culturally-biased) content is replaced by the specification of 'essential' and 'specific' outcomes. These are accompanied by 'assessment criteria' and 'performance indicators' against which students' achievement can be assessed. ${ }^{215}$ There is resistance from teachers and psychologists to adopting this approach, but this is being countered by training.

Lack of data impedes precise information on the actual numbers of SEN learners in education, as well as to what extent they participate. In 2005, 87,865 SEN learners were enrolled in 404 special schools (representing $0.6 \%$ of all South African schools) and 32,463 were in regular schools. According to the 2001 census, there were 585,589 children and youth with disabilities (Statistics South Africa, 2005). In 2001, the proportion of disabled people without any formal schooling was twice as high (30\%) as their non-disabled peers (15\%). Access to education for disabled children aged 6-18 years is 10 per cent lower on average than for non-disabled children.

From 2003, SEN learners' access to education seems to have been improving. In the early post-apartheid period (1995-2003), school attendance fell by about 24 per cent for 7-15 year-old SEN learners and by about 28 per cent for 16-18 year-olds (Department of Education, 2006). Since 2003, however, the number of SEN learners enrolled in special education rose from 0.52 per cent of all South African learners (64,603 learners) in 2001 to 0.68 per cent in 2005. In addition, there is considerable regional variation, with Gauteng having more special schools and the Free State more emphasis on mainstream. At the same time in Limpopo and Northern Cape, numbers attending mainstream and special schools fell.

In 2007, the government invited the OECD to evaluate its educational practice, including its approach to inclusive education. The OECD study (2008) made the following recommendations after interviews, field visits and a literature search.

- Develop a precise, reliable and consistent data-gathering system on SEN students and on the school system's ability to improve each learner's skills, to meet efficiency, as well as equity, requirements and to increase inclusion
Baanbreker Primary School, Boksburg, South Africa. CREDIT: Richard RIESER 


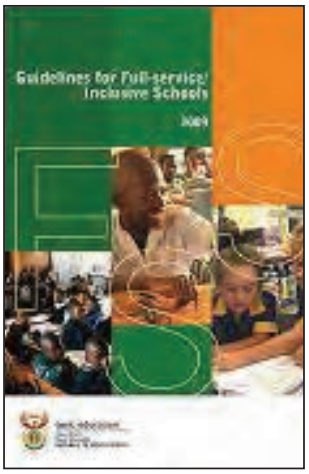

South African Ministry of Basic Education, Guidelines for FullService Inclusive Schools opportunities. Data should therefore focus on the enabling or disabling effect of policies and practices instead of looking primarily at learners' disadvantages and difficulties.

- Strengthen financial and methodological incentives and supports at provincial, local and school level, leading stakeholders to include inclusiveness for all in their strategies and empowering them to fulfil their missions. Schools should be invited to implement tools for for individualising educational approaches, diversifying educational options and identifying appropriate support.

- Support special schools more effectively in their new roles and missions by improving facilities, as well as by empowering teachers to provide high quality teaching and social workers to provide appropriate services.

- Make mainstream schools, full-service schools and special schools accountable for their pedagogical, physical and social accessibility strategies, and link modes of funding with performance management. Schools should be required to provide an annual report showing data and stakeholder comments on physical, as well as pedagogical, accessibility.

- Training schemes offered to teachers, paramedical personal and social workers should focus on problem solving and the development of learners' strengths and competences rather than shortcomings. Initial, as well as continuous, training should bring together parents and professionals from educational, social and health departments, allowing for the sharing of professional culture and improving co-operation.

- The Departments of Education, Health, Social Development and Labour should co-ordinate their policies at national, provincial and local level to foster multisectoral approaches to improving the appropriateness of services and increasing students' transition opportunities between types of provision, as well as between the various levels of education and employment.

- Foster distance learning opportunities to overcome physical barriers and improve SEN learners' education opportunities on a short-term basis.

- Develop measures and initiatives empowering parents and learners to be aware of their rights and needs and to participate actively in the educational process, as well as in society.

Some of these issues are being addressed. In 2008, the Department of Education introduced the National Strategy for Screening, Identification and Assessment and Support (SIAS). ${ }^{216}$ The aims were first to outline a process of identifying individual learner needs in relation to the home and school context, and to establish the extent of additional support that is needed; and second to outline a process for enabling the accessing and provision of this support at different levels. SIAS is intended to foster parents' involvement, as well as interdepartmental and intersectoral co-ordination of services and schools. It outlines guidelines to assist parents, teachers and support teams at institutional level, and managers and district teams, to engage in screening processes, develop forms of screening and identify learners who are facing barriers to their development, together with ways of addressing these barriers.

Since 2008 there has been a substantial increase in national funding for inclusion, but how this is spent depends on the provinces. In 2010 the 
Education Department produced Guidelines for Full-Service/Inclusive Schools, based on field tests undertaken between 2004 and 2009 (South African Department of Basic Education, 2010). These provide a coherent rational for the development of inclusive practice.

The objective of the guidelines is to explain the main principles of full-service schools and outline the institutional development process, while building links with different partners at all levels for support. They are also designed to provide a practical framework for education settings to become inclusive institutions. This framework is structured around the following key components:

- Philosophy and principles of inclusivity

- Promoting a culture that welcomes, appreciates and accommodates diversity

- Whole school development and management

- Collaboration and teamwork

- Professional development

- Provision of quality support

- Assessment of learner support needs

- Inclusive curriculum

- Flexible teaching and inclusive classroom practices;

- Support on behaviour

- Physical and material resources and transport

- Family and community networks

Table 6.2. Support at district level in South Africa

\begin{tabular}{llll}
\hline Levels & $\begin{array}{l}\text { Levels of support provisioning } \\
\text { to address barriers to learning }\end{array}$ & $\begin{array}{l}\text { Type of educational institution } \\
\text { where additional support will } \\
\text { be available on a full-time or } \\
\text { part-time basis }\end{array}$ & $\begin{array}{l}\text { Degree and nature of intervention } \\
\text { of district-based support team }\end{array}$ \\
\hline $1-2$ & Low levels of support & Ordinary and full-service schools & $\begin{array}{l}\text { General and focused on building } \\
\text { capacity of all educators and ILSTs. } \\
\text { Short-term or one-off consultative } \\
\text { support around individual cases }\end{array}$ \\
\hline 3 & Moderate levels of support & Ordinary and full-service schools & $\begin{array}{l}\text { More specific and providing short- } \\
\text { to medium-term consultation } \\
\text { support around individual cases }\end{array}$ \\
\hline $4-5$ & $\begin{array}{l}\text { High-intensive and very } \\
\text { high-intensive support }\end{array}$ & Full-service and special schools & $\begin{array}{l}\text { Intensive, frequent and specific and } \\
\text { providing consultative support } \\
\text { around individual cases }\end{array}$
\end{tabular}

To back up this work a range of resources are available online at Thutong, the South African Education Portal, http://www. thutong.doe.gov.za/inclusiveeducation/tabid/1341/Userld/37007/Default.aspx

Developing Inclusive Education in South Africa is a film showing inclusive practice in ten primary schools in Mpumalanga, Guateng, Eastern Cape and Western Cape, made by World of Inclusion and Redweather Productions. Copies are available from www.worldofinclusion.com. View at http://www.redweather.co.uk/developing-inclusive-education-in-south-africa.html

- Participation in the district support network for purposes of care and support

The guidelines also address specific issues, such as assessment in inclusive education and training. 
Table 6.2 outlines how support should be organised at district level and provides a new method of weighting: a school must have support systems in place.

\section{Box 6.27 Sri Lanka: Slow progress towards inclusion}

Sri Lanka was a signatory to the Salamanca Statement in 1994. This was followed by the enactment of legislation in 1997 to ensure compulsory schooling for children aged 5-14 years. The 1997 reforms support inclusive education. They also include assessment and recording procedures for every child on admission to the formal education system. The reforms were introduced into schools in 1998, and demonstrate a positive trend towards an inclusive education policy. Statistics for 2002 produced by the Department of Nonformal, Continuing and Special Education show considerable integration of disabled children in schools. 41.9 per cent of Sri Lanka's 10,000 schools have ten or more disabled pupils; 29 per cent have between one and nine disabled pupils; but, worryingly, 29.1 per cent of schools report no disabled pupils (UNESCO, 2003: 5).

A UNICEF report in 2003 criticised Sri Lanka's slow progress from segregation and integration to full inclusive education, although it identified a few examples of good practice. Over 97 per cent of children attend school, there are high levels of literacy and free primary education for nine years.

The first national conference on inclusive education was held in December 2003, with more than 100 participants, including government representatives, educators, parents, children, teachers, NGOs and INGOs. The ultimate aim was to contribute to policy and practice development, and progress towards inclusive education for all. It was proposed that a national policy on inclusive education should be formulated and a consensus reached between the political authorities and key national level personnel such as directors of education around the establishment of a national committee which would take policy decisions on conducting research on all aspects of inclusive education and make structural changes in the education system.

In consonance with past policies and programmes, the Sri Lanka sector-wide approach (SWAp) or Education Sector Development Framework and Programme (ESDFP) adopted a rights-based stance on a quality education for all and on the reduction of disparities. The SWAp was not preceded by a special analysis of equity or social exclusion. It drew on intensive work following the 1997 reforms, the reviews and a report from the National Education Commission (2002-2003), studies of cognitive achievement of students by the National Education Research and Evaluation Centre and recent donor-funded education projects. Quantitative data on disparities is available in surveys by the Department of Census and Statistics and the Central Bank. School census provincial and district data and qualitative data are found in micro-studies.

Social equity is an all-encompassing concern in the SWAp-based Education Sector Programme. In addition to the social exclusion of poor people and the marginalisation of people in remote villages and the plantation sector, the NEC report urged the inclusion of especially vulnerable groups, such as disabled children, and street and destitute children. Since the 1980s, non-formal 
education has been seen as a mechanism for offering a 'second chance' to out-of-school children and as an avenue of transition to formal education, but it has been under-resourced. The ESDFP envisages revitalising the role of the Non-Formal Education and Special Education Division in the Ministry of Education and the provinces in bringing out-of-school children into the education system. ${ }^{217}$

In the last five years, primary school teachers have received five days training on inclusive education. The training focuses on providing basic knowledge on how to identify a child with special educational needs. It has mainly been an awareness-raising programme and the intention has been to bring about a change in teachers' attitudes towards disabled children. One-day orientation sessions have also been conducted for school administrators to sensitise them regarding educational inclusion. ${ }^{218}$ The training is co-ordinated by the university and distance learning courses are also run by the Open University.

Disabled children are educated in special schools, special education units and mainstream schools. Ninety-five special schools are non-government schools that are assisted by government grants. Special units were introduced as an interim measure to prepare children for inclusion in the mainstream; however, mainstreaming of children in these units appears to take place only rarely. In reality, children tend to remain in the units until the age of 13-14, when their education usually comes to an end. However, there are a number of examples of children who have been included successfully in mainstream education. This has generally been on an ad hoc basis, largely through the personal efforts of education officers and teachers. As was seen from the 2002 statistics, many more disabled children have been integrated, but without the right attitude and training this does not develop into successful inclusion.

Save the Children had a project working with disabled children in Early Childhood Education and Development (0-5 years). In 2005, a Save the Children study found that disabled children made up a significant proportion of those excluded. This was due to social stigma, the lack of early screening systems and the perceived inability of ECCD teachers to accommodate disabled children in their programmes.

Save the Children started a programme of community mobilisation and awareness to help stakeholders understand the importance of ECCD from a rights perspective. They stressed that all children, regardless of their abilities or status, should enjoy the right to survival, growth and development, participation, and to be heard. However, they found there was a lack of user-friendly materials and relevant inclusion training. They therefore developed a culturally appropriate teacher training package with modules, session plans and a training-of-trainers programme. The package was created through a consultative process with communities, and government and non-government ECCD actors.

More than 5,000 ECCD teachers have been trained to identify, enrol and include disabled children, and to regard difference as a resource for learning and development, rather than as a problem. So far, over 300 disabled children have been given a better start in life. The training package is recognised by the government and government officers have also been trained. ${ }^{219} \mathrm{~A}$ useful illustrated guide, Children who have Disability in Early Childhood Care and Development Centres: A Resource Book for Teachers (Save the Children, 
$2006 \mathrm{~b})$, sets out examples of how to accommodate a wide range of children with different impairments in ECCD.

\section{Box 6.28 St Lucia: Including blind children}

A member of the St Lucia Blind Welfare Association reports:

In 1964, when I was a student, we only had one Braille slate, shared by the teacher and six blind students in the St Lucia School for the Blind. We had a school and a workshop, but the emphasis was on basket weaving rather than academic education. We were sending our children to the school for blind children in Trinidad and Tobago, but not everyone could go. In 1984 we decided to educate the children in the mainstream. When we made this change, we stopped sending the blind children to Trinidad and the school was closed.

We realised that blind children were going to become adults and have to function in mainstream society. We needed to change society to make it more accommodating to blind people. By exposing our children at an early age to the world, they can develop the skills needed to handle wider society. Children who go to school with blind children will also be in the workplace and they will remember going to school with blind students. The process of change will be advanced by this early contact and blind people will be better off because of it.

In 1986 we began to integrate the first blind children in mainstream schools. We chose the brightest children because we wanted to make a point. We held a workshop for school principals, run by the Ministry of Education and we teamed up with the other special schools in St Lucia. The principals identified children with visual impairments and convinced the teachers. We had three children in the Anglican school, which was the first to take blind children. Then a few months later we brought in the TV for a big media splash to convince the other principals. Now we have blind students at college level we are beginning to see the fruits of the step we took in 1986. We didn't have all the support systems in place when we started, but if we'd waited until we had, we would never have got going.

We didn't want to create a school for the blind within a sighted school, so we began to develop resource rooms in mainstream schools. Here the teachers prepare the children and produce Braille and large print versions of textbooks. We realised that we would soon have the responsibility for setting up resource rooms throughout the island. But that is the government's job. The best role for the association is to advocate for the resource rooms and make sure that they cater for visually impaired children.

The St Lucia Blind Welfare Association is a catalyst for change, rather than a service provider. ${ }^{220}$

\section{Box 6.29 Inclusive education projects in Tanzania}

The Norwegian Association for Development Research has been supporting 
two inclusive education projects in Tanzania - one on the mainland and another in Zanzibar - since 2004. In both projects there is close cooperation between a local disabled persons organisation and the Ministry of Education and Vocational Training (MoEVT), with responsibility divided between them. The MoEVT is responsible for the training of teachers (both in-service and pre-service in Zanzibar and in-service on the mainland), and has produced practical manuals on sign language, Braille and behavioural modification. The teachers are also trained in how to make individual education plans and keep a file for every student.

The most significant contribution of the project has been to show that inclusive education is achievable and to provide practical examples of how it can be carried out. It has underscored the importance of teacher training, teaching/ learning materials, community and parental involvement and modification of the school environment to create an inclusive environment for disabled children and young people.

The project has highlighted barriers to inclusive education and to improving the quality of learning within the wider education system. There are a limited number of classrooms, large class sizes, shortage of learning materials, low teacher motivation, few basic facilities, lack of understanding of the needs of disabled children and young people, and a lack of assistive devices and medical support.

The specific achievements of the project include:

- Its contribution to the formulation of the inclusive education policy and its subsequent implementation;

- Improved attitudes towards the education of children and youth with developmental and other disabilities and reduction in the stigma associated with disability at grassroots level;

- Increased enrolment of disabled children and young people in schools - in 2006, there were 730 disabled students ( 407 boys and 323 girls) in the 20 pilot schools, three times more than in 2004;

- An improvement in the ability of teachers to handle children with diverse learning needs: in Zanzibar there is discussion of changing the curriculum in teacher training colleges and in schools, and plans to reassess examination methods;

- Increased technical capacity of the MoEVT and schools to deliver inclusive education;

- Involvement of the special needs education/inclusive education unit in the MoEVT in developing and delivering training - thereby improving prospects for sustainability;

- An increase in the range of resource materials available for inclusive education;

- Establishment of parent support and community support mechanisms for
Altogether better - at school in Tanzania.

CREDIT: CBM 
disabled children and young people;

- Better aspirations for disabled children and young people.

The project in Zanzibar has come furthest by initiating a new education policy which promoted inclusive education. The project consolidated its efforts in the initial 20 pilot schools and expanded to 20 more in 2009.

The MoEVT in Zanzibar now has a very positive attitude to inclusive education. It has even changed the title of the 'special needs education office' to 'inclusive education unit'.

In summer 2007, NFU's local partner, the Zanzibar Association for People with Developmental Disabilities (ZAPDD), the MoEVT and Professor Roy McConkey produced a documentary on how inclusion can be achieved. They have also produced a DVD on Kiswahili sign language. The inclusive education unit in Zanzibar has been collaborating with a USAID-supported initiative called MKEZA ('improving the quality of education in Zanzibar'), now renamed CREATE. In addition, the Swedish aid agency SIDA is aiming to provide a large amount of funding to the education sector through the World Bank.

On the Tanzanian mainland, the MoEVT took over the pilot project. It was already running a national pilot scheme and it has adopted several of the features of the pilot project supported by NFU. This involves 22 schools in four districts ( 16 primary, 2 secondary and 4 folk development colleges (FDCs)), and was a collaboration between a local DPO, Tanzania Association for the Mentally Handicapped, the MoEVT, the Ministry of Labour, Youth Development and Sports (MoLYDS) and the Ministry of Health. NFU was unable to continue supporting this pilot project after 2007, but a Finnish agency was looking at education policy on the Tanzanian mainland. It was hoped that the MoEVT would try to combine these two initiatives to create a more holistic approach.

Seven teachers from each school (including school inspectors and head teachers) received intensive training courses on a general introduction to inclusive education, what it means, how it benefit students and teachers, placement in class, sign language and Braille, behaviour modification, making of individual education plans and files, how to produce and use teaching and learning materials using locally available resources, and assessment and identification of the needs of students. Although there are 20 pilot schools, 144 teachers have been trained in advanced Braille and sign language. These teachers then trained their colleagues, so that all teachers at the school have knowledge of the various inclusive education concepts. Sometimes this worked well, but in other cases it would be more beneficial to provide training for all the teachers. Resources were limited, so this was the only way to reach more schools.

A specialist team has assessed 528 students, 162 of whom were diagnosed as having an impairment. By the end of 2006, assistive devices (for example glasses and tricycles) were provided to some of the students. One hundred and eighty textbooks for Maths, English, Kiswahili, social sciences and natural science were translated into Braille for schools in Zanzibar in 2006. There have been many changes, particularly in attitudes, among teachers, students and local communities. Although big challenges remain, the project has shown that inclusive education can be achieved with very limited resources. (See DVD 2 for 
a film of this project. $)^{221}$

\section{Box 6.30 Uganda: Inclusive planning and international co-operation}

Inclusion is not a new concept in Uganda; people who were different have always been protected by their families and tribes. They learned how to do practical chores and participated in daily activities in accordance with their ability.

When formal education was introduced, so was segregation. This was based on cultural background as well as disability. From 1990 to 2001 the Danish international development agency DANIDA supported the Ugandan Government in the development of education for disabled learners.

As a plank of its commitment to rebuild the social and economic fabric of the country, the government has given the highest priority to the education of all its children. Free primary education is guaranteed to four children in every family, with priority given to disabled children, as well as to girls. As a result, the number of children enrolled in primary school rose from 2.5 million in 1996 to 7.6 million in 2003, while the number of teachers increased from 38,000 in 1980 to 90,000 in 1998. Today all children are enrolled.

In 1997 the policy on universal primary education (UPE) was introduced, providing for education facilities for all children, including disabled children, without tuition fees (fees can be charged for materials and meals). The concept of learners with special needs included all children who were marginalised because of social, cultural, economic, political conditions and/or impairment. However, to begin with there were not enough resources to include all children in UPE, so each family could send four children to school with the following priorities: disabled children, girls, boys. Today all children are enrolled. In other words, UPE implies inclusion. 222

The commitment to UPE has been made within the framework of the UNESCO Education for All target. Uganda was one of the first countries to apply for debt relief under the Heavily Indebted Poor Countries (HIPC) Initiative, in return for a commitment to invest the money saved in health and education. In addition, several international NGOs have entered into partnership agreements with the government and grants have been provided by the World Bank, the African Development Bank, the EU and the UNDP, supported by UNICEF. Twenty per cent of project funds have been allocated to the Ministry of Education for school construction and a bursary scheme for poor children.

When DANIDA finished its input, the Department of Special Needs Education, University of Oslo, initiated a project with the Ugandan Faculty of Special Needs and Rehabilitation to develop two pilot inclusive schools. This includes upgrading the entire school staff (including headteachers) and developing material that will be distributed to schools, teachers' colleges and resource persons. The project was completed in 2008.

Each year the Ugandan Government reviews the implementation of its plan. There is involvement at national level from the National Union of Disabled Persons of Uganda (NUDIPU) and five disabled members of Parliament elected 
to represent disabled people's interests, as well as involvement at district level of disabled people's organisations. ${ }^{223}$

Ugandan teachers reported that ignorance, fear and a lack of confidence were the root causes of their attitudes towards disabled children before these children entered their classrooms. As they got used to the children, they reported increased confidence, coping strategies and positive changes of attitude.

In this general context, the Ugandan Government has taken specific steps to ensure that the needs of disabled children are given priority:

- A Department of Special Needs Education and Careers Guidance has been created within the Ministry of Education and Sports;

- The Ugandan National Institute of Special Education (UNISE) has been renamed the Faculty of Special Needs and Rehabilitation, Kyambogo University, and provides training of teachers in special needs education;

- UNISE has developed a special needs education/assessment and resource services centre in each of the country's 45 administrative districts, staffed by three special teachers specially upgraded so that they can make assessments, suggest school placements and give guidance to parents;

- Co-ordinating centre tutors (CCTs) now have the main responsibility for providing guidance for all teachers and teacher colleges. Schools are divided into clusters and each CCT is responsible for a cluster. The CCTs have also been provided with a re-orientation and upgrading programme.

- The Norwegian Association of the Disabled supports inclusive education in three districts.

However, significant hurdles still need to be overcome - reform of the school curriculum, training and retraining of teachers is a slow process. ${ }^{224}$ Much of the work carried out with DANIDA support seems to have since disappeared.

On 3 December 2008 the President announced that a building programme of special schools would commence. This had been lobbied for by some disability and parents' groups as a reaction to the slow development of inclusive education. The idea was to have a school for deaf children and one for blind children in each of 15 districts. This has not resolved the structural barriers and problems disabled children and students face. The infrastructure of schools in many rural areas and in the north of the country is of such poor quality that children with physical impairments face many access barriers. The Government has ratified the UNCRPD and the Ministry of Education is committed to implementing inclusive education, but in the absence of substantial public sector reform, where the operational modalities of service delivery are significantly overhauled, it is difficult to see how the goal of achieving UPE, which is underpinned by the principles of inclusive education, will be achieved throughout Uganda in the short to medium term. ${ }^{225}$

The Compulsory Education Act 2008 made basic schooling compulsory for all children. This can be effectively tied into UPE and the National Disability Act 2006, which specifically states that education is a right for all disabled children, as well as other national poverty alleviation strategies. Implementing an inclusive education project in conjunction with the Ministry of Education and 
Sports is therefore timely, but requires extra effort to ensure government buy-in.

Other NGOs are beginning to work in this sector. For example, Leonard Cheshire Disability is piloting an inclusive education programme in two districts, Budaka and Mukono, as a model programme, which has the potential to be scaled up and replicated in other districts. Project partners include the Ministry of Education and Sports, Kyambogo University, the National Council of Cheshire Services of Uganda, district education offices in the above two districts, the respective schools and communities. The main aim of this particular project is to facilitate full participation of disabled children in education by attending local mainstream schools. It is anticipated that 1,000 disabled children will benefit from this project by enrolling in the 20 schools in the two districts (500 children per district).

It should be noted that while the Government of Uganda has embraced UPE since 1996, the majority of disabled children do not benefit from this policy. There are a number of barriers limiting their full participation. The project is addressing some of these barriers.

To date, 90 teachers from Mukono and Budaka districts have been trained in special and inclusive education. The purpose is to introduce teachers to disability and development issues, the theoretical aspects of inclusive education and development, global conventions and declarations on special and inclusive education, the Ugandan Government's policies on disability, special and inclusive education methods, the various impairments they may encounter while teaching, and the methodology of teaching children with special needs.

\section{Box 6.31 UK: Good practice under threat}

Until the twentieth century most disabled children in the UK were either integrated into mainstream schools or did not attend school. From the 1880s, a growing number of segregated special schools were set up for disabled children, because it was felt these establishments best met their needs. After the passing of the 1944 Education Act, disabled children were medically assessed and placed in 11 different types of special school. This led to demands from parents and teachers for new types of special school, such as schools for autistic and maladjusted children. In the 1960s and 1970s there was a movement, now under threat, for comprehensive schools.

In 1978 the Warnock Report recommended dropping medical labels and replacing them with Statements of special educational needs. The report also recommended that more disabled children should be integrated into mainstream schools. However, the thinking still identified the deficiencies in the child rather than examining the system. This led to the 1981 Education Act. Some local education authorities, such as the London Borough of Newham, moved towards inclusive education, but most retained the notion of 'a fixed continuum of provision to meet a continuum of needs', i.e. a range of special schools. This created the idea that the mainstream was not responsible if it failed to integrate the disabled child, because the child could always go somewhere else. So schools and teachers did not have to restructure themselves 


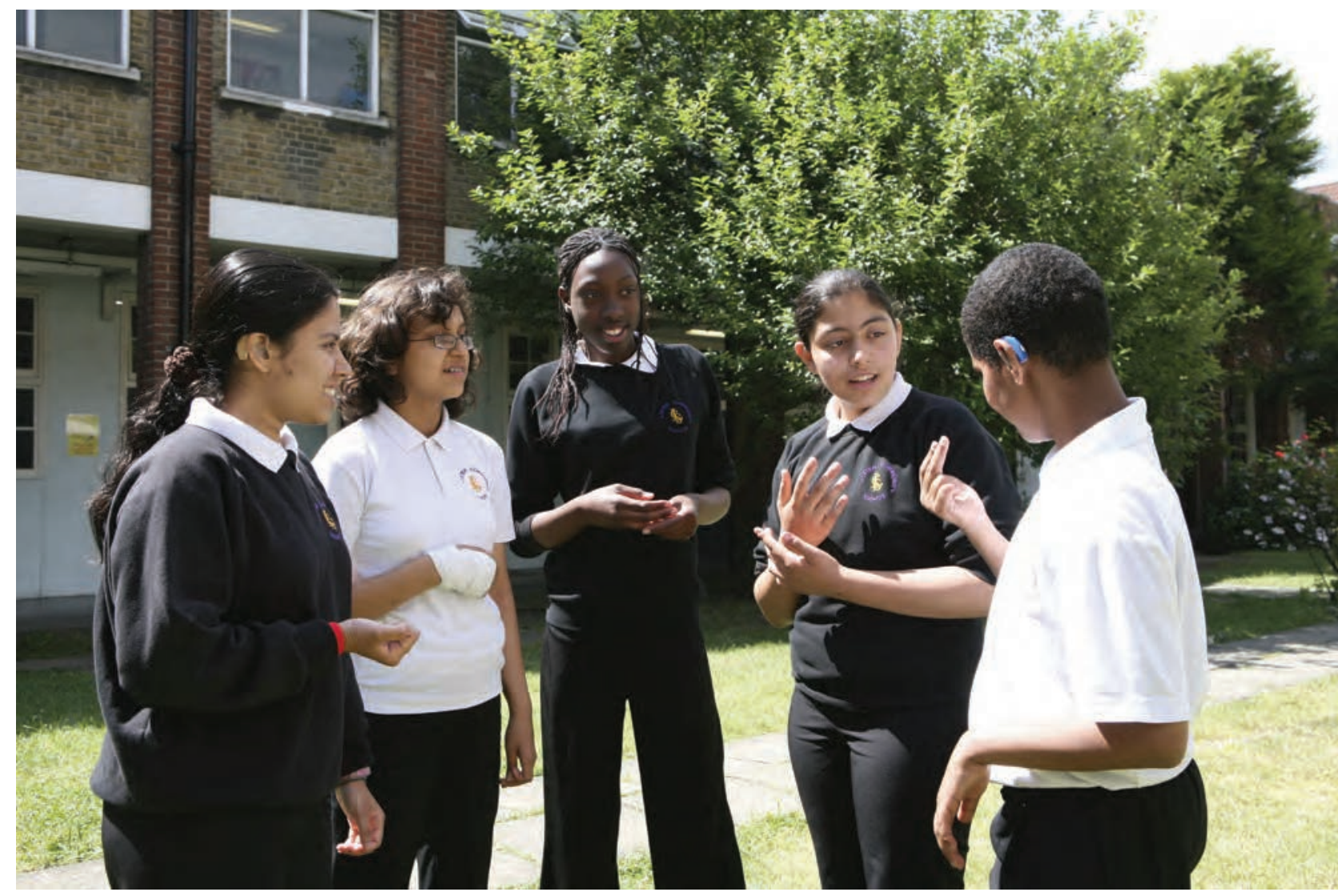

Signed conversation at Lister Secondary School, Newham, London.

Credit: Carlos Reyes Manzo to accommodate the needs of all learners.

In 1997, a Labour government was elected on a manifesto that made a commitment to enforceable civil rights for disabled people. The government adopted the Salamanca Declaration and produced a Green Paper, Education for All, which promoted the development of inclusive education. In 2001, the Disability Discrimination Act included education and in 2006 schools were given a duty to promote disability equality. The government did not ensure that all schools had disability equality training. Schools which had this changed their practice to become more inclusive. However, only around 20 per cent of schools include disabled pupils effectively ${ }^{226}$ and there has been no overall fall in the number of disabled pupils in segregated settings over the last 12 years.

The 'marketisation' of education and competitive school attainment tables are often cited as reasons for the lack of progress in inclusion. ${ }^{227}$ The main reasons why parents withdraw their children is because they are not made welcome and staff do not know how to meet their children's needs. Some parents are 'refugees' from mainstream schools because their children were bullied or their needs were not met. Recent studies suggest that the large majority of parents are happy with their child's placement in special or mainstream schools. 'The main trend is that most parents of children based in either special or mainstream settings were satisfied with current school placement for their child and favoured their current form of provision over an alternative. ${ }^{228}$

In 2004, the government produced a ten-year strategy for developing inclusive education and meeting special educational needs in England (DfES, 2004). Arising from this, a government project was developed to demonstrate good 
practice in schools at making adjustments to successfully include disabled children and young people.

Forty-one schools were visited and filmed, showing five and a half hours of good practice. After interviewing more than 300 staff, pupils and parents, the project team at Disability Equality in Education identified some key factors that led to these schools being effective. They asked why these schools were good at inclusion and similarly resourced schools with similar intakes not so good (DCSF, 2006).

The project's key findings were that these schools had an inclusive ethos, strong leadership and a 'can do' attitude on the part of the staff. The most important factors were a vision and values based on an inclusive ethos; a proactive approach to finding practical solutions to barriers; strong collaborative relationships with pupils and parents; a meaningful voice for pupils; a positive approach to managing behaviour; strong leadership; effective staff training; the use of expertise from outside the school'; building disability into resourcing arrangements; a sensitive approach to the impairment-specific needs of pupils; regular evaluation; and positive images of disability. (See examples in Chapter 8 and DVD 2.)

Although inclusive practice is well established in a minority of schools in the UK, the majority practise integration, many poorly, as evidenced by OFSTED, the school inspection service, in 2004. OFSTED (2006) identified additionally resourced mainstream schools with additionally trained teachers as the most effective at including disabled children. OFSTED (2010), perhaps responding to the changed political environment, maintained that the type of school made no difference, but that it was the quality of teaching that counted most. ${ }^{229}$ However, latest government figures demonstrate that for every type of impairment, children in mainstream schools do far better than those in special schools (see Chapter 10). The coalition government is committed to 'removing the bias to inclusive education', but this has never existed. In fact there is still a bias to segregation built into the system in the UK.

\section{Box 6.32 Ethiopian teachers visit Zambia: An example of international collaboration}

A small group of Ethiopian teachers and administrators visited Zambia on a study tour arranged and led by EENET staff and co-researchers. The Ethiopian teachers were impressed by the teachers' meetings in Zambia, which included practical problem-solving sessions. These enabled teachers to respond to the particular needs of the disabled children in their classes. Since the visit, all 89 Ethiopian teachers have agreed, for the first time, to have disabled children in their classes. ${ }^{230}$ Source: EENET, www.eenet.org.uk

\section{Inclusion and the HIV/AIDS pandemic ${ }^{231}$}

Increasingly, children who are HIV-positive are surviving on antiretroviral drugs and should be classified as disabled under the Convention. The large number of children

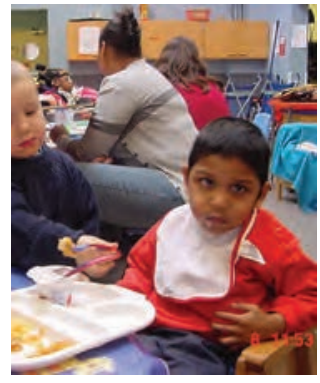

Lunchtime at Cleves School, Newham, London.

CREDIT: RichaRD RIESER 
Surviving the AIDS pandemic in Uganda. orphaned by AIDS puts extra pressure on attempts to achieve inclusive education, and increases poverty, the need for work and homelessness.

The links between HIV/AIDS and education are increasingly evident. Good quality

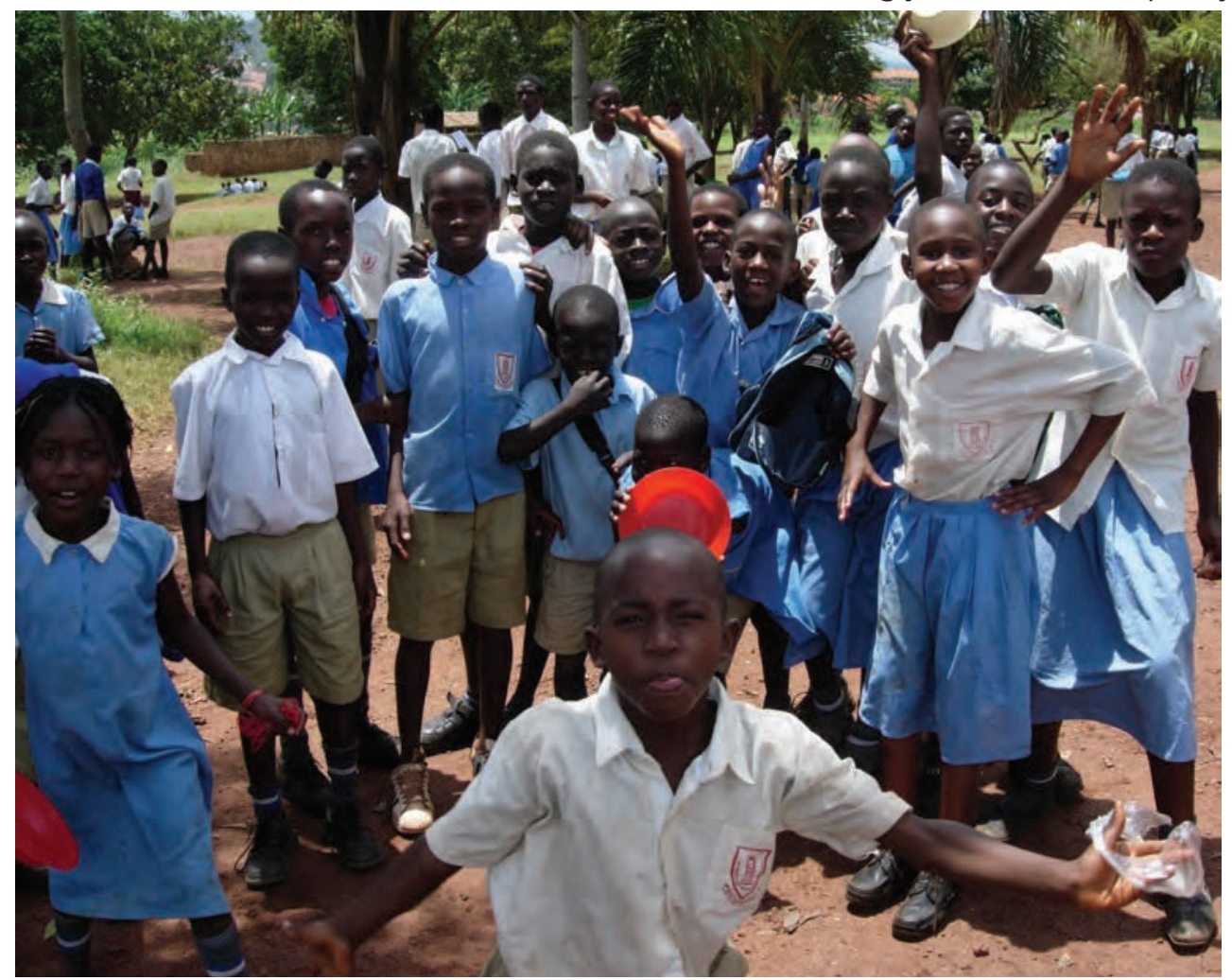

education is a powerful tool against HIV/AIDS. However, the pandemic impacts on learning opportunities and education systems in a myriad of ways. HIV/AIDS threatens the development of education, through the sickness and deaths of policy-makers, teachers and administrators, and damage to the resource base.

On the supply side, evidence suggests that teachers are among the professional groups most at risk. Sub-Saharan Africa, in particular, is experiencing a sharp increase in teacher mortality rates. In 1999, an estimated 860,000 children lost their teachers to AIDS in sub-Saharan Africa. In Zambia, for example, about 1,000 teachers - or half of those trained annually - die of AIDS each year, while the disease caused 85 per cent of 300 teacher deaths in the Central African Republic in 2000. Teacher absenteeism - due to illness, attendance at funerals, patient care at home and psychological trauma - has risen sharply, affecting education both qualitatively and quantitatively, as well as increasing sector costs.

On the demand side, in many countries AIDS is likely to affect the number of school-age children. 508,000 children aged 0-14 years died from AIDS in 2001 (UNAIDS, 2002). Some 14 million children aged 0-14 years have lost one or both of their parents. The proportion of orphans to all children in Africa, estimated at about 2 per cent prior to the epidemic, has now risen to 15-20 per cent in some countries. School enrolment rates could fall further because of drop-out among orphans.

\section{Box 6.33 Zambia: The impact of HIV/AIDS}

In Zambia in 2005, 19 per cent of children under the age of 18 were AIDS orphans. In Copperbelt province there were 344,704 known orphans. Teacher shortages have been addressed by community schools run by non-trained 
adults. The removal of school fees in 2003 led to a 50 per cent reduction in out-of-school children.

The continuing loss of teachers and administrators puts extra pressure on those who remain, with 9,000 teaching vacancies. Since the agreement reached by the G8 at Gleneagles in 2005, the World Bank ban on recruitment has been lifted. This four-year ban had a major negative impact.

The integration of HIV/AIDS education in the curriculum is helping to dispel stigma. This is being extended into the community by schools, but it requires effective community liaison and the development of empathetic relationships with families affected by the epidemic.

A study of six schools by Kanyanta (2005) reported that between 13 and 40 per cent of their pupils had been orphaned. The group had a higher drop-out rate due to inability to pay for uniforms, new responsibilities and loss of parental guidance. Orphans who did not drop out had high rates of absenteeism. Some reported bullying and 20 per cent said they had been sent away because they had no books or pens. They received no formal counselling. Many teachers thought that the concentration on HIV/AIDS prevention meant that the needs of orphans and teachers already affected were neglected.

The study found that students, teachers and other professionals discussed issues concerning HIV/AIDS and made the following suggestions:

- Additional government efforts to recruit extra teachers and reduce class size;

- Redirection of resources to teacher support and school development;

- Shift from a focus on prevention to dealing with orphans and HIV-positive people;

- Develop a stronger inclusive ethos and welcome those who have been stigmatised;

- Develop and deliver a curriculum which emphasises income-generating skills, personal, health, social and emotional skills, and critical learning skills;

- Training for all education professionals to challenge their prejudices;

- Training for teachers on making the inclusive classroom work;

- Support for community schools to enhance the quality of teaching and learning.

HIV/AIDS is likely to increase education sector costs, in a context where the adverse macroeconomic impacts of the pandemic affect domestic resource availability in the public sector and constrain the flow of resources from the private and household sectors. According to the 2002 EFA Global Monitoring Report, HIV/AIDS has added US\$975 million per year to the cost of achieving EFA. This reflects:

- The incremental costs of training additional teachers to replace those lost to AIDS and paying death benefits;

- The costs of training and paying temporary teachers to replace those on extended periods of sick leave; 


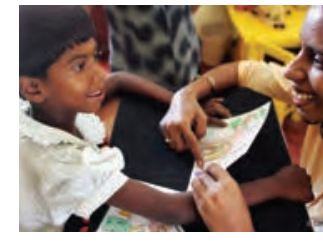

Learning can be fun. CREDIT: CBM/LOHNES

- The incremental school and education programme costs of mainstreaming HIV/AIDS preventive education in curricular and other areas of school life;

- The social subsidies needed to encourage or enable orphans and vulnerable children from families affected by AIDS to attend school.

UNESCO's Flagship on Education for All states:

To achieve EFA goals will necessitate putting HIV/AIDS as the highest priority in the most affected countries, with strong, sustained political commitment; mainstreaming HIV/AIDS perspectives in all aspects of policy; redesigning teacher training and curricular; and significantly enhancing resources to these efforts.

More concretely, the Flagship seeks to address the impact of AIDS on education through effective skills-based prevention education, using formal and non-formal approaches. Education remains a powerful and proven tool for prevention. 